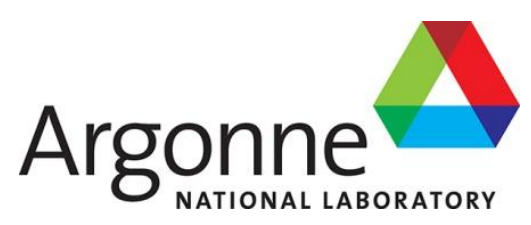

\title{
Loss-of-Flow and Loss-of-Pressure Simulations of the BR2 Research Reactor with HEU and LEU Fuel
}

Nuclear Engineering Division 
About Argonne National Laboratory

Argonne is managed by UChicago Argonne, LLC

U.S. Department of Energy under contract DE-AC02-06CH11357. The

Laboratory's main facility is outside Chicago, at 9700 South Cass

Avenue, Argonne, Illinois 60439. For information about Argonne and its

pioneering science and technology programs, see www.anl.gov.

\section{DOCUMENT AVAILABILITY}

Online Access: U.S. Department of Energy (DOE) reports produced after 1991 and a

growing number of pre-1991 documents are available free via DOE's SciTech

Connect (http://www.osti.gov/scitech/)

\section{Reports not in digital format may be purchased by the public from the National Technical Information Service (NTIS):}

U.S. Department of Commerce National

Technical Information Service 5301

Shawnee Rd

Alexandra, VA 22312

www.ntis.gov

Phone: (800) 553-NTIS (6847) or (703) 605-6000

Fax: (703) 605-6900

Email: orders@ntis.gov

Reports not in digital format are available to DOE and DOE contractors from the Office of Scientific and Technical Information (OSTI):

\section{U.S. Department of Energy}

Office of Scientific and Technical Information

P.O. Box 62

Oak Ridge, TN 37831-0062

www.osti.gov

Phone: (865) 576-8401

Fax: (865) 576-5728

Email: reports@osti.gov

\footnotetext{
Disclaimer

This report was prepared as an account of work sponsored by an agency of the United States Government. Neither the United States Government nor any agency thereof, nor UChicago Argonne, LLC, nor any of their employees or officers, makes any warranty, express or implied, or assumes any legal liability or responsibility for the accuracy, completeness, or usefulness of any information, apparatus, product, or process disclosed, or represents that its use would not infringe privately owned rights. Reference herein to any specific commercial product, process, or service by trade name, trademark, manufacturer, or otherwise, does not necessarily constitute or imply its endorsement, recommendation, or favoring by the United States Government or any agency thereof. The views and opinions of document authors expressed herein do not necessarily state or reflect those of the United States Government or any agency thereof, Argonne National Laboratory, or UChicago Argonne, LLC.
} 


\section{Loss-of-Flow and Loss-of Pressure Simulations of the BR2 Research Reactor with HEU and LEU Fuel}

prepared by

J. Licht ${ }^{1}$, A. Bergeron ${ }^{1}$ and B. Dionne ${ }^{1}$

${ }^{1}$ Nuclear Engineering Division, Argonne National Laboratory, Argonne, IL 60439

and

E. Sikik², G. Van den Branden ${ }^{2}$ and E. Koonen ${ }^{2}$

${ }^{2} \mathrm{BR} 2$ Reactor Department, SCK・CEN

March, 2016

This work is sponsored by the

U.S. Department of Energy, National Nuclear Safety Administration (NNSA),

Office of Material Management and Minimization (NA-23) Reactor Conversion Program 


\section{Table of Contents}

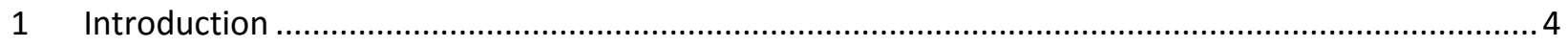

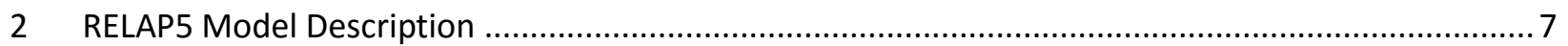

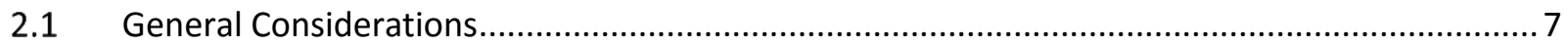

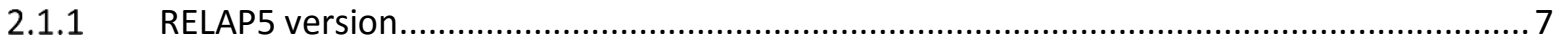

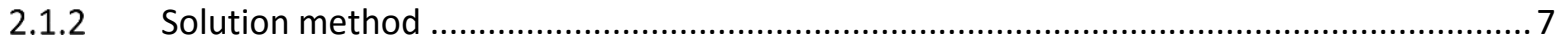

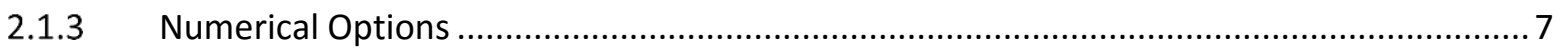

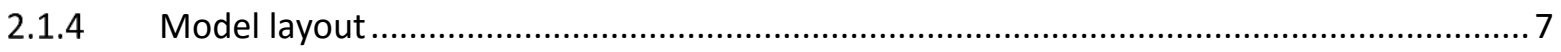

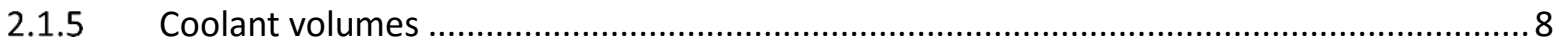

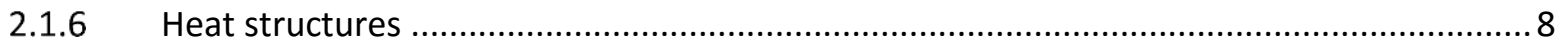

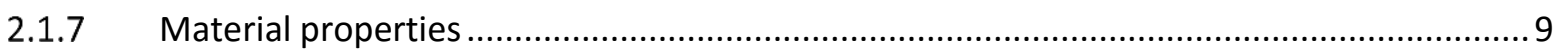

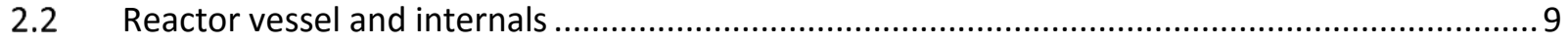

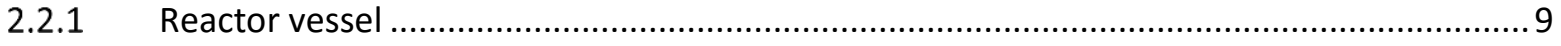

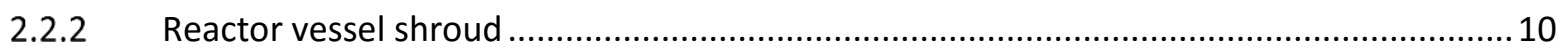

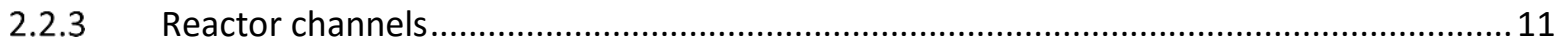

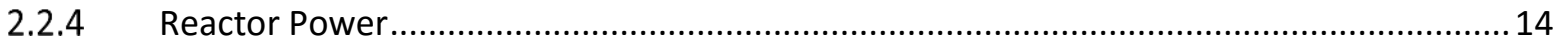

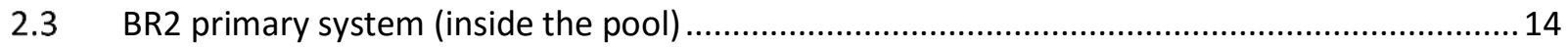

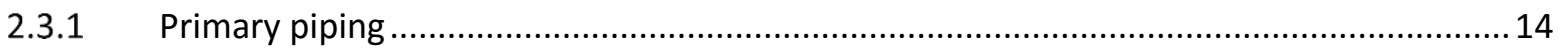

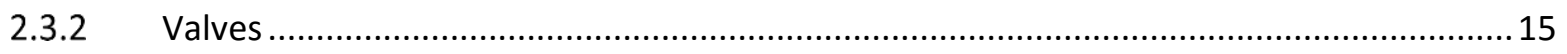

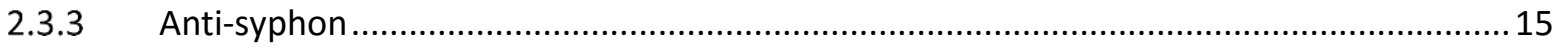

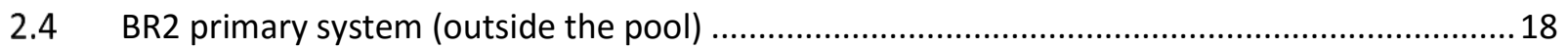

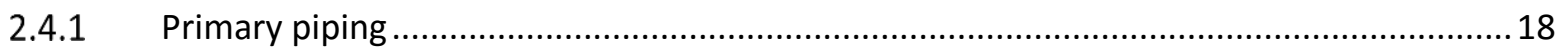

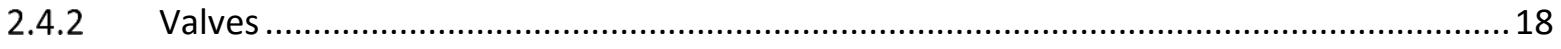

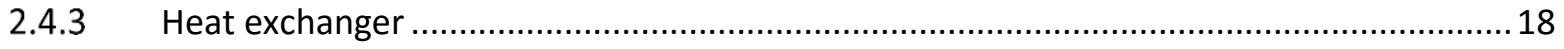

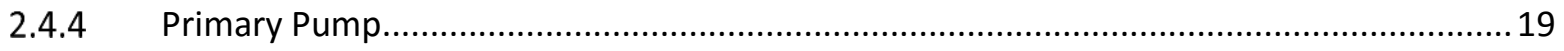

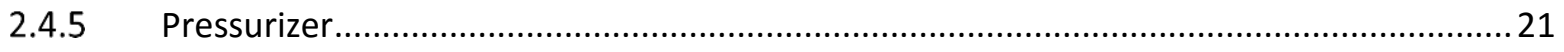

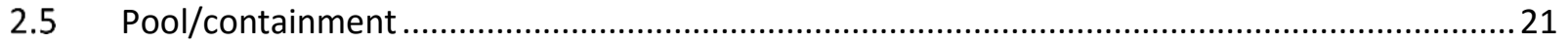

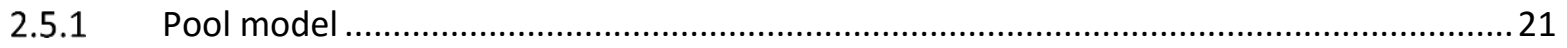

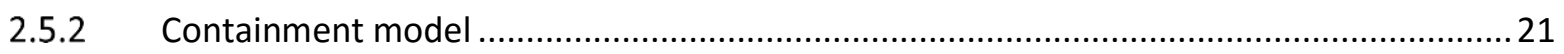

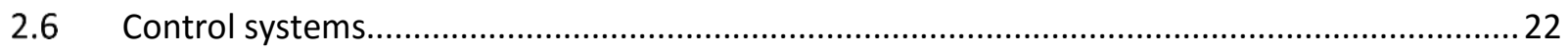

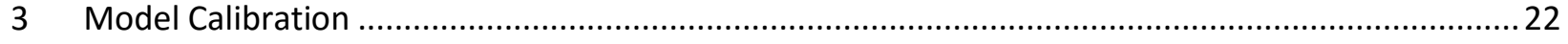

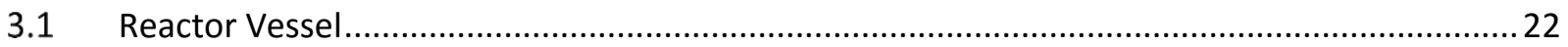




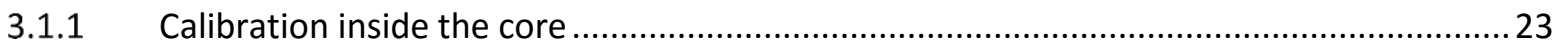

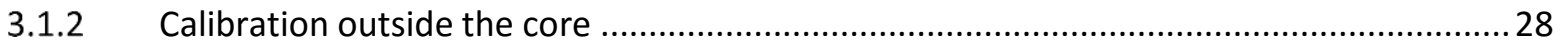

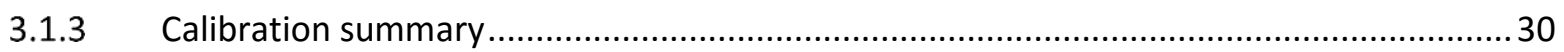

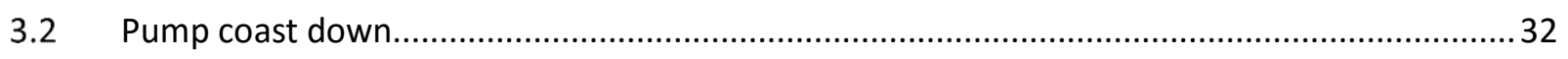

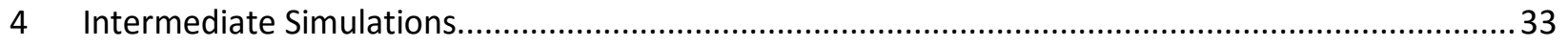

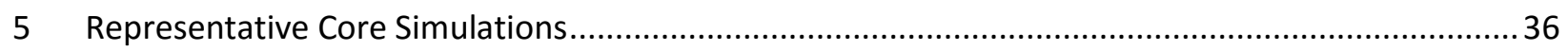

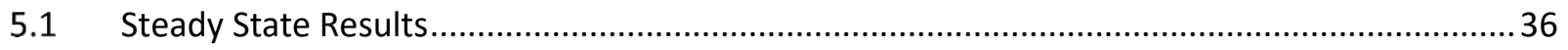

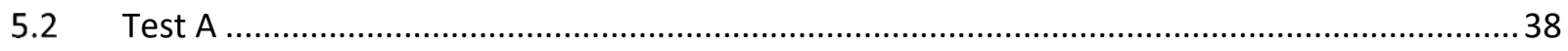

$5.3 \quad$ Test C

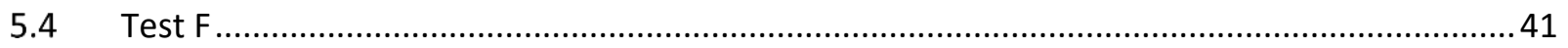

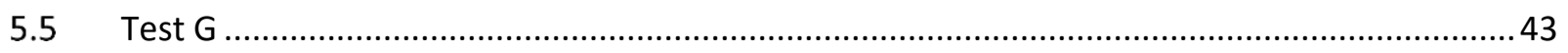

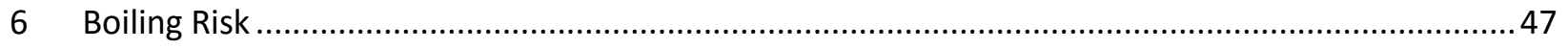

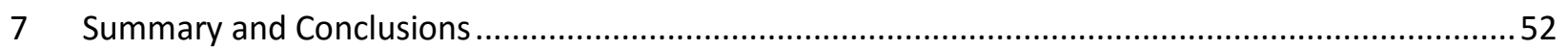

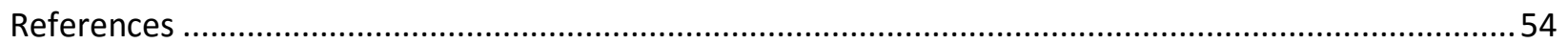

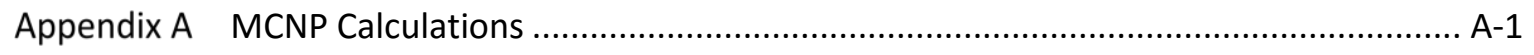

Appendix B Power Distribution and Kinetics Parameters..................................................... B-1

Appendix C Evaluation of Power Following Scram .............................................................

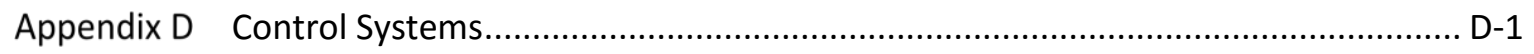

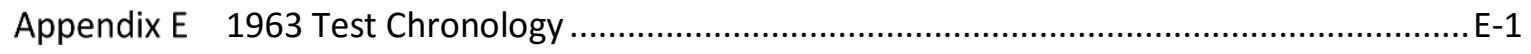

Appendix F Validation for Long Term Cooling …................................................................. F-1

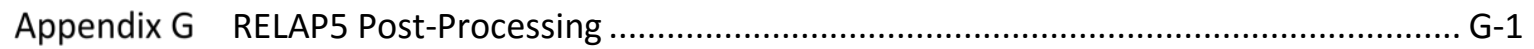




\section{Introduction}

Belgian Reactor 2 (BR2) is a research and test reactor located in Mol, Belgium and is primarily used for radioisotope production and materials testing. The Materials Management and Minimization $\left(\mathrm{M}^{3}\right)$ Reactor Conversion Program of the National Nuclear Security Administration (NNSA) is supporting the conversion of the BR2 reactor from Highly Enriched Uranium (HEU) fuel to Low Enriched Uranium (LEU) fuel.

The reactor core of BR2 is located inside a pressure vessel that contains 79 channels in a hyperboloid configuration (Figure 1). The core configuration is highly variable as each channel can contain a fuel assembly, a control or regulating rod, an experimental device, or a beryllium or aluminum plug. Because of this variability, a representative core configuration (Figure 2), based on current reactor use, has been defined for the fuel conversion analyses [1].

The code RELAP5/Mod 3.3 [2] was used to perform the transient thermal-hydraulic safety analyses of the BR2 reactor to support reactor conversion. The input model has been modernized relative to that historically used at BR2 taking into account the best modeling practices developed by Argonne National Laboratory (ANL) and BR2 engineers. This included, for example:

- Verifying and updating the reactor vessel and primary piping components based on current design documents, drawings and supporting analyses [3] [4].

- Performing sensitivity studies and computational fluid dynamic (CFD) simulations to properly discretize the model of the limiting fuel assembly [5] [6].

- Using experimental data obtained in 1962 for steady-state flow and pressure distributions in both the BR2 and hydraulic mock-up facility for various core configurations to generate the generic minor loss coefficients required to obtain the correct channel flow rates and reactor pressure distributions suitable for any given core configuration (Section 3.1).

To assure credibility of the modeling approach, Loss-of-Flow/Loss-of-Pressure (LOF/LOP) simulations were performed with the 1963 core configuration to compare simulation results with select experiments that were performed in the BR2 reactor at that time [7]. In short, the simulation results have shown that the model produces good agreement with the measured steady-state and transient cladding temperatures.

This report describes the extension of the RELAP5 model to the representative core and compares results for HEU and LEU fuel for these same accident scenarios (test cases) at current heat flux limits:

Test A - Total loss of flow followed by opening of the bypass valve with an initial heat flux at the maximum limit of $470 \mathrm{~W} / \mathrm{cm}^{2}$,

Test C - Untimely opening of the bypass valve with an initial heat flux at the temporary limit of $600 \mathrm{~W} / \mathrm{cm}^{2}$, 
Test F - Untimely opening of the pool connection valve (total loss of pressure) followed by opening of the bypass valve with an initial heat flux at the maximum limit of $470 \mathrm{~W} / \mathrm{cm}^{2}$, and

Test G - Untimely opening of the pool connection valve (total loss of pressure) without opening of the bypass valve with an initial heat flux at the maximum limit of $470 \mathrm{~W} / \mathrm{cm}^{2}$.

Of particular interest in this work is to update the BR2 RELAP5 transient analyses to represent current reactor use and demonstrate that conversion to LEU fuel does not compromise the fuel plate integrity due to core cooling perturbations while operating at the maximum heat flux limit of $470 \mathrm{~W} / \mathrm{cm}^{2}$ and the temporary heat flux limit of $600 \mathrm{~W} / \mathrm{cm}^{2}$.

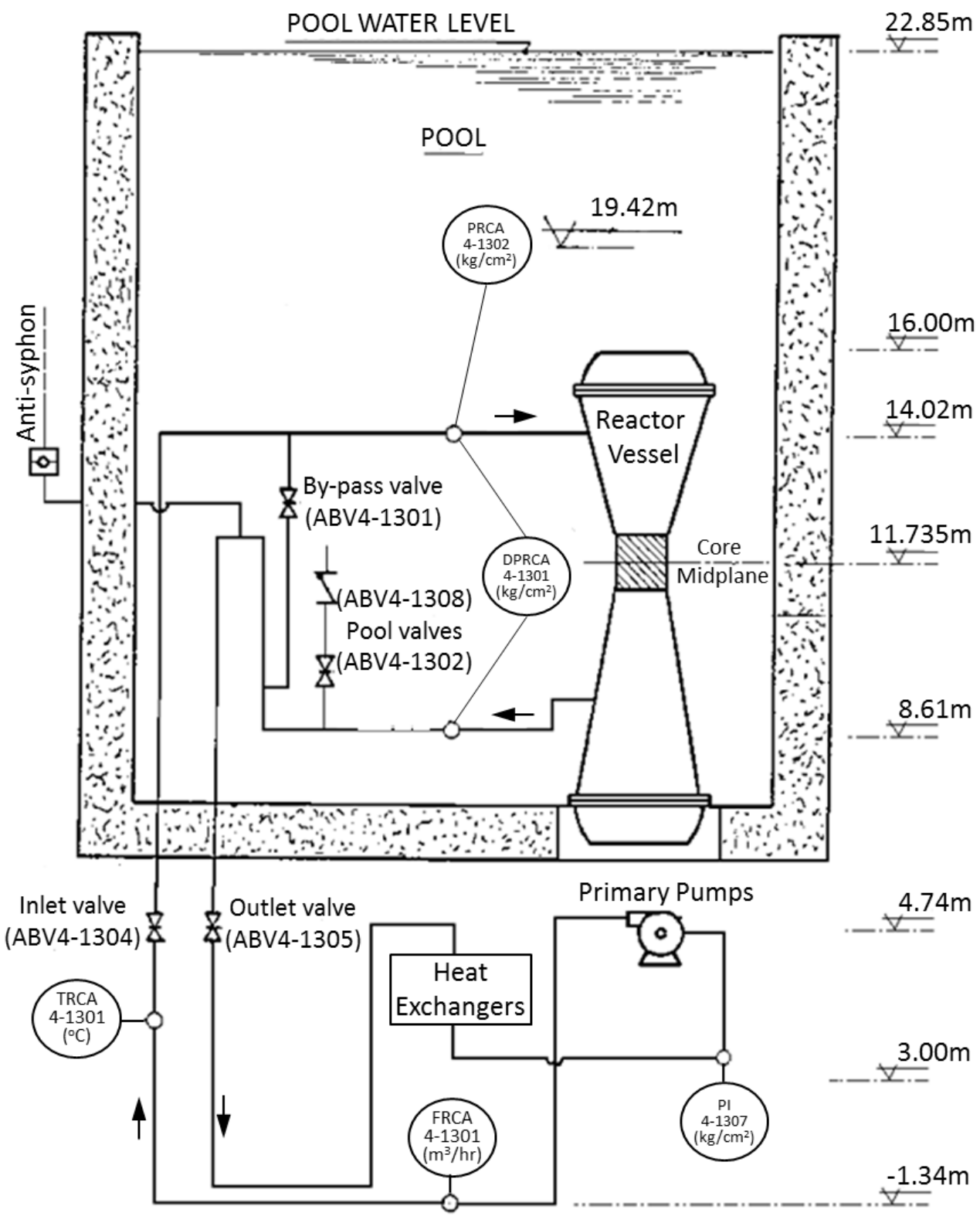

Figure 1 Conceptual drawing of BR2. 
1963 Core Configuration

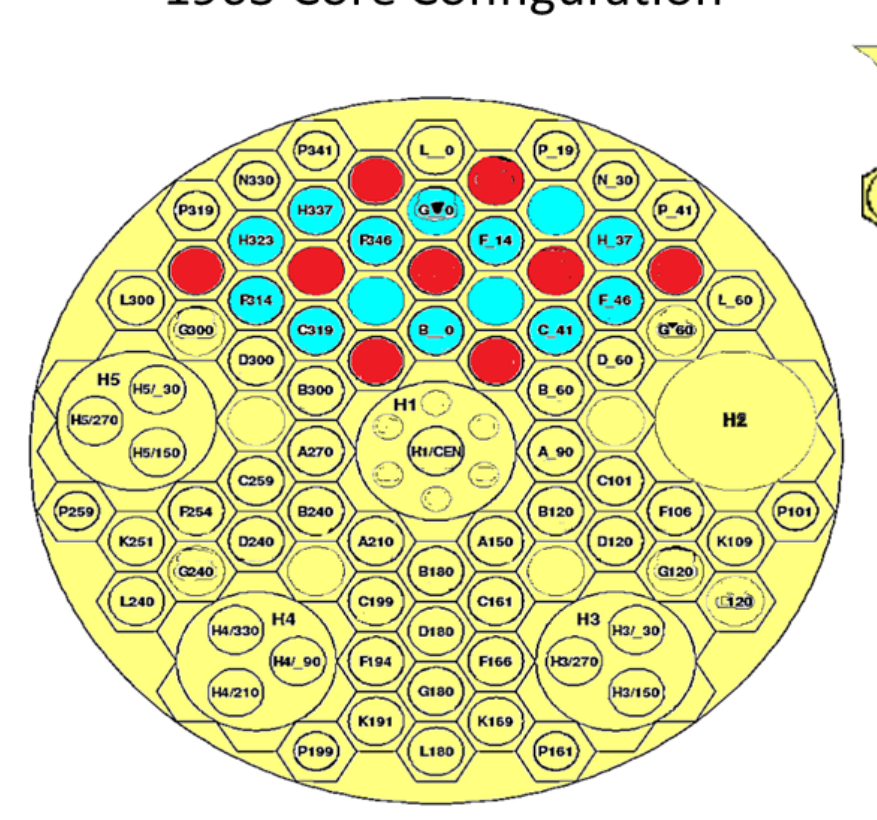

Representative Core Configuration

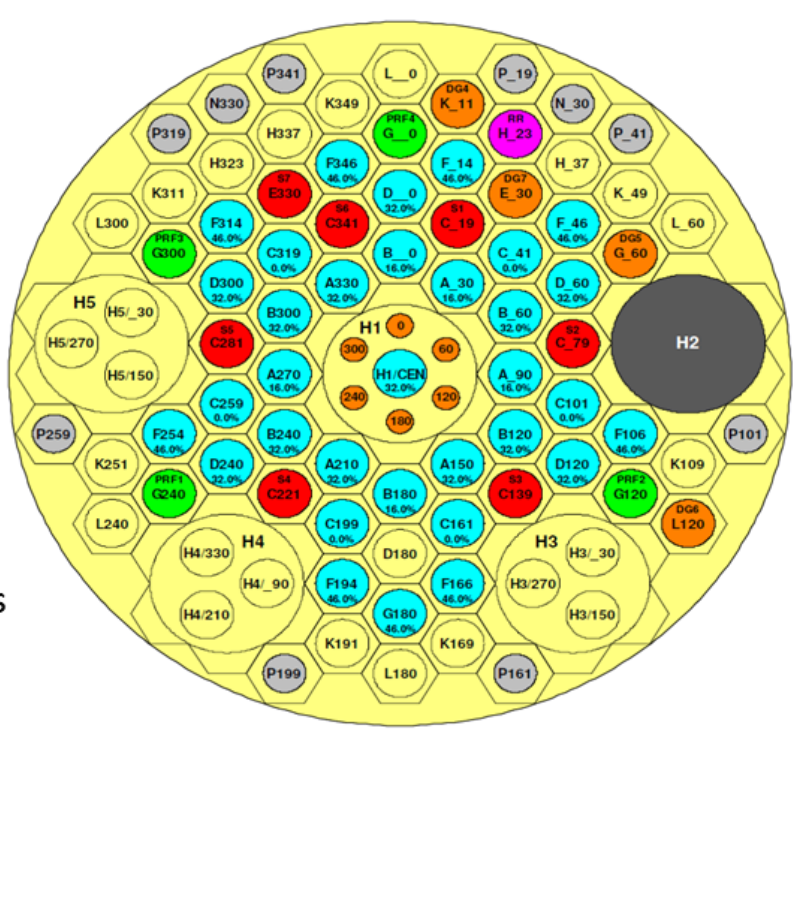

Figure 2 The 1963 and representative core configurations. 


\section{RELAP5 Model Description}

\subsection{General Considerations}

\subsubsection{RELAP5 version}

The model described in this document was developed for RELAP5/Mod 3.3 [2]. Throughout the remainder of this document, RELAP5/Mod 3.3 will be referred to as RELAP5.

\subsubsection{Solution method}

The options selected for running the RELAP5 simulations summed to control option 7, which means the following options have been implemented:

- The hydrodynamics advancement setting was selected; it uses a mass error analysis to control the time step between the minimum and maximum time step (set to $1.1 \mathrm{e}-12 \mathrm{~s}$ and $0.1 \mathrm{~s}$, respectively).

- The heat conduction/transfer time step was set to be the same as the hydrodynamic time step.

- The heat conduction/transfer and hydrodynamics were coupled implicitly for the transient simulation. Note that the explicit method was used to achieve steady-state conditions before switching to the implicit method.

\subsubsection{Numerical Options}

The RELAP5 code contains options that can be activated in order to overcome calculation failures by changing numerical or modeling methods. The following is a list and brief description of the options that were utilized in some of the RELAP5 simulations to overcome calculation failures ${ }^{1}$ :

Option 5: This option smooths the heat transfer coefficients using an exponential-type smoothing function $\left(1-e^{-t / \tau}\right)$. The time constant is set equal to time step with the limitation that the time constant cannot be greater than 0.5 seconds.

Option 18: Activates sharp interface and void profile logic used in RELAP5/Mod 2.5.

\subsubsection{Model layout}

The RELAP5 model can be thought of as being separated into three parts; the reactor vessel, the primary coolant system within the pool and the primary coolant system outside the pool. The model of the primary coolant system within the pool has been modernized by the BR2 team and is described in Ref. [4]. The model of the primary coolant system outside the pool has only received a limited number of changes and simplifications relative to previous ANL and BR2 versions of the BR2 model ${ }^{2}$. These changes have been described in Ref. [7] and in this document. The reactor vessel model has been modernized by the conversion team at BR2 and ANL and is described in detail in Ref. [7]. The extension of the reactor vessel model to the representative core configuration is described in this document.

\footnotetext{
${ }^{1}$ These options were used to overcome calculation failures that occurred in preliminary simulations of Test $F$ and $G$ transients. Experience has shown that these options do not noticeably impact the simulation results.

2 Previous versions of the BR2 input model can be found in the ANL archive of the BR2 conversion files.
} 


\subsubsection{Coolant volumes}

Coolant volumes within the reactor vessel model were largely based on the data extracted from previous RELAP5 models and verified by comparison with legacy notes provided by BR2. Default parameters for coolant volumes and junctions within the reactor vessel are given here:

The junction control flags efvcahs for pipe and sngljun component were by default set to 0001000 :

- $\quad \mathrm{e}=0$ : modified PV term not used

- $f=0$ : CCFL model not applied

- $\quad \mathrm{v}=0$ : option not available

- $\quad c=1$ : choking model not applied
- $a=0$ : smooth area change

- $\mathrm{h}=0$ : non-homogeneous model applied

- $s=0$ : momentum flux both to and from volume

The volume control flags tlpvbfe for pipe and snglvol components were by default set to 0000000 :

- $\mathrm{t}=0$ : no thermal front tracking

- I=0: no mixture level tracking

- $p=0$ : water packing scheme used

- $\mathrm{v}=0$ : vertical stratification model used
- $b=0$ : pipe interphase friction model used

- $\mathrm{f}=0$ : wall friction along $\mathrm{x}$-axis calculated

- $\mathrm{e}=0$ : non-equilibrium model used

For pipes, the hydraulic diameter and area for the internal junctions of all volumes were by default set to 0 (internally calculated).

To be consistent with previous input models, the wall roughness for the internal surface of the reactor channels was specified as $1.6 \times 10^{-6}$ and the wall roughness for the remainder of the reactor vessel was specified as $3.2 \times 10^{-6}$. These values are not expected to significantly effect RELAP5 simulations. ${ }^{3}$

\subsubsection{Heat structures}

Heat structures throughout the reactor vessel model and primary piping were discretized into 4 radial intervals. Heat structures containing fuel where discretized into 9 radial intervals, 3 for each of the cladding faces and 3 for the fuel. The following default parameters were set for the heat structure components without heat generation:

- the 9 word format was selected

- $\quad$ convection boundary = 101 (default convection correlations)

- $\quad$ heat transfer hydraulic diameter $=0$ (i.e. same as volume hydraulic diameter)

- $\quad$ the forward and reverse heated length $=>100$ (i.e. neglect entrance effects)

- forward and reverse loss coefficients $=0$ (not required for current geometry)

- local boiling factor $=1.0$ (no heat generation)

The following natural circulation lengths were used for heat structure components with heat generation (12 word format):

- fuel $=0.762 \mathrm{~m}$

- $\quad$ vertical pipes = pipe length

- $\quad$ horizontal pipes = pipe diameter

\footnotetext{
${ }^{3}$ Theses surface roughness values are typical of the materials used in the reactor. The moody diagram shows that even an order of magnitude increase in surface roughness has little impact on the friction factor for the Reynolds numbers typical of the BR2 primary system and reactor vessel.
} 


\subsubsection{Material properties}

Table 1 provides a summary of the relevant material properties for use in the RELAP5 model [8]. The fuel properties for the high heat flux fuel assembly (average burnup $=16 \%$ ) and long irradiated beryllium were used in the analyses presented in this document ${ }^{4}$.

Table 1 Material Properties used in the RELAP5 model.

\begin{tabular}{|c|c|c|c|c|c|c|}
\hline $\begin{array}{c}\text { RELAP5 } \\
\#\end{array}$ & \multirow{2}{*}{ Material } & Applies to: & Density & $\begin{array}{c}\text { Specific } \\
\text { Heat }\end{array}$ & Heat Capacity & $\begin{array}{c}\text { Thermal } \\
\text { Conductivity }\end{array}$ \\
\cline { 4 - 6 } & & {$\left[\mathrm{kg} / \mathrm{m}^{3}\right]$} & {$[\mathrm{J} / \mathrm{kg}-\mathrm{K}]$} & {$\left[\mathrm{J} / \mathrm{m}^{3}-\mathrm{K}\right]$} & {$[\mathrm{W} / \mathrm{m}-\mathrm{K}]$} \\
\hline 1 & AG3NE & Cladding & 2670 & 880 & $2.3496 \mathrm{e} 6$ & 130 \\
\hline 2 & Al 6061-T6 & Structure & 2700 & 896 & $2.4192 \mathrm{e} 6$ & 167 \\
\hline 3 & $\begin{array}{c}\text { UAlx-Al } \\
\text { (HEU) }\end{array}$ & Burnup $=16 \%$ & 3580 & 646 & $2.3124 \mathrm{ee} 6$ & 64 \\
\hline 5 & $\begin{array}{c}\text { U-7Mo-Al } \\
\text { (LEU) }\end{array}$ & Burnup = 16\% & 9870 & 275 & $2.7143 \mathrm{e} 6$ & 36 \\
\hline 8 & Be & Long irradiation & 1836 & 1925 & $3.5343 \mathrm{ee}$ & 50 \\
\hline 9 & SS 304L & Vessel etc. & 8000 & 500 & $4.0000 \mathrm{e} 6$ & 16 \\
\hline 10 & C steel & Heat exchanger inlet pipe & & & $3.8775 \mathrm{ee}$ & 46.05 \\
\hline $13 / 16$ & Al 5083 & Heat exchanger & & & $2.3940 \mathrm{e} 6$ & 117 \\
\hline $14 / 17$ & Al 3103 & Primary piping & & & $2.4379 \mathrm{e} 6$ & 193 \\
\hline
\end{tabular}

\subsection{Reactor vessel and internals}

\subsubsection{Reactor vessel}

A conceptual drawing of the reactor vessel and its internal components, as modeled in RELAP5, is shown in Figure 3. The details of the components were obtained from Ref. [3] as well as from notes describing previous RELAP5 models.

The main bodies of the vessel (structures 101 through 105) were modeled as aluminum cylinders where the inner diameters were based on the internal volumes and heights and the outer diameters were specified to conserve the structure volumes ${ }^{5}$. The covers at the top and bottom of the vessel (structure 100 and 106, respectively) were specified as stainless steel with a spherical geometry.

The internal vessel components included the flow diffuser (120), channel supports (140 and 201), the flow guide (202) and the support grid (203 and 220).

\footnotetext{
${ }^{4}$ The burnup for BR2 fuel elements is difficult to generalize since the core is heterogeneous and the shuffling scheme is variable. However, a typical fuel element undergoes 4 cycles with BOC average burnup values of approximately $0 \%, 16 \%, 32 \%$ and $48 \%$. The highest heat flux occurs for a fuel element with a BOC average burnup of $16 \%$. The thermal properties for the high heat flux fuel element are based on this burnup value. Due to the difficulty in determining an average set of thermal properties for the remaining fuel elements, the values for the high heat flux fuel element have been applied to all fuel elements in the RELAP5 model. This approximation is not expected to have a large impact on the results.

${ }^{5}$ The wall thickness of the pressure vessel structures specified in the RELAP5 model will be slightly different than the actual values.
} 


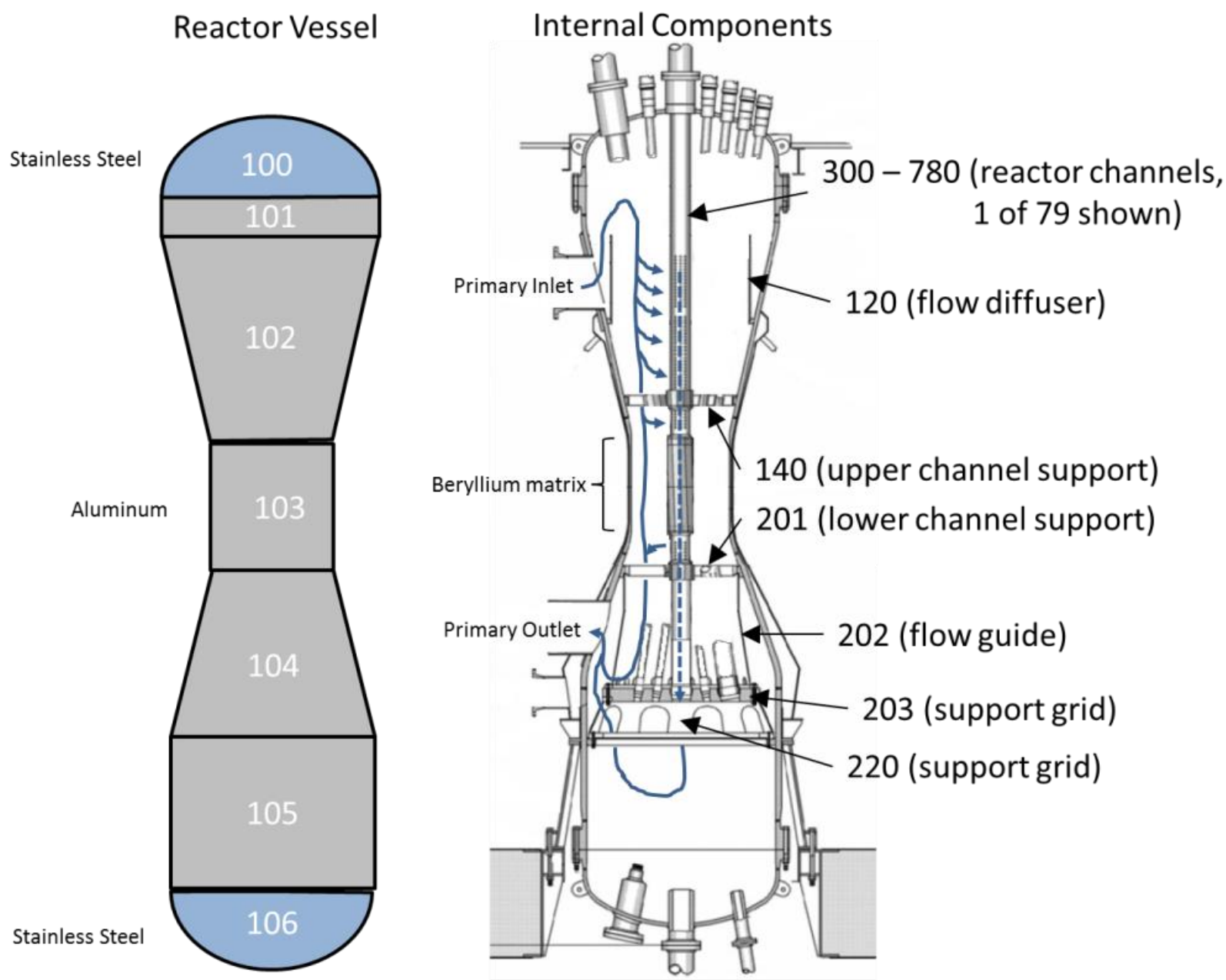

Figure 3 Heat structure numbers in the RELAP5 model of the BR2 reactor vessel and internal structures.

\subsubsection{Reactor vessel shroud}

The geometrical data for the pressure vessel outer wall and shroud inner wall were extracted from figures in Ref. [3] and the results are plotted here in Figure 4. The cooling shroud was described as a single coolant pipe (RELAP5 \#166) discretized into 31 axial volumes (annular cylinders). The selected discretization scheme for the fluid volumes was in part to take advantage of the reactors convenient geometrical shapes for creating the model (Figure 4: blue numbers and blue vertical dashes). For example, the total coolant volume for RELAP5 volume 166-1 was determined from volume equations for a cylinder and/or conical frustum utilizing dimensions of the vessel and shroud at that location. The total surface area was determined in a similar manner and the two values were used to obtain a hydraulic diameter (hydraulic diameter $=\frac{\text { volume }}{\text { surface area }}$ ). Although not evident in the figure, there is a flow constriction between the shroud and reactor vessel at junction 4 and 27 (between volumes 4 / 5 and 27 / 28, respectively). The abrupt area change model was applied at these locations.

The heat structure connections are also shown (Figure 4: red numbers and colored background). For example, the shroud coolant volumes 166-1 and 166-2 are thermally connected to pressure vessel heat 
structure number 105. The thickness of the shroud wall is $6.35 \mathrm{~mm}$ in the core region and $9.5 \mathrm{~mm}$ elsewhere ${ }^{6}$. It is thermally connected to the pool.

A time dependent volume has been placed at each end of the cooling shroud. The outlet pressure was specified as $1.94 \mathrm{e} 5 \mathrm{~Pa}$ and the inlet temperature and flow rate were specified as $33^{\circ} \mathrm{C}$ and $111 \mathrm{~kg} / \mathrm{s}$.

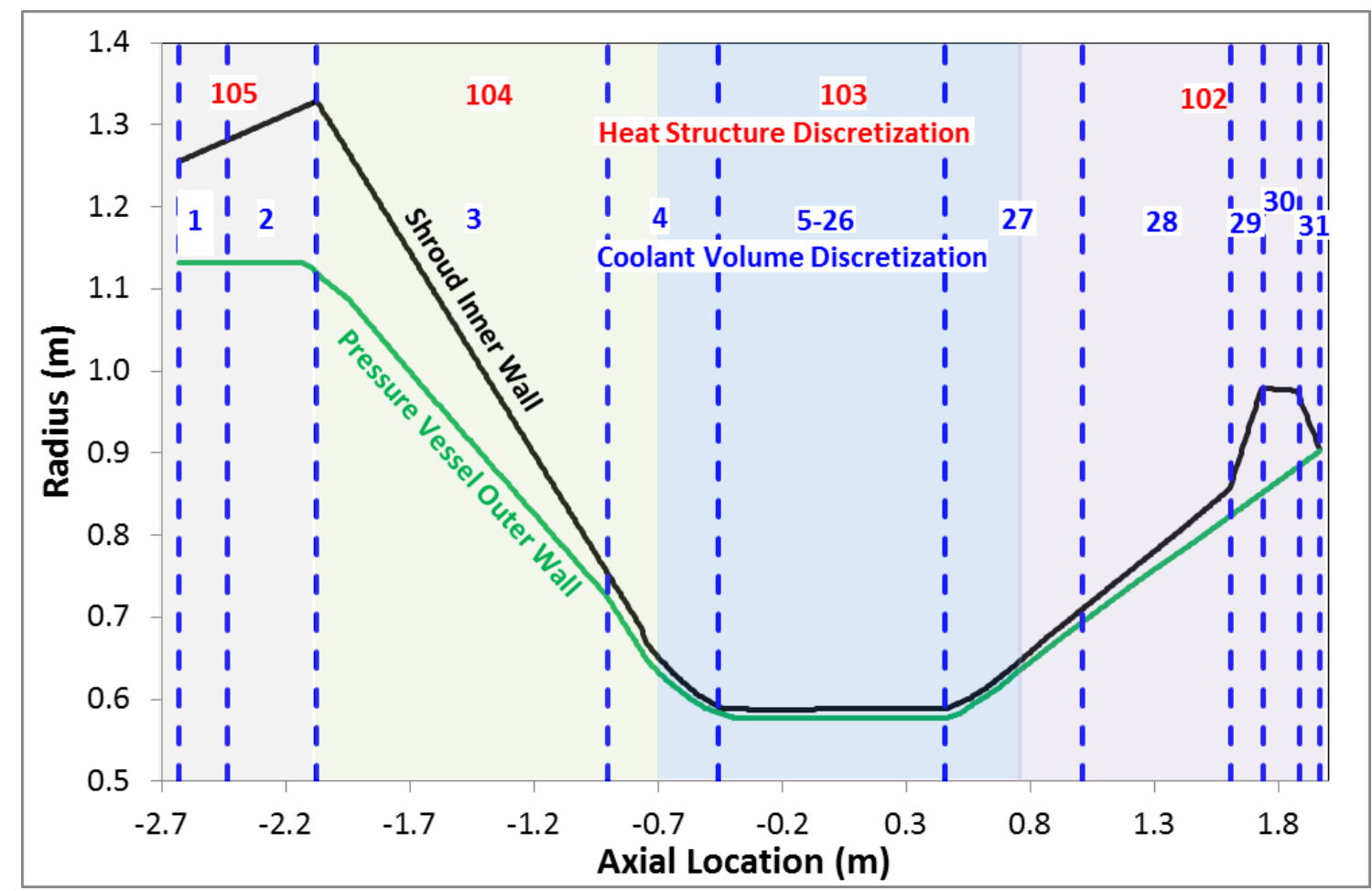

Figure 4 Shroud dimensions and discretization.

\subsubsection{Reactor channels}

In order to appropriately model the BR2 channels and maintain a simplified RELAP5 model, the 79 channels ( 80 including the bypass flow) have been consolidated into 4 representative flow channels (Figure 5); including the bypass flow (volumes 10-20), a single flow channel containing the highest heat flux fuel assembly (volumes 30-40), the remaining fuelled flow channels (volumes 50-60) and all remaining non-fuelled flow channels (volume 70-80). The volume containing the highest heat flux fuel assembly (volume 36) was further discretized (volumes 360, 365, 366, and 367) to better represent individual sub-channels associated with the fuel plates (Figure 6). The fuel assembly geometry was based on the CERCA design currently used in BR2 reactor [3]. Previous work has shown that 3 explicit sub-channels are sufficient to predict the peak cladding temperature in a LOF/LOP simulation [6]. The sub-channels represent only a 10 degree arc of the fuel assembly sector to properly model the azimuthal power peak-to-average ratio [9]. Computational fluid dynamic (CFD) simulations [5] have demonstrated the validity of this approximation since both azimuthal coolant mixing and azimuthal heat conduction in the fuel plate are relatively small.

${ }^{6}$ Sikik, E., Private communication, August $24^{\text {th }}, 2015$. 


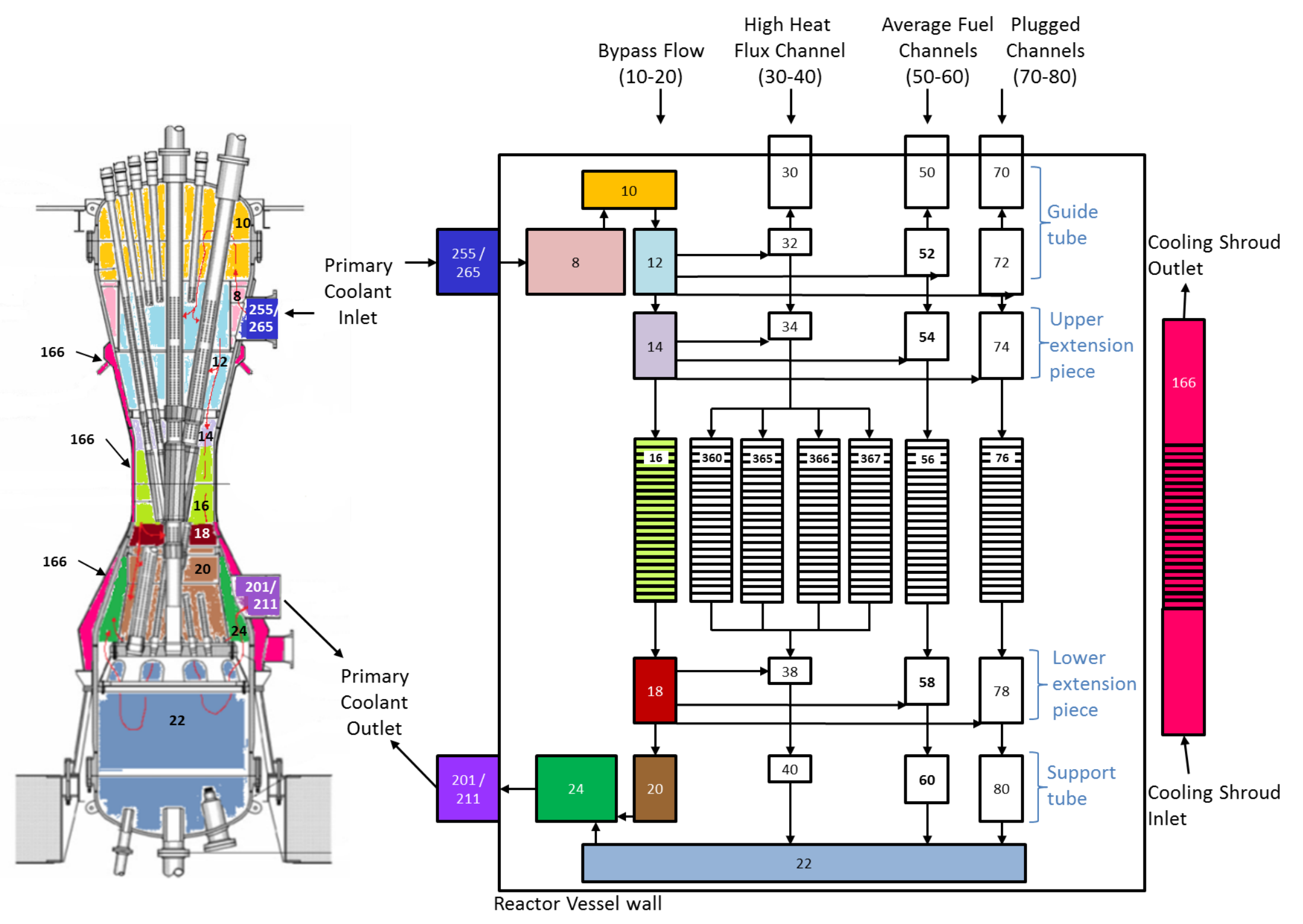

Figure 5 Coolant volume numbers in the RELAP5 model of the BR2 Reactor Vessel. 


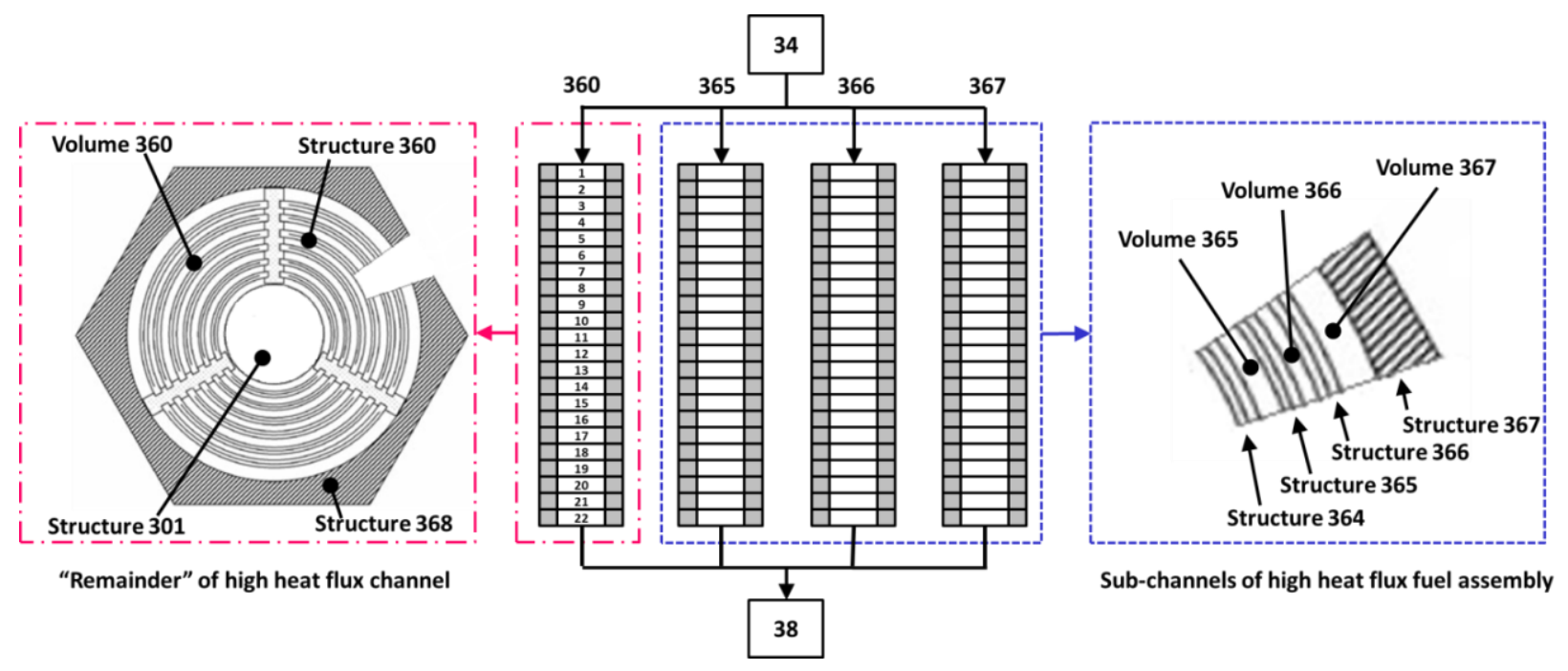

Figure 6 Discretization of the high heat flux fuel assembly (CERCA type).

The four flow channels have been discretized into six axial sections: one volume for the section of channel located in the upper plenum (Volumes 10, 30, 50 and 70); one volume for the perforated section of channel above the upper channel support (Volumes 12, 32, 52 and 72); one volume for the section of channel above the core but below the upper channel support (Volumes 14, 34, 54 and 74). Within the core region the coolant volumes were described using pipe components and were discretized using the same axial nodalization as the fuel heat structure illustrated in Figure 6. That is, 20 segments were used to describe the fuelled region with an additional sub-volume at the top and bottom end to describe the non-fuelled part of the fuel assembly (total of 22 segments). Previous work [6] has shown that this level discretization is sufficient for a mesh independent solution of peak cladding temperatures. Below the core region the channels were split into two regions; one volume between the core and the lower support guide (Volumes 18, 38, 58 and 78) and another for the remainder of the channel (Volumes 20, 40, 60 and 80).

Cross flow occurs between the bypass channel and the other three channels through a number of channel perforations in three different axial regions (guide tube and upper and lower extension pieces) of the channel walls. The hydraulic diameter of the perforations in the guide tubes and lower extension pieces was $6.35 \mathrm{~mm}$ and the respective flow areas depends on the number of reactor channels associated with each of the RELAP5 channels. The hydraulic diameter of the perforation in the upper extension piece just above the core was $4.76 \mathrm{~mm}$ for the $84 \mathrm{~mm}$ channels and $6.35 \mathrm{~mm}$ for the other channel sizes. Thus, for the representative core configuration, the hydraulic diameter of the upper extension piece for the RELAP5 channel representing the plugged channels was $5.71 \mathrm{~mm}$.

As described earlier, the channels form a hyperboloid configuration where only the center channel is vertical and the off axis angle increases to $\sim 10$ degrees at the outermost channels. For simplicity, each of the channels has been modeled as vertical. This was done for two reasons. First, if the angles were included, updating the model for different core configurations requires updating almost all of the RELAP5 input parameters that make up the channel volumes and heat structures. Modeling the channels with a vertical orientation significantly reduces the number of parameters that must be 
updated and reduces the likelihood for error in transcribing parameters. Second, the small offset from vertical does not influence the heat transfer or flow regime models used within RELAP5. The only impact is the small discrepancy between actual and projected lengths of components within each axial region, which is not expected to significantly affect simulation results.

The heat structures describing the channels outside and inside the core region were modeled as stainless steel and beryllium cylinders, respectively. The hexagonal shape of channel exterior in the core region was approximated as a cylinder with an outer diameter that results in a conservation of the beryllium volume. The components inside the channels were modeled as cylinders with the outer diameter chosen to conserve material volumes. The fuel elements were modeled with a 3-layer plate structure (clad/fuel/clad) with both cladding surfaces thermally connected to the coolant. As shown in Figure 6 , the fuel element in the high heat flux channel contained 4 plate structures to capture the local power peaking $(360,364,365,366)$. The fuel elements in the average fuel channel have been consolidated into a single representative fuel plate.

\subsubsection{Reactor Power}

MCNP5 calculations (described in Appendix A) were performed for the current representative core at BOC conditions (fresh core, no Xenon, "full power") with both HEU and LEU fuel to obtain the power distribution and kinetics parameters for RELAP5 (Appendix B). The MCNP5 model included 20 uniform axial nodes in the fuel region (same as the RELAP5 model). For each axial node in the $4^{\text {th }}, 5^{\text {th }}$ and $6^{\text {th }}$ plates, the azimuthal discretization included 9 non-uniform segments per sector to resolve the azimuthal power peaking; the remaining plates were not discretized in the azimuthal direction. The power from the central segments of the $4^{\text {th }}, 5^{\text {th }}$ and $6^{\text {th }}$ plate were modeled explicitly in the RELAP5 model as the "hot stripe" containing the maximum heat flux (Figure 6). Heat generation was also applied to the beryllium channel and internal structures (e.g. fuel and plug). For the fuel plates, the heat was assumed to be generated completely within the fuel meat.

The RELAP5 point kinetics model was used to calculate the steady state and transient fission power. The neutronics parameters are given in Appendix B. The decay heat values were obtained within RELAP5 using ANSI/ANS-5.1-1979 [10] for thermal fission of ${ }^{235} \mathrm{U}$ at $200 \mathrm{MeV} /$ fission and 24 hours of steady state operation. The justification for selecting 24 hours of steady-state operation for decay heat is given in Appendix C.

\subsection{BR2 primary system (inside the pool)}

The RELAP5 model describing the section of primary system located between the isolation valves and reactor vessel (Figure 7) has been updated and documented separately by the BR2 team [4]. A brief description is given here. The pool itself is described in Section 2.5.

\subsubsection{Primary piping}

The piping material is primarily aluminum 3103 and is thermally connected to the pool. This section of piping contains four rupture disks which have not been included in the model. They are instead modeled as closed end volumes (209, 219, 251 and 261). 


\subsubsection{Valves}

The pool connection valve (ABV4-1308) connects one of the hot legs from the reactor vessel to the pool. It has been modeled as a servo valve with a $0.067 \mathrm{~s}^{-1}$ opening rate. It remains closed until the pressure difference between the primary piping and pool is less than $3 \mathrm{~kg} / \mathrm{cm}^{2}$. In the RELAP5 model it can also be opened manually (e.g. as required for Test $F$ to simulate failure of the valve).

A bypass valve (ABV4-1301) connects the hot and cold leg pipes within the pool and is used to enhance natural circulation within the reactor vessel under accident conditions. The valve was modeled as a servo valve with a $0.067 \mathrm{~s}^{-1}$ opening rate. The normalized valve area was equal the valve position which ranges from 0 (fully closed) to 1 (fully open).

These valves are actuated by the control system described in Section 2.6.

\subsubsection{Anti-syphon}

A simplified model of the anti-syphon was included in the model. The anti-syphon piping was assumed to be 2 inch schedule 40 piping (inner diameter $=5.26 \mathrm{~cm}$ ) and is connected to the top of the " $\mathrm{C}$ shaped" outlet leg of the primary piping, just before the piping exits below the pool. In the event of a pipe break below the reactor pool and failure of the outlet pipe valve, the anti-syphon is intended to prevent draining of the reactor vessel under certain accident scenarios. However, it was evaluated that the anti-syphon does not participate significantly to the events being simulated in this report and therefore an isolation valve has been included to disconnect it from the primary system. This model should be refined and evaluated prior to performing simulations that require implementation of the anti-syphon. 


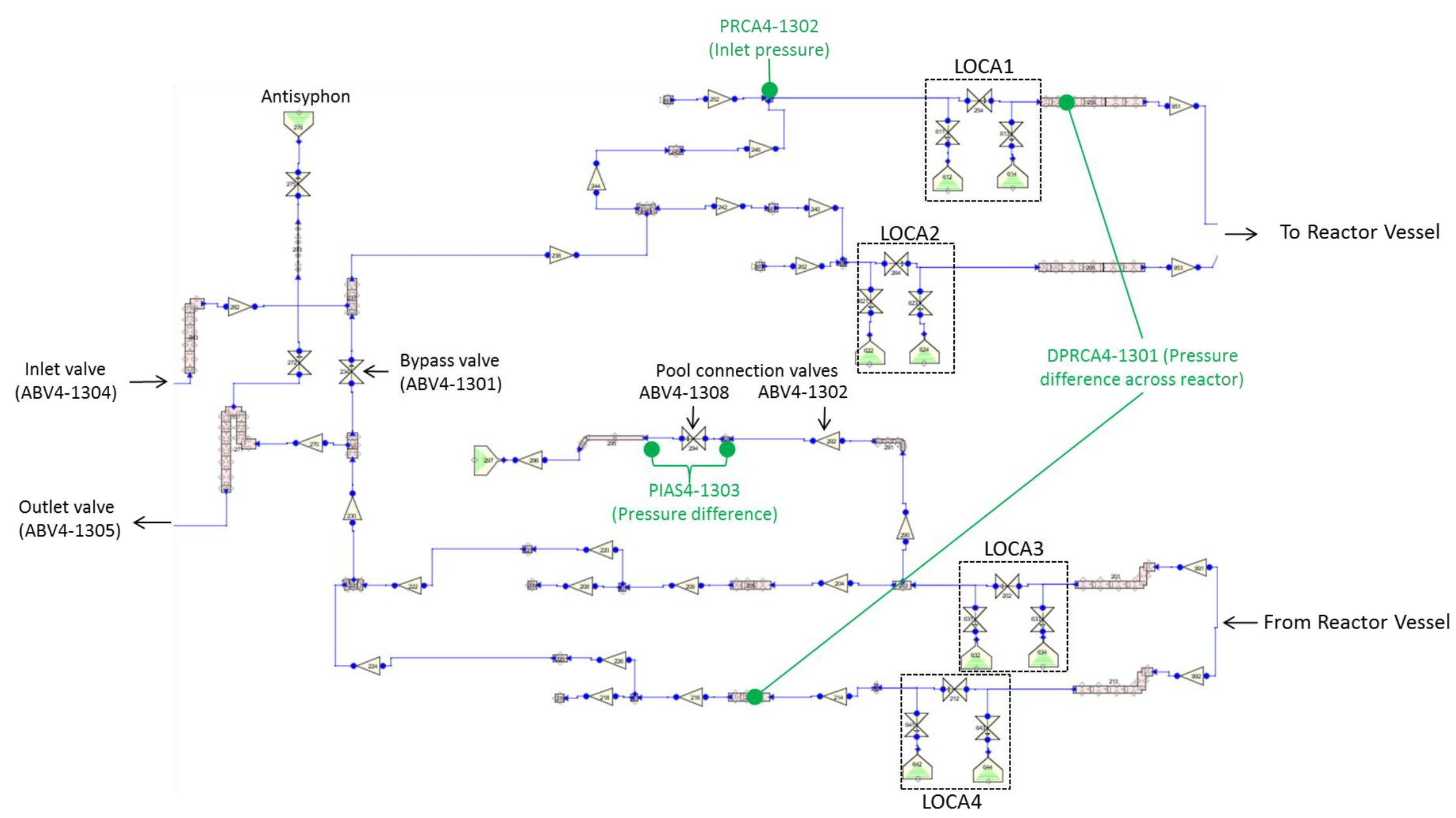

Figure 7 RELAP5 model of the BR2 primary system located inside the pool. 


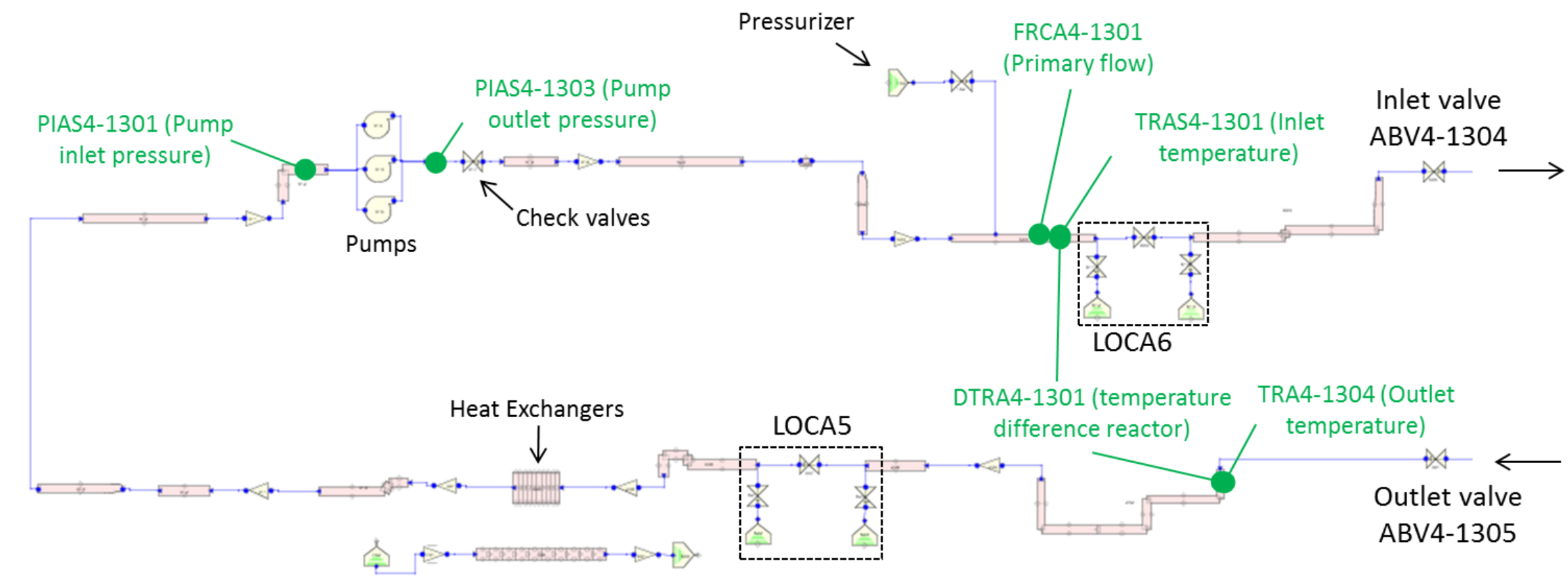

Figure 8 RELAP5 model of the BR2 primary system located outside the pool. 


\subsection{BR2 primary system (outside the pool)}

A model of the section of primary system located outside of the pool is shown in Figure 8. It includes the primary pumps, heat exchangers, pressurizer model and valves. The air purge and purification lines have not been included in the RELAP5 model.

\subsubsection{Primary piping}

The piping material is primarily aluminum 3103 and is thermally connected to a model of the containment atmosphere (pressure $=1.01 \mathrm{e} 5 \mathrm{~Pa}$, temperature $=25^{\circ} \mathrm{C}$ ).

\subsubsection{Valves}

ABV4-1304 and ABV4-1305 are the cold and hot leg isolation valves, respectively. These valves were modeled as servo valves with a $0.067 \mathrm{~s}^{-1}$ opening rate. The normalized valve area was equal the valve position which ranges from 0 (fully closed) to 1 (fully open).

The check valves following the primary pumps (V.P.C 13, V.P.C 14 and V.P.C $15^{7}$ ) were approximated with a single motor valve in the RELAP5 model. The change rate and valve area where adjusted during the calibration to approximate the stopping of the flow due to the valve closure (see section 3.2).

These valves are actuated by the control system described in Section 2.6.

\subsubsection{Heat exchanger}

The primary heat exchangers used during the 1963 experiments were replaced in 1971 with a new system containing 3 parallel pipes each containing a single heat exchanger. For the current model, these have been consolidated into a single equivalent heat exchanger and piping. The parameters for this system were obtained from previous RELAP5 models provided to ANL (Table 2$)^{8}$.

Table 2 Heat exchanger parameters.

\begin{tabular}{|c|c|}
\hline Number of heat exchangers & 3 \\
\hline Measured pressure drop [kPa] & 77 \\
\hline Measure flow rate $\left[\mathrm{m}^{3} / \mathrm{hr}\right] /[\mathrm{kg} / \mathrm{s}]$ & $6761 / 1878$ \\
\hline \multicolumn{2}{|c|}{ Coolant (volume 300) } \\
\hline Total flow area $\left[\mathrm{m}^{2}\right]$ & 6.116 \\
\hline Coolant volume length [m] & 4.66 \\
\hline Total volume $\left[\mathrm{m}^{3}\right]$ & 28.5 \\
\hline Hydraulic diameter [m] & 0.081 \\
\hline \multicolumn{2}{|c|}{ Outer wall of heat exchanger (Heat Structure 3000) } \\
\hline Length $[\mathrm{m}]$ & 13.98 \\
\hline Outer heat transfer diameter $[\mathrm{m}]$ & 1.608 \\
\hline Inner heat transfer diameter [m] & 1.554 \\
\hline \multicolumn{2}{|c|}{ Secondary side piping (Heat Structure 3001) } \\
\hline Length $[\mathrm{m}]$ & 35863 \\
\hline Outer heat transfer diameter $[\mathrm{m}]$ & 0.018 \\
\hline Inner heat transfer diameter [m] & 0.015 \\
\hline
\end{tabular}

\footnotetext{
${ }^{7}$ Personal communication with Emre Sikik 9/21/2015.

${ }^{8}$ Previous versions of the BR2 input model can be found in the ANL archive of the BR2 conversion files.
} 
An average of the measured pressure drop per heat exchanger was found to be $77 \mathrm{kPa}$ for a primary system flow rate of $1878 \mathrm{~kg} / \mathrm{s}$. This was achieved in the RELAP5 model by applying a minor loss coefficient of 8.0 to the junctions at the inlet and outlet of the heat exchanger.

The secondary side of the heat exchanger was modeled with a temperature control system to achieve the desired inlet temperature $\left(\sim 35^{\circ} \mathrm{C}\right)$ for simulation of tests $\mathrm{A}, \mathrm{C}, \mathrm{F}$ and $\mathrm{G}$.

\subsubsection{Primary Pump}

The BR2 primary system contains 4 primary pumps and 2 auxiliary pumps. One of the primary pumps is considered a reserve pump. Both the reserve pump and 2 auxiliary pumps were excluded from the model. Therefore only 3 operating primary pumps were included in the model (components 413, 414 and 415). The piping was consolidated into a single pipe with identical hydraulic characteristics. The primary pump specifications are given in chapter 9.2.1.1 of Ref. [11] and are summarized here in Table 3.

Table 3 Parameters for the BR2 main pumps.

\begin{tabular}{|l|c|c|}
\hline Parameter & Rated Value & RELAP5 Value \\
\hline Speed & $1430[$ RPM] & $149.75[\mathrm{rad} / \mathrm{s}]$ \\
\hline Flow & $35\left[\mathrm{~m}^{3} / \mathrm{m}\right]$ & $0.5833\left[\mathrm{~m}^{3} / \mathrm{s}\right]$ \\
\hline Head & $76.2[\mathrm{~m}]$ & $76.2[\mathrm{~m}]$ \\
\hline Torque & $2754[\mathrm{lbf}-\mathrm{ft}]$ & $3734.6[\mathrm{~N}-\mathrm{m}]$ \\
\hline Moment of Inertia & $230\left[\mathrm{~kg}-\mathrm{m}^{2}\right]$ & $230\left[\mathrm{~kg}-\mathrm{m}^{2}\right]$ \\
\hline
\end{tabular}

The homologous curves for the BR2 pumps (Figure 9) were obtained from previous RELAP5 models and were developed from the manufacturer's pump data. As can be seen from the figures, a discontinuity exists between flow regimes for several instances (likely due to lack of data points). This is not an issue for the current simulations since the pump is expected to remain in the normal ${ }^{9}$ pump regime (i.e. quadrant 1 in Figure 9, where the rotational velocity $(\alpha)$ and flow rate $(v)$ are greater than or equal to 0$)$.

A proportional-integral controller, described in Section 2.6, was used to set the pump speed to obtain the target flow rate within the primary system at steady-state conditions. For accident conditions where the pump has been tripped, flow is controlled by the hydraulic resistance of the reactor, the homologous curves and the torque friction described in Section 3.2.

\footnotetext{
${ }^{9}$ Check valves downstream of the pumps prevent the pumps from operating in the dissipation and turbine modes. The reverse mode has been disabled and is not allowed within the model.
} 


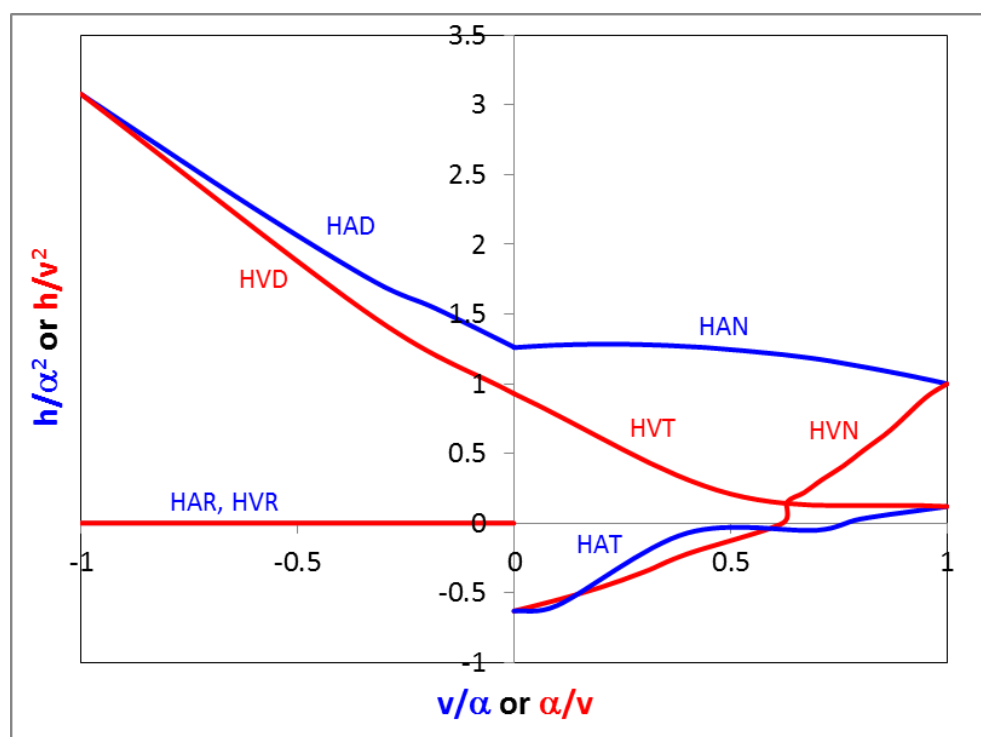

(a)

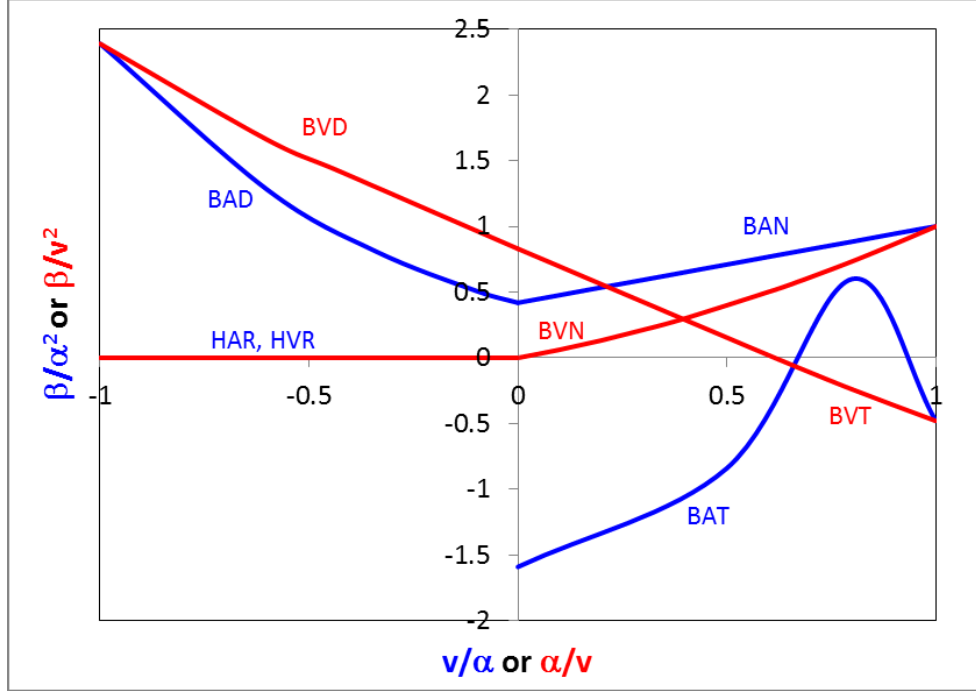

(b)

Figure 9 Homologous curves for the BR2 main pumps; (a) head, (b) torque. ${ }^{10}$

${ }^{10} \alpha=$ rotational ratio; $v$ = volumetric flow ratio; $h=$ head ratio; and $\beta=$ torque ratio; HAN, BAN, HVN, BVN = normal pump mode;

$H A D, B A D, H V D, B V D=$ dissipation mode;

HAT, BAT, HVT, BVT = turbine mode;

HAR, BAR, HVR, BVR = reverse mode.

See Ref. [2] for further details. 


\subsubsection{Pressurizer}

A detailed model of the pressurizer has been used in past simulations performed by BR2 but was found not to play a significant role in the LOF/LOP events considered in this report. For simplicity, the pressurizer was modeled as a time dependent volume (150) and trip valve (102) connected to pipe $504(1)$ with a cross-flow connection. The pressurizer coolant temperature was set to $35^{\circ} \mathrm{C}$ (typical inlet temperature). A controller described in Section 2.6 was used to modify the pressurizer pressure to set the system pressure to $12.6 \mathrm{~kg} / \mathrm{cm}^{2}$, as measured at pipe 253(1) (same location as BR2 measured inlet pressure). The trip valve was closed for Test $F$ and $G$ to facilitate a loss of pressure simulation.

\subsection{Pool/containment}

The RELAP5 model of the pool/containment for the 1963 core configuration utilized a time dependent volume for the pool. The time dependent volume acts like an infinite heat sink since the temperature does not change with heat gained or lost. For the representative core model, a more detailed pool/containment model was included for future additional simulations (e.g. pool heat up transients).

\subsubsection{Pool model}

The BR2 pool contains $870 \mathrm{~m}^{3}$ of light water with a depth of about $15 \mathrm{~m}$. A model of the pool has been included to approximate the heat transferred from the reactor components (Figure 10). Since RELAP is not a suitable tool for modeling the 3 dimensional aspects of the pool, the correlations for natural convection are relied upon. However, a limitation of the RELAP5 model is that the correlation is dependent on the orientation of the connected volume rather than the orientation of the heat structure. The Churchill-Chu natural convection correlation is used by RELAP5 for vertical structures and the McAdams natural convection correlation is used for horizontal structures. For this application, the Churchill-Chu correlation can predict a heat transfer coefficient approximately 5 times larger than the McAdams correlation. There are several ways that this issue could be handled and each has its own limitations. The method used here was to split the pool volume into two equal sized pieces, in which one was oriented vertical and the other horizontal. The vertical pool volume was connected to all of the vertical heat structures. The horizontal pool volume was connected to all of the horizontal heat structures. The horizontal pool volume was connected to the midplane of the vertical pool volume so that both volumes contain the same median pressure. To ensure equal temperature for both of the pool volumes, an artificial heat structure was included with material properties characteristic of high heat transfer and low thermal mass.

\subsubsection{Containment model}

Two time dependent volumes (one vertical, one horizontal) where used to describe the containment atmosphere. Vertical and horizontal structures where connected to the appropriate time dependent volume. The containment was assumed to be air at a pressure of $1.01 \mathrm{e} 5 \mathrm{~Pa}$ and $25^{\circ} \mathrm{C}$. 


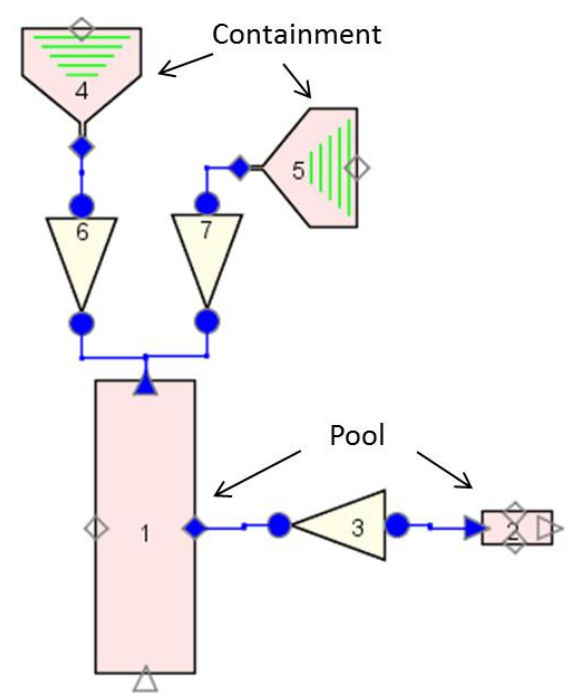

Figure 10 Pool and containment model

\subsection{Control systems}

For the 1963 experiments, measurements were made of the pump flow rate, system pressure and pressure differentials, opening and closing times for the valves, and trip times for the pumps and reactor scram. Although a control system controlled the actions of the reactor, the measured information was used to describe the transient behavior and verify cladding temperature results produced by the model. For the representative core simulations, these measurements are not available so the model includes a control system based on the current trip parameters provided in Ref. [12] and [13]. For example, in simulating Test $A$, the control system sets the steady state mass flow rate, inlet pressure and inlet temperature based on the target values. The pump is manually tripped to initiate the transient and the remaining actions are controlled by the trip set points and time delays specified in the control system. Details of the control system are described in Appendix D.

\section{Model Calibration}

\subsection{Reactor Vessel}

Calibration of the RELAP5 vessel model was performed to ensure that the calculated pressure losses and flow distributions were in agreement with known reactor performance. A significant amount of data was available for calibration for a variety of core configurations in both BR2 and a hydraulic mock-up facility. The hydraulic experiments performed in BR2 in 1962 supplied the primary data for model calibration. Calibration of pressure losses across the RELAP5 vessel model can be separated into five relevant sections; the inlet piping to the upper plenum, the upper plenum to the upper core matrix, across the core matrix, below the core matrix to the lower support grid and from the lower support grid to the outlet piping (Figure 11). Precisely modeling the BR2 pressure losses is extremely difficult due to numerous flow paths but relatively coarse distribution of pressure measurements. The pressure at any given axial location can vary depending on its proximity to channels of varying velocities, and hence 
pressures. For example, between the core and upper channel support, the coolant in the fuel channels has a relatively high velocity and low pressure which results in a cross flow from the bypass into the channels. The opposite is true for plugged channels where the net cross flow is from the channels to the bypass [14]. The calibration strategy employed was to first calibrate the known flow distribution and pressure drop in the core region. Following this, additional loss coefficients outside the core were applied in way that resulted in the correct global pressure loss but maintained the same flow distribution across all channels. In other words, the calculated form loss coefficients implemented in RELAP5 were assumed to already provide a reasonable approximation to the flow distribution; only the magnitude of pressure loss was adjusted. This was considered sufficient since the local pressure losses and flow distributions were not known outside the core region.

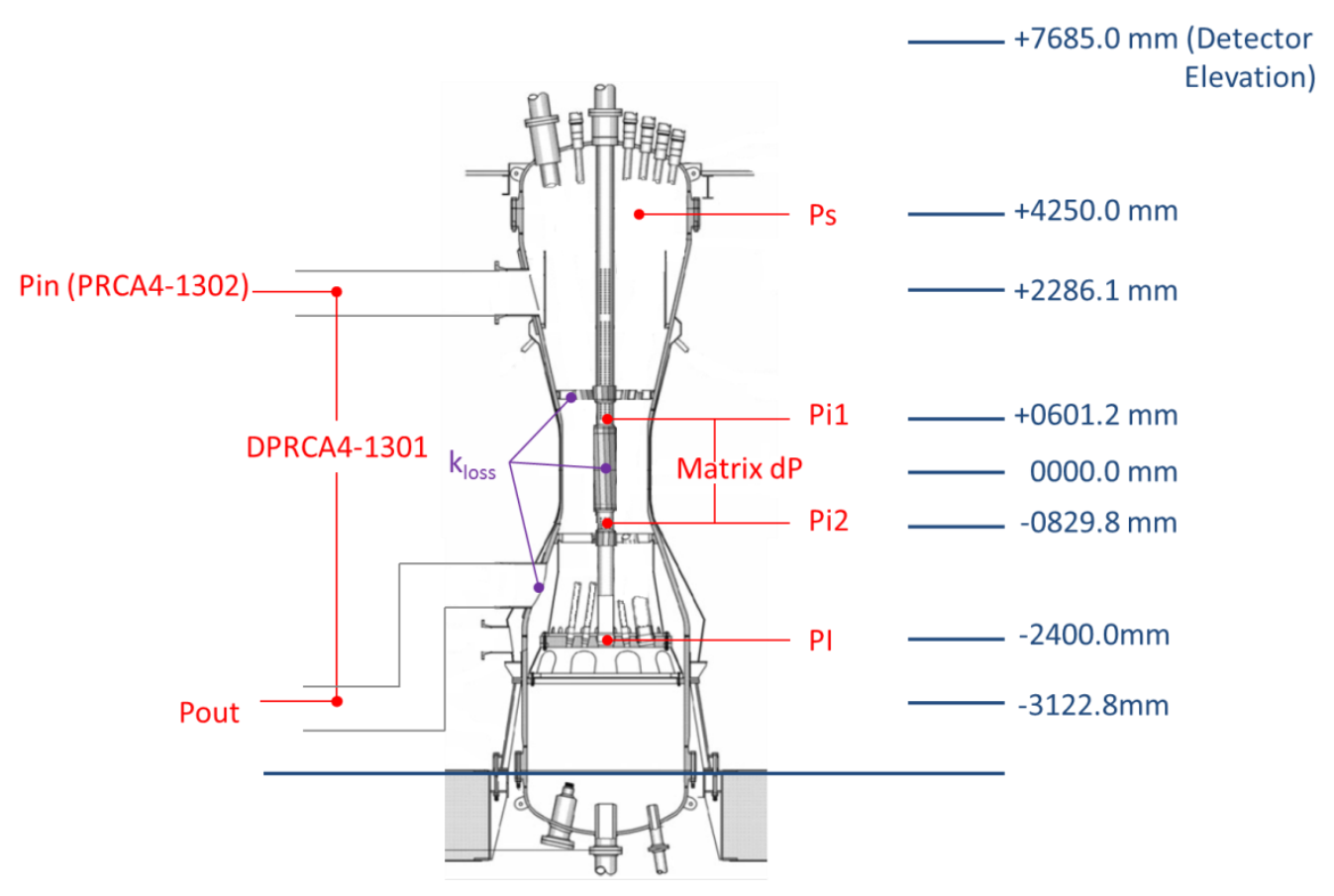

Figure 11 Location and elevation of pressure measurements. Also shown are the three locations where additional loss factors were applied to match reactor data.

\subsubsection{Calibration inside the core}

Tests performed in a hydraulic mockup facility contained data for the flow distribution between the bypass, fuel, control rod and plugged channels for eight different core configurations at an average flow rate of $2200 \mathrm{l} / \mathrm{min}$ within a fuel element ${ }^{11}$ [15]. Ref. [15] provided a detailed description of the coolant as it flows through various paths within the BR2 vessel and used detailed calculations to explain the direction of flow and predict the axial pressure distributions. This information was used in the development of an experimental program for measuring pressure distributions within BR2 (designated here as the 1962 experiments). This reference also provided the experimental results for different total flow rates and core loadings of $3,6,14,17$, and 24 fuel elements (the remainder of the core included

\footnotetext{
${ }^{11}$ Private communication with BR2 engineers indicates there was a discrepancy in the reported bypass flow (14000 $\mathrm{l} / \mathrm{min}$ versus $13360 \mathrm{l} / \mathrm{min})$. The correct value is $13360 \mathrm{l} / \mathrm{min}$.
} 
beryllium plugs). Highlights from these and other experimental results were summarized in Reference [14] and Table 4 for a pressure drop of $2.1 \mathrm{~kg} / \mathrm{cm}^{2}$ across the core.

Table 4 Summary of measured flow rates for a given channel type for a core dP of $2.1 \mathrm{~kg} / \mathrm{cm}^{2}$.

\begin{tabular}{|l|l|c|c|}
\hline \multicolumn{1}{|c|}{ Channel Type } & \multicolumn{1}{|c|}{ Channel Contents } & \multicolumn{2}{c|}{ Flow Rate } \\
\hline \multirow{3}{*}{ Standard channel $(84 \mathrm{~mm})$} & with beryllium plug & $256 \mathrm{I} / \mathrm{min}$ & $4.3 \mathrm{~kg} / \mathrm{s}$ \\
\cline { 2 - 4 } & with fuel element type VIn & $2140 \mathrm{I} / \mathrm{min}$ & $35.6 \mathrm{~kg} / \mathrm{s}$ \\
\cline { 2 - 4 } & with control rod & $442 \mathrm{I} / \mathrm{min}$ & $7.3 \mathrm{~kg} / \mathrm{s}$ \\
\hline H Channel $(200 \mathrm{~mm})$ & with beryllium plug & $1352 \mathrm{I} / \mathrm{min}$ & $22.5 \mathrm{~kg} / \mathrm{s}$ \\
\hline Reflector Channel $(50 \mathrm{~mm})$ & with beryllium plug & $135 \mathrm{I} / \mathrm{min}$ & $2.2 \mathrm{~kg} / \mathrm{s}$ \\
\hline
\end{tabular}

Of note is that Ref. [14] and [15] do not provide a reference flow rate for the bypass channel. It was reported in [15], that for nominal conditions, the flow rate in BR2 was measurably larger than the hydraulic facility $(1261 \mathrm{~kg} / \mathrm{s}$ compared to $1166 \mathrm{~kg} / \mathrm{s})$. The reasons for this were attributed to dimensional tolerance, surface roughness and differences in the diameter, distance and number of holes in the upper extension tubes [15]. Based on the reported information it seems that this discrepancy in total flow has been attributed to the bypass flow. For the hydraulic facility, the bypass flow was reported as 227.2 $\mathrm{kg} / \mathrm{s}$ for all core configurations. The bypass flow for the BR2 1962 tests of different core configurations was estimated to be $361.6 \pm 26.7 \mathrm{~kg} / \mathrm{s}$ based on the difference between total measured flow and the sum of what was expected for each channel type at nominal flow conditions.

Calibration of the core in the RELAP5 vessel model was accomplished by adding forward loss coefficients in channels $16,360,365,366,367,56$ and 76 so that the flow distributions and pressure drop matched those of nominal conditions. The reverse loss coefficients were assumed to be identical to their respective forward coefficients.

The following steps were followed in this calibration process: first, the RELAP5 model was run with the minor loss coefficients set to zero to establish the pressure losses within the core region, the pressure losses into and out of the core region, and the channel flow rates. The channel mass flow rates and their respective pressure losses were then used as input to a separate core hydraulic model based on steady state equations (designated as the EES model). This EES model contains pressure loss equations to describe friction losses within the core channels and two additional loss coefficients. Of these later two, the first is used to match the EES model results to the RELAP5 results without minor loss coefficients and the second is used to determine the loss coefficients needed to match both models to the BR2 1962 data. The loss coefficient needed to match the EES model to the RELAP5 results was small in value and mainly accounts for differences between friction factor models. For example, RELAP5 uses the Colebrook relation [16] for determining the friction factor while the EES model uses its built-in Churchill relation [17]. With the channel inlet and outlet pressures and flow distribution results from the RELAP5 model input into the EES model, the first of the two additional loss coefficients was determined; putting the two models in exact agreement regarding pressure losses and mass flow rates for each channel. Next, the target mass flow rates and pressure drop data were input into the EES model and the equations were solved to determine the second of the required loss coefficients. These loss coefficients were evenly distributed across the 21 internal junctions for each of the core volumes 
(i.e. within volumes $16,360-367,56,76$ ). The RELAP5 model was then run again to verify the calculated pressure drop and mass flow distribution were correct.

In reality, the pressure losses for each channel type are not actually identical nor are they known a priori. In determining the loss coefficients needed to reproduce the experimentally measured flow rates, an average pressure drop across the core was used as a reference in preliminary calculations. By itself, the predetermined loss coefficients were only accurate enough to achieve $+/-4 \%$ agreement between the RELAP5 flow rates and the experimentally measured values. To improve upon this, the ratio of the individual channel pressure drop and average channel pressure drop from the first RELAP5 simulations were imposed on the respective channels in the second EES calculation to achieve an approximation to the expected differences in pressure drop. In this case, the target pressure drop of $2.1 \mathrm{~kg} / \mathrm{cm}^{2}$ was imposed on the high heat flux channel while the other channels were slightly above or below this value (as predicted by RELAP5). This approach resulted in improving the flow rate accuracy to better than $+/-1 \%$ for all channels.

Core calibration results for the 3,14 and 24 element core configurations of the 1962 experiments are given in Table 5. The correct flow rates for each channel were obtained. It is also important to point out that the loss coefficient for a given channel is independent of the core configuration, except for volume 16. This is in agreement with test results that show that for nominal conditions the flow rate of each channel is independent of the core configuration. The loss coefficient of volume 16 varies significantly since, as stated earlier, this channel contains all of the flow uncertainty. 
Table 5 Loss coefficients determined for a 3, 14 and 24 element core. The average values are also given.

\begin{tabular}{|c|c|c|c|c|c|}
\hline \multirow{10}{*}{$\begin{array}{l}1962 \text { BR2 test with } 3 \\
\text { fuel elements }\end{array}$} & $\begin{array}{c}\text { RELAP5 } \\
\#\end{array}$ & $\begin{array}{l}\text { Estimated } \\
\text { loss coef. }\end{array}$ & $\begin{array}{l}\text { Target } \\
\text { flow }\end{array}$ & $\begin{array}{c}\text { Calculated } \\
\text { flow } \\
\end{array}$ & $\begin{array}{c}\% \\
\text { Difference } \\
\end{array}$ \\
\hline & & {$[-]$} & {$[\mathrm{kg} / \mathrm{s}]$} & {$[\mathrm{kg} / \mathrm{s}]$} & [\%] \\
\hline & 16 & 2.256 & 380.4 & 381.7 & +0.34 \\
\hline & 360 & 0.4829 & 35.09 & 35.23 & +0.39 \\
\hline & 365 & 0.7081 & 0.1681 & 0.1689 & +0.48 \\
\hline & 366 & 0.7200 & 0.1915 & 0.1924 & +0.47 \\
\hline & 367 & 1.2720 & 0.2531 & 0.2549 & +0.71 \\
\hline & 36 & & 35.7 & 35.8 & +0.42 \\
\hline & 56 & 0.5202 & 71.3 & 71.7 & +0.56 \\
\hline & 76 & 3.8200 & 395.4 & 393.6 & -0.46 \\
\hline \multirow{10}{*}{$\begin{array}{l}1962 \text { BR2 test with } 14 \\
\text { fuel elements }\end{array}$} & $\begin{array}{c}\text { RELAP5 } \\
\#\end{array}$ & $\begin{array}{l}\text { Estimated } \\
\text { loss coef. }\end{array}$ & $\begin{array}{l}\text { Target } \\
\text { flow }\end{array}$ & $\begin{array}{l}\text { Calculated } \\
\text { flow }\end{array}$ & $\begin{array}{c}\% \\
\text { Difference }\end{array}$ \\
\hline & & {$[-]$} & {$[\mathrm{kg} / \mathrm{s}]$} & {$[\mathrm{kg} / \mathrm{s}]$} & [\%] \\
\hline & 16 & 4.001 & 324.4 & 325.8 & +0.43 \\
\hline & 360 & 0.4794 & 35.09 & 35.14 & +0.14 \\
\hline & 365 & 0.7048 & 0.1681 & 0.1684 & +0.18 \\
\hline & 366 & 0.7168 & 0.1915 & 0.1919 & +0.21 \\
\hline & 367 & 1.2690 & 0.2531 & 0.2542 & +0.43 \\
\hline & 36 & & 35.7 & 35.8 & +0.15 \\
\hline & 56 & 0.5075 & 463.7 & 464.8 & +0.24 \\
\hline & 76 & 3.72 & 348.5 & 345.6 & -0.83 \\
\hline \multirow{10}{*}{$\begin{array}{l}1962 \text { BR2 test with } 24 \\
\text { fuel elements }\end{array}$} & $\begin{array}{c}\text { RELAP5 } \\
\#\end{array}$ & $\begin{array}{l}\text { Estimated } \\
\text { loss coef. }\end{array}$ & $\begin{array}{l}\text { Target } \\
\text { flow }\end{array}$ & $\begin{array}{l}\text { Calculated } \\
\text { flow }\end{array}$ & $\begin{array}{c}\% \\
\text { Difference }\end{array}$ \\
\hline & & {$[-]$} & {$[\mathrm{kg} / \mathrm{s}]$} & {$[\mathrm{kg} / \mathrm{s}]$} & [\%] \\
\hline & 16 & 2.614 & 395.5 & 395.8 & +0.08 \\
\hline & 360 & 0.4733 & 35.09 & 35.16 & +0.20 \\
\hline & 365 & 0.6979 & 0.1681 & 0.1686 & +0.30 \\
\hline & 366 & 0.7099 & 0.1915 & 0.1920 & +0.26 \\
\hline & 367 & 1.2630 & 0.2531 & 0.2544 & +0.51 \\
\hline & 36 & & 35.7 & 35.8 & +0.21 \\
\hline & 56 & 0.4973 & 820.3 & 822.6 & +0.28 \\
\hline & 76 & 4.200 & 305.8 & 303.2 & -0.85 \\
\hline \multirow{8}{*}{ Average and deviation } & $\begin{array}{c}\text { RELAP5 } \\
\#\end{array}$ & \multicolumn{2}{|c|}{ Loss coef. } & \multirow{8}{*}{\multicolumn{2}{|c|}{$\begin{array}{l}\text { Input to achieve } \\
\text { measured pressure drop } \\
\text { and assumed flow } \\
\text { distribution }\end{array}$}} \\
\hline & 16 & \multicolumn{2}{|c|}{$2.9570 \pm 0.753$} & & \\
\hline & 360 & \multicolumn{2}{|c|}{$0.4785 \pm 0.004$} & & \\
\hline & 365 & \multicolumn{2}{|c|}{$0.7036 \pm 0.004$} & & \\
\hline & 366 & \multicolumn{2}{|c|}{$0.7156 \pm 0.004$} & & \\
\hline & 367 & \multicolumn{2}{|c|}{$1.2680 \pm 0.004$} & & \\
\hline & 56 & \multicolumn{2}{|c|}{$0.5083 \pm 0.009$} & & \\
\hline & 76 & \multicolumn{2}{|c|}{$3.9130 \pm 0.206$} & & \\
\hline
\end{tabular}


It is also important to note that the loss coefficient in volume 76 (plugged channel) does not vary significantly for the 1962 core configurations since the hydraulic diameter and velocity remain essentially constant since all the channels contain identical plugs. Figure 12 illustrates the loss coefficient trend for the BR2 and hydraulic facility flow experiments, the 1963 BR2 core and the representative core configuration. However, in the RELAP5 model of the representative core, the minor loss coefficients for the plugged channel (volume 76) can change with core configuration since it is an approximation to a number of different channel types (e.g. plug, experimental apparatus, control rod, etc.) which, depending on the number of each type, can alter the hydraulic diameter and cross sectional flow area. Here it was useful to also analyze several core configurations from the hydraulic facility since it helps bridge the gap between the 1962 data and the representative core.

While Figure 12 shows the trend of the minor loss coefficient $(\mathrm{k})$ required to calibrate the flow in the plug channel as a function of hydraulic diameter, it was assumed to be governed by the following DarcyWeisbach equation ${ }^{12}$ :

$$
k=\frac{C 1}{\left(\frac{\dot{m}}{1000 \cdot A}\right)^{2}}-\frac{C 2}{D_{h}} ; C_{1}=487.4 \text { and } C_{2}=21.93
$$

where the coefficients $C_{1}$ and $C_{2}$ have been optimized with the 1962 core configuration data and the hydraulic facility data. Equation 1 provides a correlation for the minor loss coefficient for the RELAP5 plugged channel to obtain $\mathrm{k}$ for configurations in which there are no measurements. For the representative core, the required minor loss coefficient for volume 76 was calculated to be 17.5 $\left(\dot{m}=305 \mathrm{~kg} / \mathrm{s}, \mathrm{A}=0.06241 \mathrm{~m}^{2}\right.$ and $\left.D_{h}=0.072 \mathrm{~m}\right)$. Table 6 summarizes the minor loss coefficients of volume 76 for various core configurations.

${ }^{12} \mathrm{~A}=$ cross sectional flow area. $\mathrm{D}_{\mathrm{h}}=$ hydraulic diameter. $\dot{m}=$ mass flow rate. 


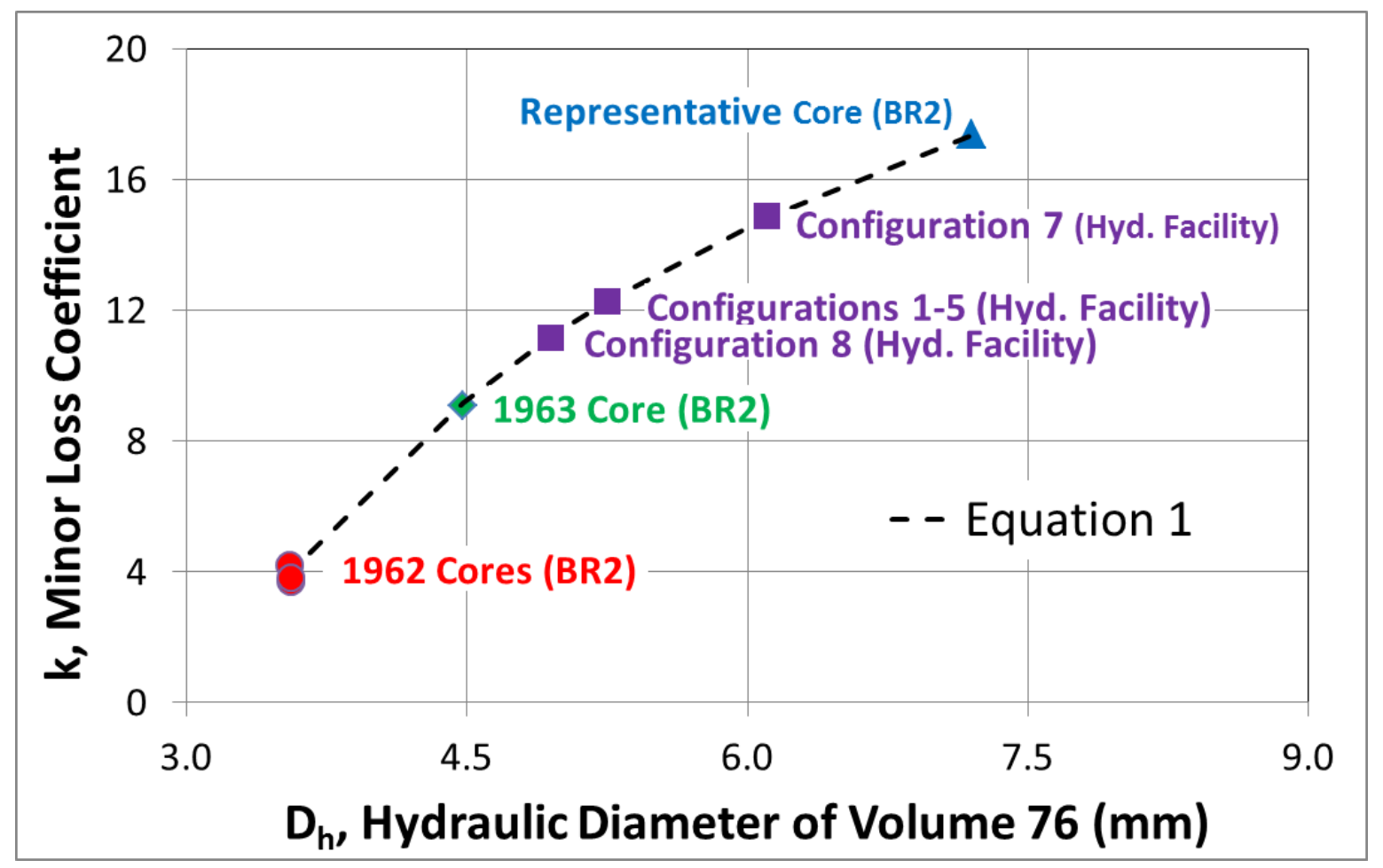

Figure 12 Loss coefficients for volume 76 as a function of various core configurations.

Table 6 Minor loss coefficient and parameters for volume 76 with various core configurations.

\begin{tabular}{|l|c|c|c|c|c|}
\hline & Mass & Flow & Hydraulic & \multicolumn{2}{|c|}{ Minor Loss Coefficient } \\
\cline { 5 - 6 } & Flow Rate & Area & Diameter & Calibration & Equation 1 \\
\cline { 2 - 3 } Core Configuration & $\mathbf{k g} / \mathbf{s}$ & $\mathbf{m}^{\mathbf{2}}$ & $\mathbf{m}$ & - & - \\
\hline 1962,24 fuel assemblies & 305.8 & 0.04368 & 3.55 & 4.20 & 3.77 \\
\hline 1962,14 fuel assemblies & 348.5 & 0.05011 & 3.56 & 3.72 & 3.92 \\
\hline 1962,3 fuel assemblies & 395.4 & 0.05719 & 3.56 & 3.82 & 4.04 \\
\hline Hydraulic facility (Configuration 8) & 433.7 & 0.07767 & 4.95 & 11.15 & 11.20 \\
\hline Hydraulic facility (Configuration 1-5) & 377.2 & 0.06931 & 5.25 & 12.26 & 12.28 \\
\hline Hydraulic facility (Configuration 7) & 290.2 & 0.05644 & 6.1 & 14.89 & 14.84 \\
\hline \hline 1963, 15 fuel assemblies & 376.4 & 0.06394 & 4.48 & & 9.17 \\
\hline Representative, 31 fuel assemblies & 305 & 0.06241 & 7.2 & & 17.36 \\
\hline
\end{tabular}

\subsubsection{Calibration outside the core}

The form loss coefficients included in the RELAP5 model prior to beginning the calibration process were assumed to provide a reasonable approximation of the flow distribution since simulations without the loss coefficients from the previous section didn't produce a flow distribution pattern that was significantly different from the measured data. After including the loss coefficient from the previous section, it was assumed the flow distribution was finalized and the only modification still required was the magnitude of the pressure drop outside the core region to match it to the DPRCA4-1301 measurement. The DPRCA4-1301 is a differential pressure measurement of the reactor vessel, with pressure taps located on the inlet and outlet piping. Additional pressure measurements are made in the upper plenum and near the lower plenum at the support grid. Review of the available data indicates 
there is general agreement in pressure loss trends for the 1962 BR2 flow tests, so for simplicity the 14 element core configuration was chosen as the basis for analysis. The loss coefficients were then demonstrated to be applicable to any core configuration over the range of data available for the 1962 BR2 hydraulic tests.

Based on the available data and notes from the BR2 team ${ }^{13}$, the pressure loss from the inlet pipe to the upper plenum and from the core outlet to the support grid was approximately $\sim 0 \mathrm{~kg} / \mathrm{cm}^{2}$. This is due the fact that the flow is decelerating, converting kinetic energy to potential energy. This is in agreement with preliminary RELAP5 simulations. No additional loss factors were required at these locations.

Between the upper plenum and the core inlet, preliminary RELAP5 simulations indicate additional losses were required to match experimental data. A loss coefficient was placed at the junction between volume 12 and 14, as well as for the other channels at this elevation. Similar to the procedure for calibration of the core region, a separate steady-state set of equations were developed to solve for the minor loss coefficient required to match the target pressure drop. Although in this case, the pressure drop was achieved without altering the flow distribution. Table 7 summarizes the loss coefficients required at this location.

Table 7 Loss coefficients included in reactor vessel model above the core region.

\begin{tabular}{|c|c|c|}
\hline RELAP5 Junction & Additional k loss & Description \\
\hline Branch \#14, Junction \#1 between volumes 12 and 14 & 2.34 & \multirow{4}{*}{$\begin{array}{l}\text { Input to achieve measured pressure } \\
\text { drop across upper channel support }\end{array}$} \\
\hline Branch \#34, Junction \#1 between volumes \#32 and 34 & 0.3113 & \\
\hline Branch \#54, Junction \#1 between volumes \#52 and 54 & 0.3119 & \\
\hline Branch \#74, Junction \#1 between volumes \#72 and 74 & 5.067 & \\
\hline
\end{tabular}

With the above minor loss coefficients included, the pressure distributions from the inlet pressure measurement to the lower support grid within the reactor vessel were in good agreement with measurements. Comparison of simulations to the 1963 DPRCA4-1301 measurement indicated that additional pressure loss was required in the model between the lower support grid and the outlet pressure measurement. However, no additional measurements were made between these two locations. After reviewing the impact of including a minor loss coefficient at various locations, it was determined that there was no location which provided the proper pressure drop for all cases. This issue might be expected since the pressure loss from the complex 3-dimensional flow pattern in the lower region of the pressure vessel cannot be modeled accurately by RELAP5 (1-dimensional code). For simplicity, a minor loss coefficient of 11.2 was placed at the junctions between the reactor vessel and outlet piping (junctions 991 and 992) to obtain the correct reactor vessel pressure drop (DPRCA4-1301) value for the 1963 core configuration. However, this minor loss coefficient, results in a deviation between the model results and experimental data for other flow rates (i.e. different core configurations). For the representative core configuration, this minor loss coefficient was removed from junctions 991 and 992 since comparison to both historical and recent reactor data in core configurations with similar flow rates suggests that it is not necessary to obtain the correct pressure drop values for DPRCA4-1301.

${ }^{13}$ RELAP5 model development notes provided by BR2 can be found in the ANL archive of the BR2 conversion files. 


\subsubsection{Calibration summary}

Figure 13 shows the results for the calibrated RELAP5 model compared to experimental data. Figure 13a includes core pressure drop measurement data for the 1962 BR2 experiments, 1973/74 BR2 experiments and the 1963 BR2 experiment. The RELAP5 simulations produce good agreement with the 1962 data for both nominal flow rates and reduced flow rates. The RELAP5 simulations for the 1963 core configuration produces the correct pressure drop but has a flow rate slightly less than its experimental counterpart. The RELAP5 flow rate is specified based on the core configuration and expected flow in each channel (see Table 4). The difference between this and the measured flow rate is likely due to the uncertainty in the flow measurement of the reactor and the uncertainty in the specified flow given in Table 4. Regardless, the target flow and velocity $(\sim 35.6 \mathrm{~kg} / \mathrm{s}, \sim 10.4 \mathrm{~m} / \mathrm{s}$ ) is achieved in the fuel element for the simulations ${ }^{14}$.

Figure $13 \mathrm{~b}$ is a similar graph that shows the pressure drop across the reactor vessel (DPRCA4-1301). The simulations for the 1962 core configurations are reasonable but do show a trend of increasing pressure drop with increased flow rate at nominal conditions. The minor loss coefficient accounting for the pressure loss in the lower region of the pressure vessel (11.2) produced results similar to the 1963 BR2 experimental measurements and so it was utilized for those simulations. Preliminary simulations of the representative core indicated that the removing the minor loss coefficient completely was required to achieve the expected results $\left(3.1 \mathrm{~kg} / \mathrm{cm}^{2}\right)$. As described above, this minor loss coefficient was not included in the representative core model.

\footnotetext{
${ }^{14}$ The calibration process has been performed for the Sylcor fuel element which contained an annular flow path within the central plug. The currently used CERCA fuel elements have an identical geometry except that there is no annular flow within the central plug and its diameter is slightly reduced. The hydraulic diameter of the Sylcor and CERCA fuel elements are $5.8 \mathrm{~mm}$ and $5.9 \mathrm{~mm}$, respectively. This results in a small increase of velocity by $0.1 \mathrm{~m} / \mathrm{s}$ which is not expected to impact simulation results.
} 


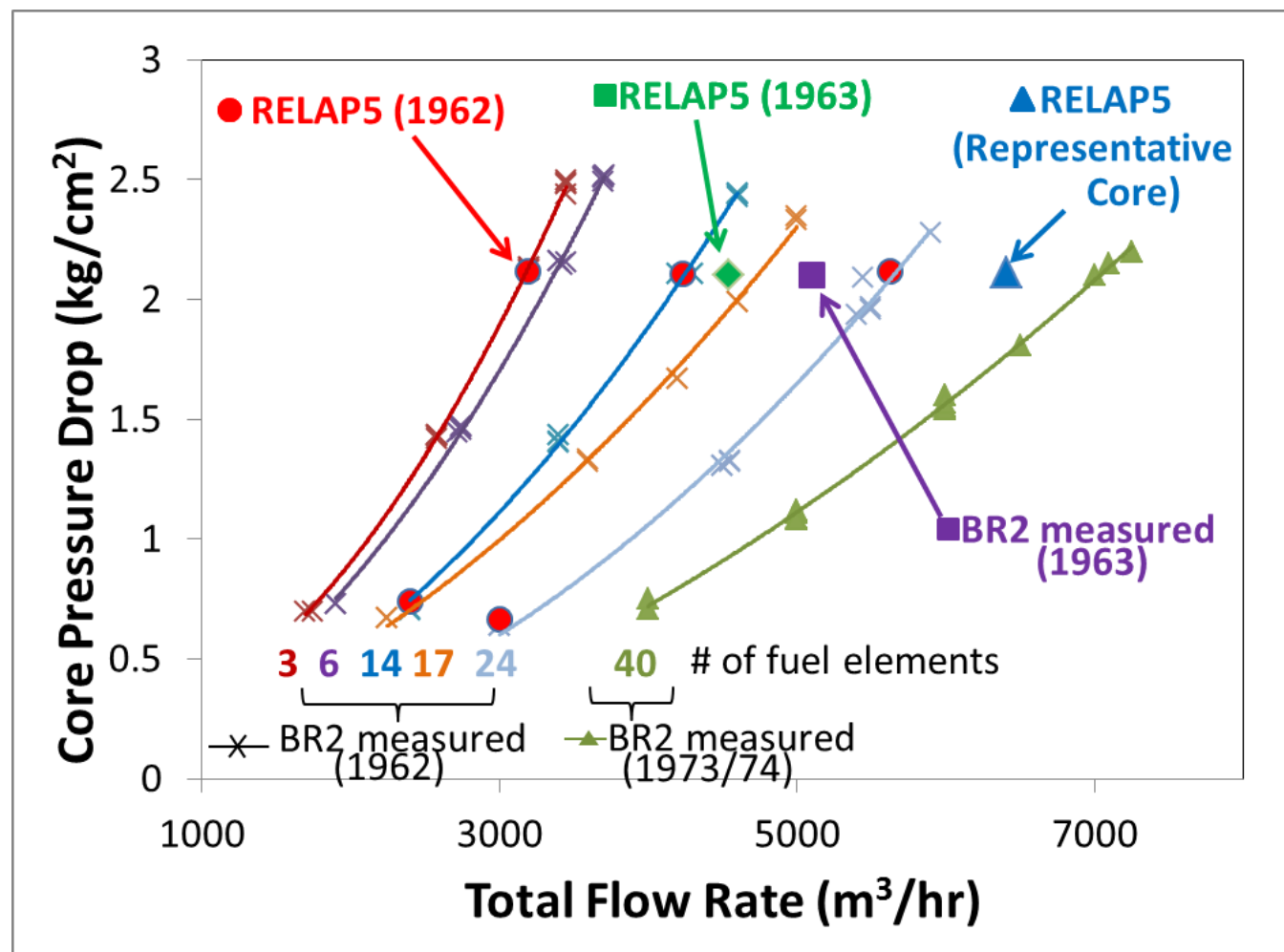

(a)

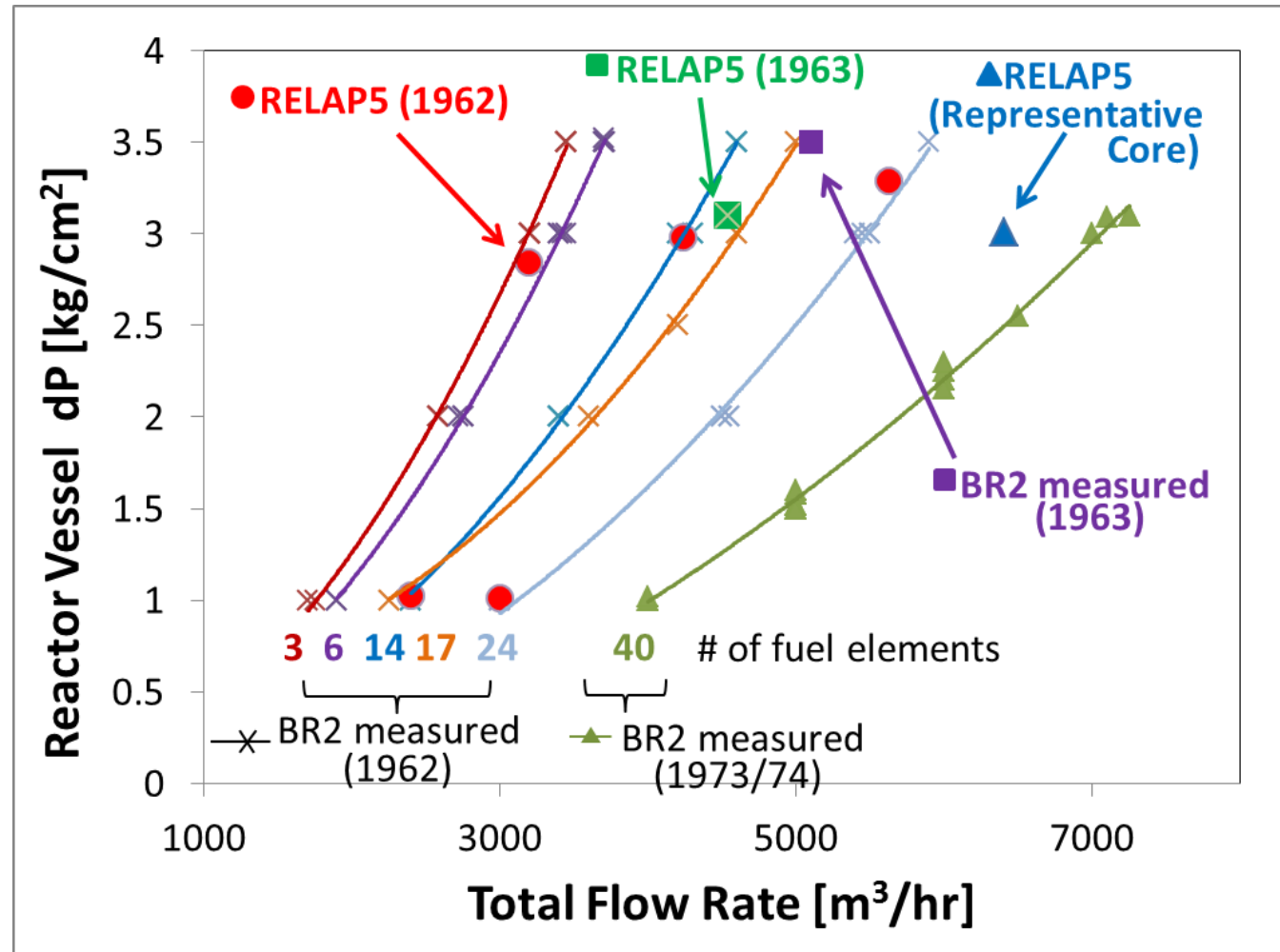

(b)

Figure 13 Comparison of RELAP5 pressure loss simulations (a: core pressure drop, b: reactor vessel pressure drop) to 1962 and 1973/74 BR2 hydraulic tests. Data for the 1963 BR2 core configuration and estimated results for the representative core are also shown. 
These minor loss coefficients, or correction factors, needed to achieve the correct flow rates and pressure losses are justified since the hydraulic parameters determined for the reference RELAP5 model do not exactly represent the reactor, but are a volume averaged approximations to it. The correction factors account for the differences between the volume averaged approximation and the reality of the reactor components. For example, the large correction factor for the bypass channel accounts for the many small triangular flow paths and their contraction at the core centerline caused by the convergence of the angled channels, details that are averaged out in the approximation of the core region. The large loss coefficient for the plugged channel, and its variability, accounts for the fact that there are a variety of hydraulic diameters for the different sections of this channel. It is inherent in the volume averaging of these channels that the resulting hydraulic diameter will under represent the hydraulic resistance of the system. The calibrated loss coefficients correct these issues. The fact that there is good agreement for the loss coefficients across many core configurations is significant because it establishes credibility for the loss coefficients and flow distribution that will be predicted for the representative core since it can be closely tied to the experimental data acquired in the late 1950's and early 1960's.

\subsection{Pump coast down}

The implementation of the pump coast down in the RELAP5 model is accomplished by a two part calibration process:

1. adjustment of the pump torque friction values to capture the coast down behavior for the normalized flow range of 1 down to $\sim 0.1$, and

2. adjustment of the pump check valves to capture the coast down behavior as the normalized flow decreases from 0.1 to 0 .

For the first part, calibration was based on three coast down tests that were performed in 2010 in the BR2 reactor [18]. All three tests produced similar results which were averaged for use in calibrating the RELAP5 model (Figure 14).

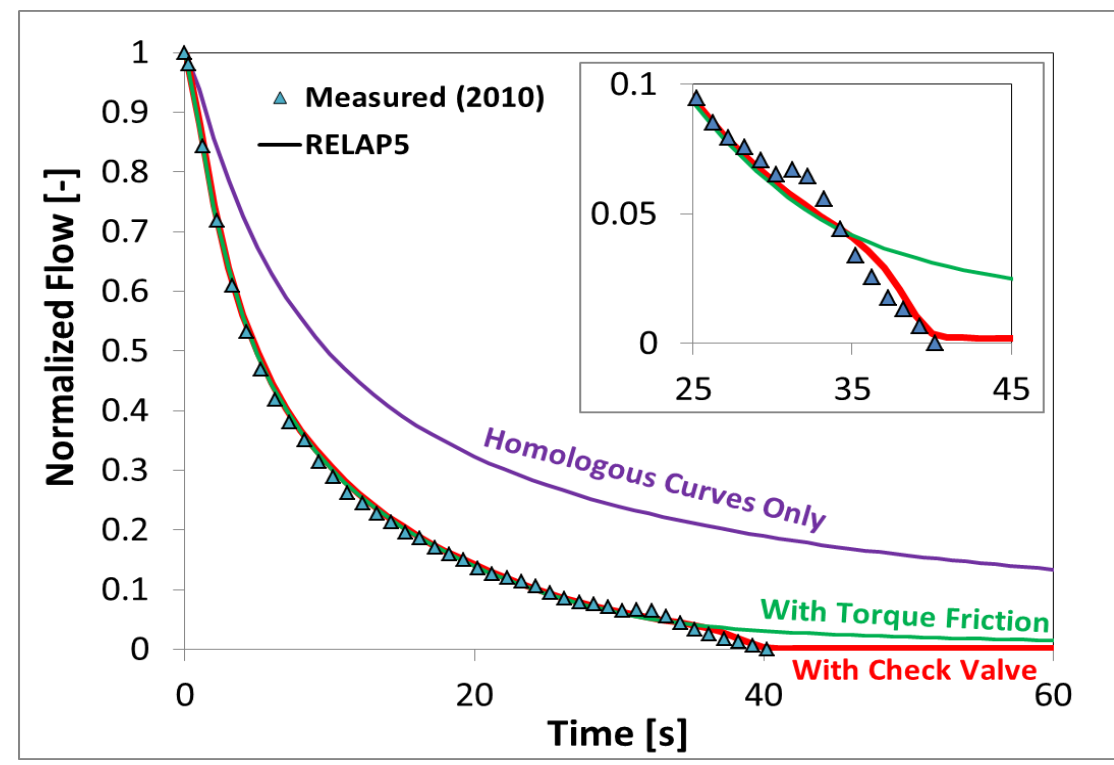

Figure 14 Comparison of the 2010 BR2 pump coast down data to RELAP5 simulations. 
From trial and error, the torque friction values were adjusted to values given in Table 8.

Table 8 Torque friction coefficients.

\begin{tabular}{|l|c|c|c|c|}
\hline Data set & TF0 & TF1 & TF2 & TF3 \\
\hline 2010 & 250 & 600 & 700 & 3900 \\
\hline
\end{tabular}

where the torque friction is a function of the ratio of current speed to rated speed $(S)$ :

$$
\text { torque friction }=T F 0+T F 1 \cdot S+T F 2 \cdot S^{2}+T F 3 \cdot S^{3}
$$

The second part of the calibration was to capture the effect of the closing of the pump check valves on the coast down. This was accomplished by adjusting the trip parameter, the normalized flow area as a function valve position and the closing rate. The trip value was selected to be $100 \mathrm{~kg} / \mathrm{s}$ and was based on the coast down curve shown in Figure 12.9 of Ref. [11]. This trip value was compared to the flow rate through the pump check valve. The normalized valve area $(y)$ was arbitrarily assumed to follow the relation $y=1-\sqrt{1-x^{2}}$ which depends on the valve position ( $x$ ) (Figure 15). This, in combination with an assumed closing rate $0.1 \mathrm{~s}^{-1}$, resulted in a reasonable approximation of the ceasing of flow measured in the 2010 tests, as shown in Figure 14.

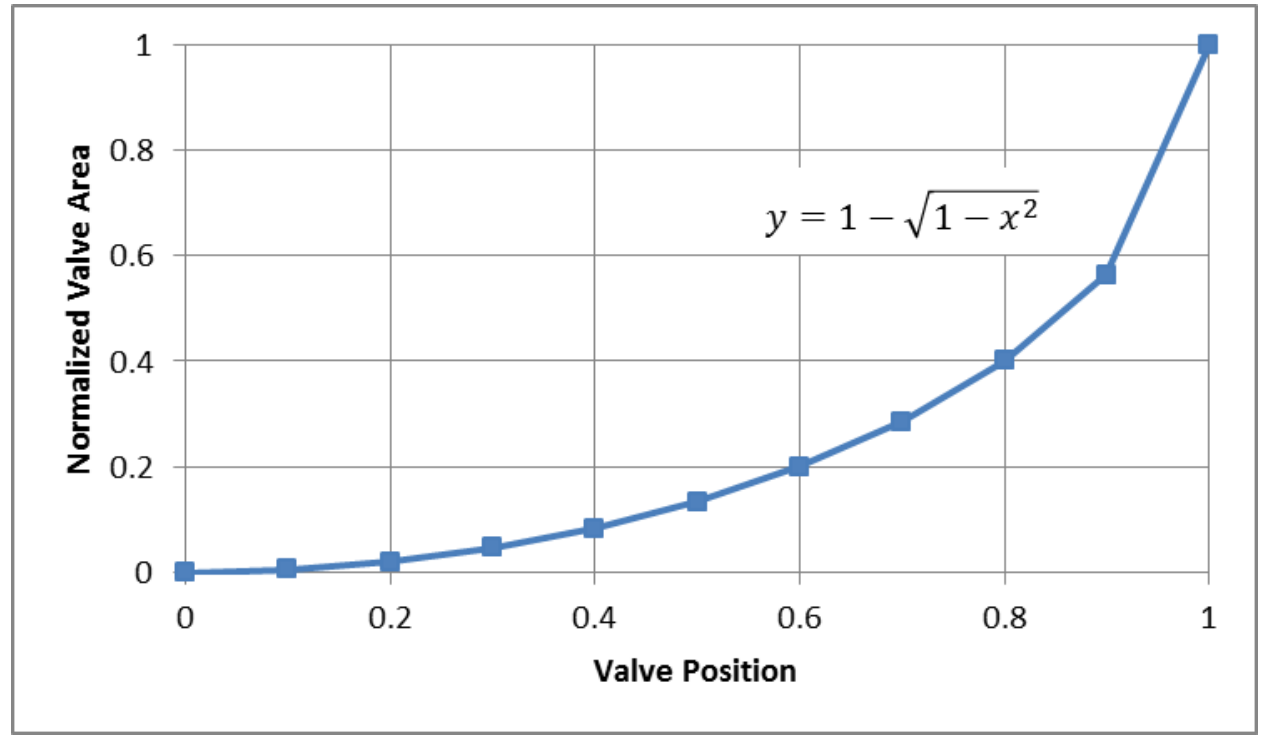

Figure 15 Relation between valve area and position for the primary pump check valve.

\section{Intermediate Simulations}

Validation of the BR2 RELAP5 model for the 1963 core configuration has been done by comparing calculation results with the experimental results [7]. In extending the RELAP5 model to the representative core configuration, several significant but important changes to the model are needed. Since there are no LOF/LOP tests performed for the BR2 representative core configuration, a set of intermediate calculations have been performed to bridge the gap between the RELAP5 1963 core and RELAP5 representative core models. 
Figure 16 and Table 9 illustrates, in a step-by-step manner, the impact on clad temperature (TC14) for Test $A$ due to model changes that have been included to move from the 1963 model to the representative core. The 1963 experimental data for Test A is given as curve (i). The RELAP5 simulation (ii) from Ref. [7] compares well with the experimental data and is based on several important assumptions that include:

1. A best estimate evaluation of the peak heat flux $\left(309 \mathrm{~W} / \mathrm{cm}^{2}\right)$ determined from MCNP calculations of the 1963 core configuration described in Ref. [19].

2. The power after scram takes into account spreading of the decay heat due to the redistribution of the gamma energy [19].

3. The residual fission power, which was estimated to be $0.1 \%$ of nominal at 20 s [20], for the 1963 core configuration, is neglected given the time of interest in the transients.

4. Specification of event times (e.g. valve position, pump trip, reactor scram, etc...) based on measured values (as shown in Appendix E).

These assumptions were updated/changed for the representative core. Beginning with item 3 from above, the fission power for the 1963 experiments was considered negligible since it decays to near zero at the time flow reversal occurs. For the representative core, the point kinetics model calculates a shutdown fission power that is significant enough to be included in the overall heat load after scram (see Appendix C). To illustrate the impact of the larger residual fission power (e.g. $0.7 \%$ at $20 \mathrm{~s}$ ) for the representative core configuration, it was added to the decay heat used for the 1963 tests. The results are shown in curve (iii) of Figure 16 . This shows that for the representative core, the additional shutdown fission power results in about a $10^{\circ} \mathrm{C}$ increase in peak cladding temperature relative to the 1963 core simulations.

Next, item 2 from above, it was found that there was significant spreading of the decay heat in the 1963 core due to redistribution of the gamma energy. It is anticipated that this spreading of decay heat may not be as significant for the representative core. Since the spreading of the decay heat has not been calculated for the representative core, it has been conservatively assumed that there is no spreading of the decay heat. Thus, the decay heat can be readily calculated with the 1979 ANS standard decay heat available within RELAP5. Curve (iv) of Figure 16 illustrates the conservatism that is added to the curve (iii) simulation results if the decay heat spreading is neglected. This level of conservatism adds approximately $40^{\circ} \mathrm{C}$ to the peak cladding temperature for the 1963 core configuration.

Item 1 from above addresses the fact that, despite Test $A$ being labeled as a test performed at $400 \mathrm{~W} / \mathrm{cm}^{2}$, best estimate MCNP calculations indicate a heat flux of $309 \mathrm{~W} / \mathrm{cm}^{2}$ for the measured core power. Curve (v) illustrates the impact of increasing the power of curve (iv) to achieve the current maximum operating heat flux limit of $470 \mathrm{~W} / \mathrm{cm}^{2}$. In this case, the power is sufficiently high that a limited amount of nucleate boiling occurs near the peak clad temperature.

Finally, item 4 is concerned with the timing of events, such as valve opening/closing times and trip delays. For the representative core model, a control system has been implemented based on the current system and recommended time delays. The impact of switching from the 1963 event times to 
the current control system of the representative core is shown by comparing curves (vi) and (v). The end result is a shifting of the flow reversal time from $\sim 30 \mathrm{~s}$ to $\sim 25 \mathrm{~s}$. Curve (vi) also illustrates the culmination of the impact for the 1963 Test A simulations results using all of the new assumptions and model changes required for the representative core model. That is, the model changes significantly increase the peak clad temperature and induce nucleate boiling in the core during flow reversal.

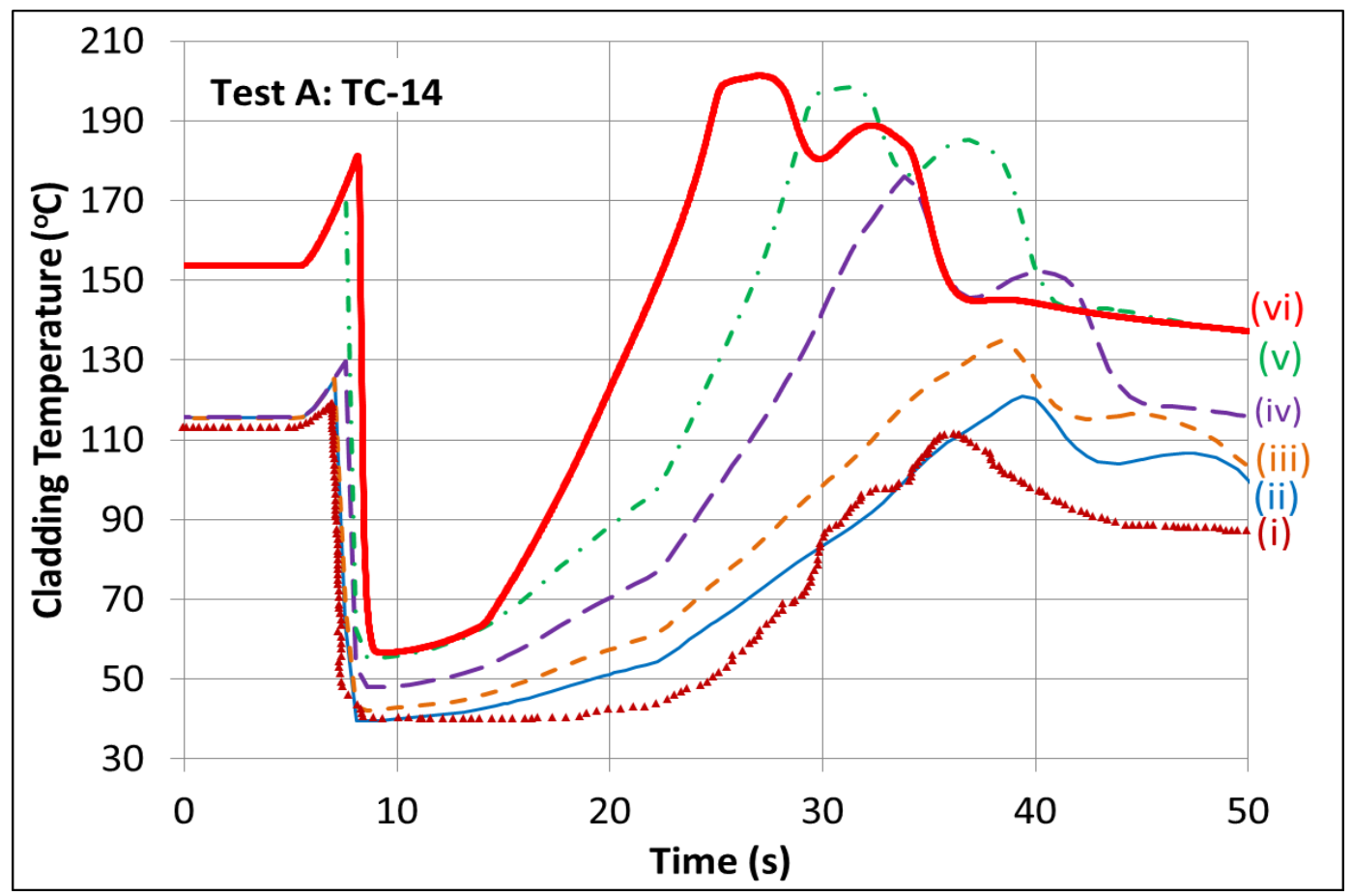

Figure 161963 Test A cladding temperature (TC-14) due to RELAP5 model changes.

Table 9 Legend and description for Figure 16.

\begin{tabular}{|c|l|}
\hline (i) & 1963 experimental data (TC-14) from Test A. \\
\hline (ii) & $\begin{array}{l}\text { RELAP5 simulation. Key assumptions include: peak heat flux of } 309 \mathrm{~W} / \mathrm{cm}^{2} \text { (MCNP calculation), } \\
\text { spreading of the decay heat due to gamma energy distribution (MCNP/ORIGIN calculations), } \\
\text { neglecting the shutdown fission power ( 0.1\% at 20s [20]) and using event times (valve } \\
\text { opening/closing, pump and power trip) based on measured values. }\end{array}$ \\
\hline (iii) & $\begin{array}{l}\text { RELAP5 Simulation. Same assumptions as } 2 \text { above, but adds to it the shutdown fission power } \\
\text { calculated for the representative core ( } 0.7 \% \text { at 20s) }\end{array}$ \\
\hline (iv) & $\begin{array}{l}\text { RELAP5 Simulation. Same assumptions as } 3 \text { above, but conservatively ignores the spreading of } \\
\text { the decay heat due to gamma energy redistribution after scram and uses the } 1979 \text { ANS decay } \\
\text { heat curve. }\end{array}$ \\
\hline (v) & $\begin{array}{l}\text { RELAP5 Simulation. Same assumptions as } 4 \text { above, but the power has been increased from the } \\
\text { best estimate value (310 W/cm²) during Test A to the current maximum allowable heat } \\
\text { flux(470 W/cm²). }\end{array}$ \\
\hline (vi) & $\begin{array}{l}\text { RELAP5 Simulation. Same assumptions as } 5 \text { above, but the event times are based on the } \\
\text { current control system trip delays. This case is representative of all the changes that are } \\
\text { required to move from modeling the } 1963 \text { LOF/LOP tests to the modeling of the same events } \\
\text { in the representative core. }\end{array}$ \\
\hline
\end{tabular}




\section{Representative Core Simulations}

This section provides the results and discussion for repeating the simulations of the selected accident scenarios from the 1963 experiments with the representative core for HEU and LEU fuel. The accident scenarios have been updated to reflect the current maximum heat flux limit of $470 \mathrm{~W} / \mathrm{cm} 2$ and current temporary heat flux limit of $600 \mathrm{~W} / \mathrm{cm}^{2}$. The tests that have been simulated for the representative core are defined as:

Test A - Total loss of flow followed by opening of the bypass valve (at the maximum heat flux limit of $470 \mathrm{~W} / \mathrm{cm}^{2}$ ),

Test C - Untimely opening of the bypass valve (at the temporary heat flux limit of $600 \mathrm{~W} / \mathrm{cm}^{2}$ ),

Test F - Untimely opening of the pool connection valve followed by opening of the bypass valve (at the maximum heat flux limit of $470 \mathrm{~W} / \mathrm{cm}^{2}$ ), and

Test G - Total loss of pressure without opening of the bypass valve (at the maximum heat flux limit of $\left.470 \mathrm{~W} / \mathrm{cm}^{2}\right)$.

For all of these simulations it is conservatively assumed that the external cooling (vessel shroud and secondary side of the primary heat exchangers) was terminated by reducing the flow to $0 \mathrm{~kg} / \mathrm{s}$ within $5 \mathrm{~s}$. It was conservatively assumed that the flow decreased to zero within $5 \mathrm{~s}$. This value was chosen to avoid calculation issues associated with an instantaneous stoppage of flow.

\subsection{Steady State Results}

A summary of the steady-state operating conditions calculated by the RELAP5 input models is given in Table 10. The measurement locations can be found in Figure 7 and Figure 8 and coincide with the BR2 reactor instrumentation. The maximum heat flux limit of $470 \mathrm{~W} / \mathrm{cm}^{2}$ was achieved by adjusting the reactor power to 77.2 $\mathrm{MW}$ and $72.4 \mathrm{MW}$ for HEU and LEU fuel, respectively. The temporary heat flux limit of $600 \mathrm{~W} / \mathrm{cm}^{2}$ was achieved by adjusting the reactor power to $98.5 \mathrm{MW}$ and $93.3 \mathrm{MW}$ for HEU and LEU fuel, respectively. Figure 17 shows the axial heat flux distribution for the HEU and LEU fuel element produced by the RELAP5 model at steady state. ${ }^{15}$ The coolant flow rate was set by a controller in the RELAP5 model to achieve the target pressure drop across the reactor $\left(3.1 \mathrm{~kg} / \mathrm{cm}^{2}\right)$. At this condition, the core pressure drop value is calculated to be $2.1 \mathrm{~kg} / \mathrm{cm}^{2}$. The inlet pressure was set to the nominal value of $12.6 \mathrm{~kg} / \mathrm{cm}^{2}$ using a pressure controller within the pressurizer model. The inlet temperature has been set to the nominal value of $35^{\circ} \mathrm{C}$ by controlling the temperature of the secondary side of the primary heat exchanger. For simplicity, the clad temperatures have been taken at the locations of the thermocouples used in the 1963 experiments. The thermocouples were located at the following elevations from the fuel centerline:

- TC11: $+300 \mathrm{~mm}$

- TC12: $+150 \mathrm{~mm}$

- TC13: $0 \mathrm{~mm}$

- TC14: $-150 \mathrm{~mm}$

\footnotetext{
${ }^{15}$ The jagged nature of the peak heat flux, induced by the power profile, is likely due to the presence of the control rod (about half inserted) which may cause a local flux depression at the control rod level and a flux spike just below the control rod.
} 
The peak clad temperature (at steady state and usually for the transient) occurs at heat structure node 15 for HEU and 14 LEU. TC14 is located between these two nodes and is taken as the average. For convenience, the value at TC14 is used when discussing peak temperatures.

Table 10 Steady-state values calculated by RELAP5 model.

\begin{tabular}{|c|c|c|c|c|c|}
\hline \multirow{2}{*}{\multicolumn{2}{|c|}{$\begin{array}{l}\text { Peak Heat Flux } \\
\text { Fuel Type }\end{array}$}} & \multicolumn{2}{|c|}{$470 \mathrm{~W} / \mathrm{cm}^{2}$} & \multicolumn{2}{|c|}{$600 \mathrm{~W} / \mathrm{cm}^{2}$} \\
\hline & & \multirow[t]{2}{*}{ HEU } & \multirow[t]{2}{*}{ LEU } & \multirow[t]{2}{*}{ HEU } & \multirow[t]{2}{*}{ LEU } \\
\hline Label & Description & & & & \\
\hline N/A & Power (MW) & 77.2 & 72.4 & 98.5 & 93.3 \\
\hline FRCA4-1301 & Coolant Flow $\left(\mathrm{m}^{3} / \mathrm{hr}\right)$ & \multicolumn{2}{|c|}{6478} & \multicolumn{2}{|c|}{6482} \\
\hline DPRCA4-1301 & Pressure drop across reactor $\left(\mathrm{kg} / \mathrm{cm}^{2}\right)$ & \multicolumn{4}{|c|}{3.1} \\
\hline $\mathrm{N} / \mathrm{A}$ & Pressure drop across core $\left(\mathrm{kg} / \mathrm{cm}^{2}\right)$ & \multicolumn{4}{|c|}{2.1} \\
\hline PRCA4-1302 & Reactor inlet pressure $\left(\mathrm{kg} / \mathrm{cm}^{2}\right)$ & \multicolumn{4}{|c|}{12.6} \\
\hline TRAS4-1301 & Coolant inlet temperature $\left({ }^{\circ} \mathrm{C}\right)$ & \multicolumn{4}{|c|}{35.0} \\
\hline TRA4-1304 & Coolant outlet temperature $\left({ }^{\circ} \mathrm{C}\right)$ & 45.2 & 44.5 & 48.1 & 47.3 \\
\hline DTRA4-1301 & Temperature difference $\left({ }^{\circ} \mathrm{C}\right)$ & 10.3 & 9.6 & 13.1 & 12.4 \\
\hline TC11 & $\begin{array}{l}\text { Clad temperature }\left({ }^{\circ} \mathrm{C}\right) \\
\text { Elevation }=\text { fuel centerline }+300 \mathrm{~mm}\end{array}$ & 78.7 & 84.9 & 90.5 & 99.2 \\
\hline TC12 & $\begin{array}{l}\text { Clad temperature }\left({ }^{\circ} \mathrm{C}\right) \\
\text { Elevation }=\text { fuel centerline }+150 \mathrm{~mm}\end{array}$ & 117.1 & 123.5 & 138.3 & 147.5 \\
\hline TC13 & $\begin{array}{l}\text { Clad temperature }\left({ }^{\circ} \mathrm{C}\right) \\
\text { Elevation }=\text { fuel centerline }+0 \mathrm{~mm}\end{array}$ & 143.9 & 145.8 & 170.6 & 174.4 \\
\hline TC14 & $\begin{array}{l}\text { Clad temperature }\left({ }^{\circ} \mathrm{C}\right) \\
\text { Elevation }=\text { fuel centerline }-150 \mathrm{~mm}\end{array}$ & 153.2 & 152.8 & 181.0 & 182.1 \\
\hline PIAS4-1303 & Pressure difference across ABV4-1308 $\left(\mathrm{kg} / \mathrm{cm}^{2}\right)$ & \multicolumn{4}{|c|}{9.2} \\
\hline PIAS4-1301 & Pump inlet pressure $\left(\mathrm{kg} / \mathrm{cm}^{2}\right)$ & \multicolumn{4}{|c|}{9.9} \\
\hline PIAS4-1303 & Pump outlet pressure $\left(\mathrm{kg} / \mathrm{cm}^{2}\right)$ & \multicolumn{4}{|c|}{15.9} \\
\hline
\end{tabular}
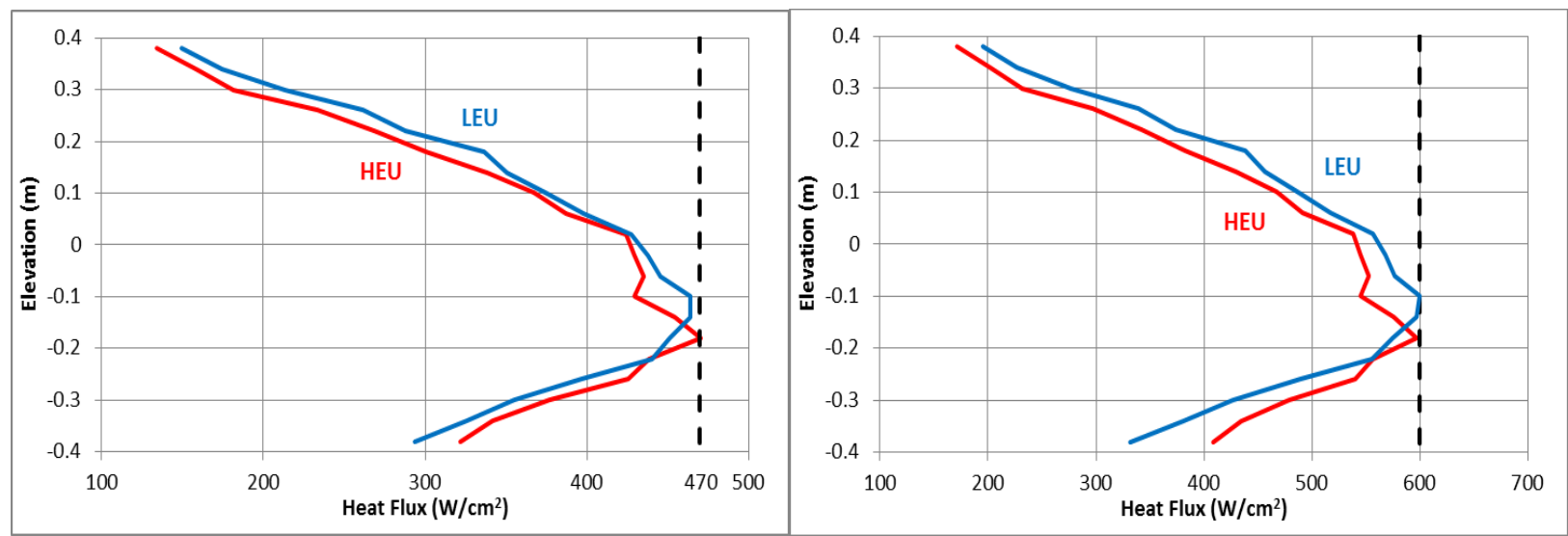

Figure 17 Axial heat flux distribution for the HEU and LEU fuel element calculated by RELAP5 model. 


\subsection{Test A}

The Test A transient is defined as a total loss of flow followed by opening of the bypass valve with an initial steady-state heat flux of $470 \mathrm{~W} / \mathrm{cm}^{2}$. Figure 18 shows a time line of the important events in the transient for an HEU core. The pumps were tripped at time $=0 \mathrm{~s}$ to initiate the transient. At $1.92 \mathrm{~s}$ the reactor scram occurs due to a trip on the reactor vessel pressure differential (DPRCA4-1301 < $1.8 \mathrm{~kg} / \mathrm{cm}^{2}$ ). Other reactor scram (RS) trips occur at a later time and do not impact the transient \{valve movement RS(ABV) [movement of ABV4-1301 at 9.74 s] and flow rate RS (F) [FRCA4-1301 < 4500 at $2.70 \mathrm{~s}]\}$. At $9.486 \mathrm{~s}$ the bypass valve ABV4-1301 begins to open due to the trip on reactor vessel pressure differential (DPRCA4-1301 $<0.5 \mathrm{~kg} / \mathrm{cm}^{2}$ ). The peak cladding temperature $\mathrm{TC} 14=197.3^{\circ} \mathrm{C}$ occurs at $27.1 \mathrm{~s}$ followed by a flow reversal in RELAP5 channel 367 at $30.1 \mathrm{~s}$. The pump check valves close at $35.01 \mathrm{~s}$. This information is summarized and compared to the LEU core in Table 11. The results obtained for an LEU core are nearly identical to that obtained with an HEU core. As a reference, Appendix E contains the 1963 test chronology. ${ }^{16}$



Figure 18 Chronology of important events in Test A transient with HEU core.

\footnotetext{
${ }^{16}$ A direct comparison of the representative core and 1963 data has not been included here since complete details of the control system used during the 1963 tests were not available.
} 
Table 11 Chronology of Test A transient for HEU and LEU fuel

\begin{tabular}{|l|c|c|}
\hline Event & HEU & LEU \\
\hline \hline Pump Stop & $0.00 \mathrm{~s}$ & $0.00 \mathrm{~s}$ \\
\hline RS(dP) & $1.91 \mathrm{~s}$ & $1.91 \mathrm{~s}$ \\
\hline RS(F) & $2.69 \mathrm{~s}$ & $2.69 \mathrm{~s}$ \\
\hline ABV1301 & $9.48 \mathrm{~s}$ & $9.47 \mathrm{~s}$ \\
\hline RS(ABV) & $9.73 \mathrm{~s}$ & $9.72 \mathrm{~s}$ \\
\hline TC14 max time (temp) & $26.2 \mathrm{~s}\left(199.8^{\circ} \mathrm{C}\right)$ & $26.1 \mathrm{~s}\left(200.1^{\circ} \mathrm{C}\right)$ \\
\hline Flow at TC14 $=0$ & $29.70 \mathrm{~s}$ & $29.0 \mathrm{~s}$ \\
\hline Pump check valves & $34.95 \mathrm{~s}$ & $34.97 \mathrm{~s}$ \\
\hline
\end{tabular}

Figure 19 shows the transient temperature results for HEU and LEU cores. The peak cladding temperature occurs at TC-14 for HEU $\left(199.8^{\circ} \mathrm{C}\right)$ and at TC-14 for LEU $\left(200.1^{\circ} \mathrm{C}\right)$ and occurs at $26.1 \mathrm{~s}$ and $26.2 \mathrm{~s}$, respectively. At $\sim 25 \mathrm{~s}$ into the transient, the cladding briefly undergoes $\sim 2 \mathrm{~s}$ of nucleate boiling near the location of the peak heat flux (for both HEU and LEU fuel).

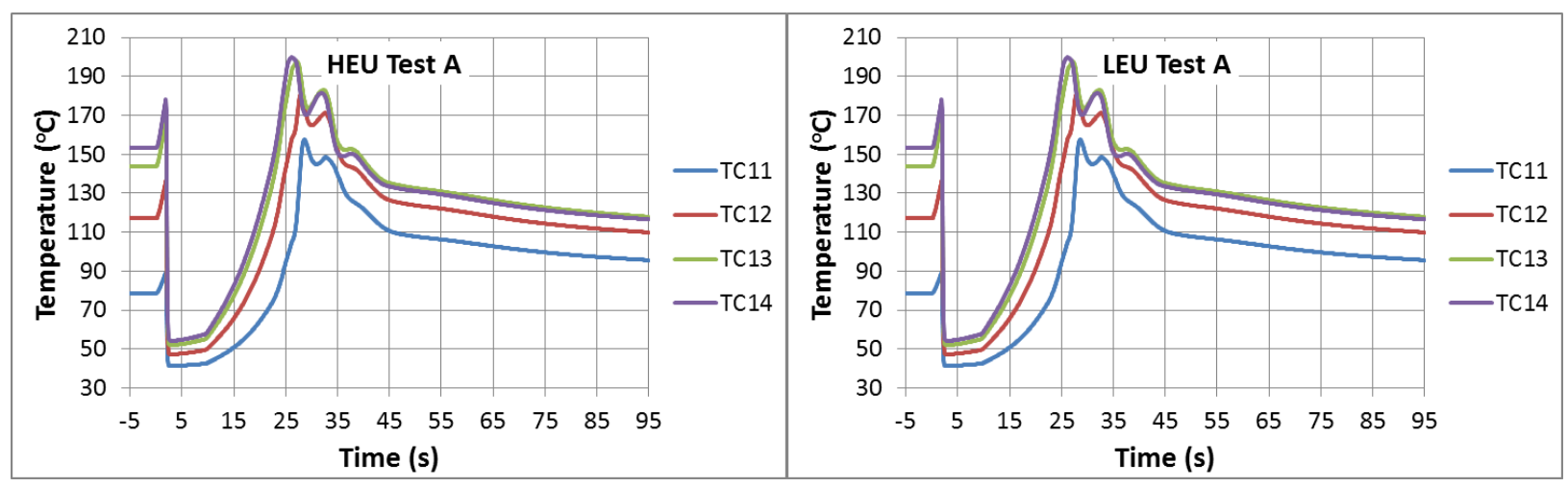

Figure 19 Test A cladding temperature for HEU core (left) and LEU core (right).

\subsection{Test C}

The Test $C$ transient is defined as an untimely opening of the bypass valve with an initial steady-state heat flux of $600 \mathrm{~W} / \mathrm{cm}^{2}$. Figure 20 shows a time line of the important events in the transient for an HEU core. The opening of the bypass valve (ABV4-1301) was initiated at time $=0 \mathrm{~s}$. The reactor scram occurs $250 \mathrm{~ms}$ following the valve in wrong position while the pump trip delay is $1640 \mathrm{~ms}$. Other RS trips occur at a later time and do not impact the transient \{reactor vessel pressure differential RS(dP) [DPRCA4$1301<0.5 \mathrm{~kg} / \mathrm{cm}^{2}$ at $1.96 \mathrm{~s}$ ] and flow rate RS(F) [FRCA4-1301 4500 at $5.70 \mathrm{~s}$ ] . Flow reversal occurs in RELAP5 channel 367 at $21.1 \mathrm{~s}$. The pump check valves close at $36.70 \mathrm{~s}$. This information is summarized and compared to the LEU core in Table 12. The results obtained for an LEU core are nearly identical to that obtained with an HEU core. 


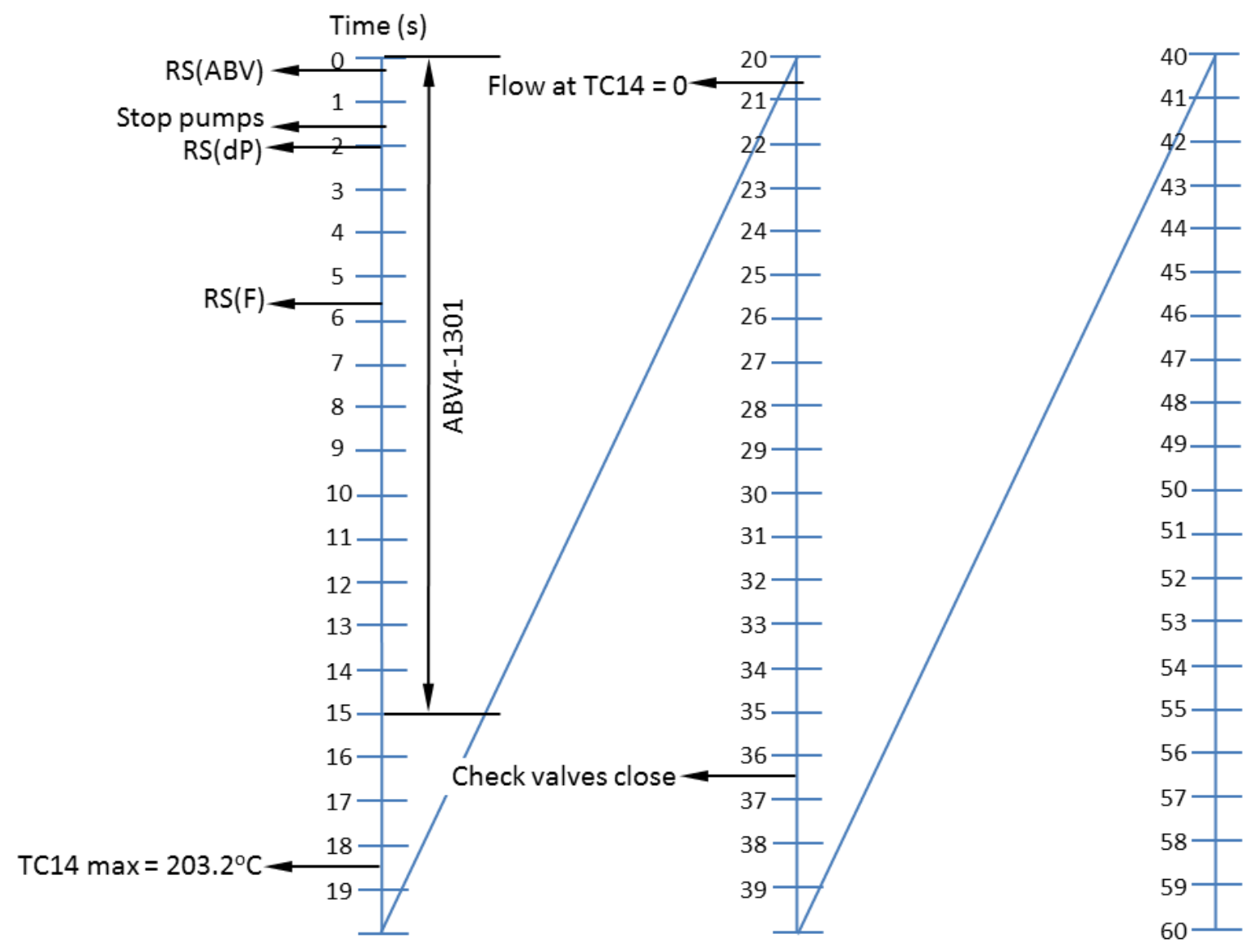

Figure 20 Chronology of important events in Test C transient with HEU core.

Table 12 Chronology of Test C transient for HEU and LEU fuel.

\begin{tabular}{|l|c|c|}
\hline Event & HEU & LEU \\
\hline \hline ABV1301 & $0.00 \mathrm{~s}$ & $0.001 \mathrm{~s}$ \\
\hline RS(ABV) & $0.25 \mathrm{~s}$ & $0.25 \mathrm{~s}$ \\
\hline Pump Stop & $1.64 \mathrm{~s}$ & $1.64 \mathrm{~s}$ \\
\hline RS(dP) & $1.95 \mathrm{~s}$ & $1.95 \mathrm{~s}$ \\
\hline RS(F) & $5.69 \mathrm{~s}$ & $5.68 \mathrm{~s}$ \\
\hline TC14 max time (temp) & $18.4 \mathrm{~s}\left(203.2^{\circ} \mathrm{C}\right)$ & $17.9 \mathrm{~s}\left(203.3^{\circ} \mathrm{C}\right)$ \\
\hline Flow at TC14 = & $20.6 \mathrm{~s}$ & $20.2 \mathrm{~s}$ \\
\hline Pump check valves & $36.28 \mathrm{~s}$ & $36.28 \mathrm{~s}$ \\
\hline
\end{tabular}

Figure 21 shows the transient temperature results for HEU and LEU cores. The peak cladding temperature for HEU $\left(203.2^{\circ} \mathrm{C}\right)$ and LEU $\left(203.3^{\circ} \mathrm{C}\right)$ fuel occurs at $18.4 \mathrm{~s}$ and $17.9 \mathrm{~s}$, respectively. For this scenario, the increased heat flux does not result in a significant change in peak clad temperature since the temperature increase is limited by the brief occurrence ( $8 \mathrm{~s})$ of localized nucleate boiling near the region of peak heat flux. 


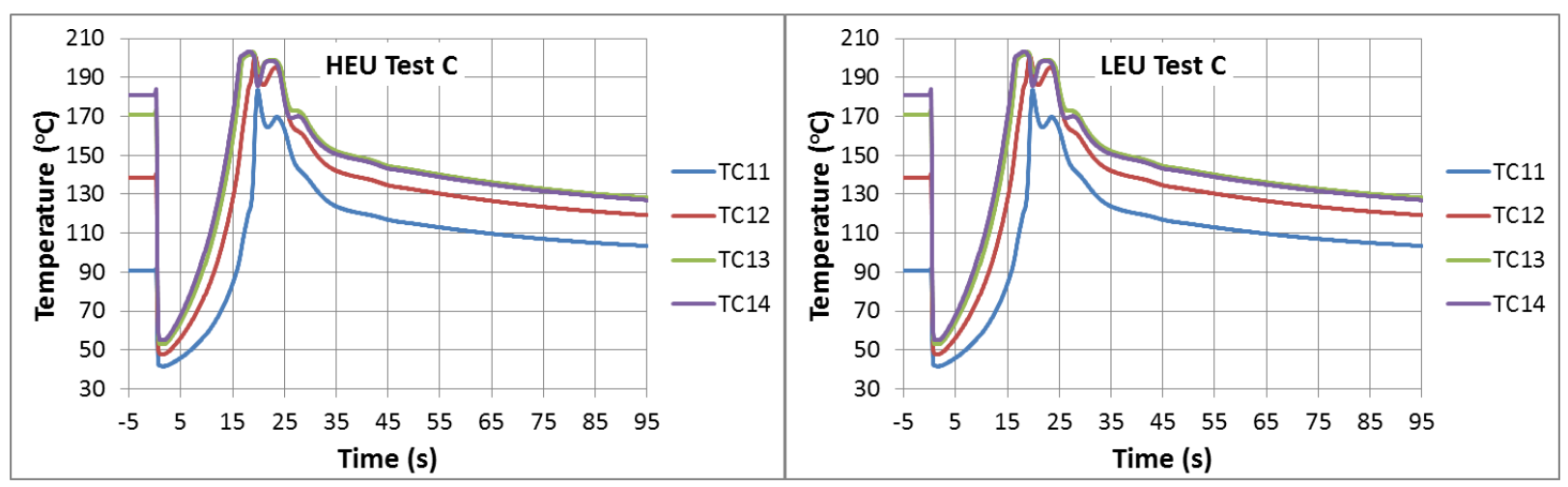

Figure 21 Test C cladding temperature for HEU core (left) and LEU core (right).

\subsection{Test F}

The Test $\mathrm{F}$ transient is defined as an untimely opening of the pool connection valve (total loss of pressure) followed by the opening of the bypass valve at an initial steady-state heat flux of $470 \mathrm{~W} / \mathrm{cm}^{2}$. Figure 22 shows a time line of the important events in the transient for an HEU core. The transient was initiated at $\mathrm{t}=0 \mathrm{~s}$ by manually tripping the pool connection valve ABV4-1308 (the pressurizer has been isolated from the primary system). The reactor scram occurs $250 \mathrm{~ms}$ following the valve in wrong position while the pump trip delay is $1640 \mathrm{~ms}$. Other RS trips occur at a later time and do not impact the transient \{Reactor vessel inlet pressure RS(P) [PRCA4-1302 $<9.0 \mathrm{~kg} / \mathrm{cm}^{2}$ at $0.65 \mathrm{~s}$ ], reactor vessel pressure differential RS(dP) [DPRCA4-1301 $<0.5 \mathrm{~kg} / \mathrm{cm}^{2}$ at $3.74 \mathrm{~s}$ ] and flow rate RS(F) [FRCA4-1301 < 4500 at $4.54 \mathrm{~s}$ ] . Valves ABV4-1304/5 begin to close at $2.63 \mathrm{~s}$ and were fully closed $15 \mathrm{~s}$ later. The pump check valves close at $16.60 \mathrm{~s}$. Flow reversal occurs in RELAP5 channel 367 at $26.0 \mathrm{~s}$. This information is summarized and compared to the LEU core in Table 13. The results obtained for an LEU core are nearly identical to that obtained with an HEU core. 


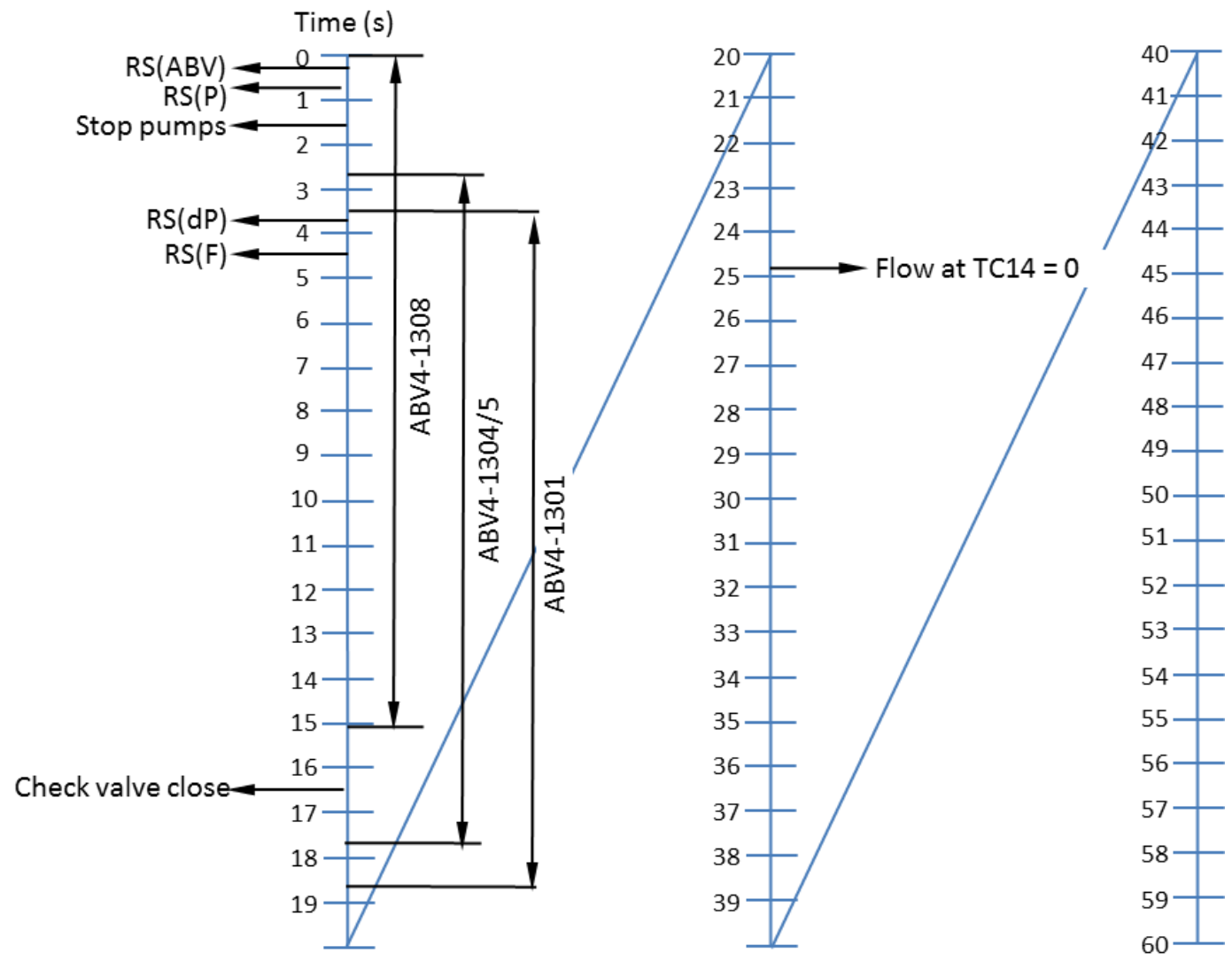

Figure 22 Chronology of important events in Test F transient with HEU core.

Table 13 Chronology of Test F transient for HEU and LEU fuel.

\begin{tabular}{|l|c|c|}
\hline Event & HEU & LEU \\
\hline \hline ABV4-1308 & $0.00 \mathrm{~s}$ & $0.00 \mathrm{~s}$ \\
\hline RS(ABV) & $0.25 \mathrm{~s}$ & $0.25 \mathrm{~s}$ \\
\hline RS(P) & $0.64 \mathrm{~s}$ & $0.64 \mathrm{~s}$ \\
\hline Pump Stop & $1.64 \mathrm{~s}$ & $1.64 \mathrm{~s}$ \\
\hline ABV4-1304/5 & $2.63 \mathrm{~s}$ & $2.63 \mathrm{~s}$ \\
\hline ABV4-1301 & $3.45 \mathrm{~s}$ & $3.44 \mathrm{~s}$ \\
\hline RS(dP) & $3.56 \mathrm{~s}$ & $3.56 \mathrm{~s}$ \\
\hline RS(F) & $4.53 \mathrm{~s}$ & $4.53 \mathrm{~s}$ \\
\hline Pump check valves & $16.52 \mathrm{~s}$ & $16.53 \mathrm{~s}$ \\
\hline Flow at TC14 $=0$ & $24.9 \mathrm{~s}$ & $25.3 \mathrm{~s}$ \\
\hline TC14 max time $^{17}$ (temp) & $19-34 \mathrm{~s}\left(136.4^{\circ} \mathrm{C}\right)$ & $19-34 \mathrm{~s}\left(137.5^{\circ} \mathrm{C}\right)$ \\
\hline
\end{tabular}

Figure 23 shows the transient temperature results for HEU and LEU cores. The peak cladding temperature for $\mathrm{HEU}\left(136.4^{\circ} \mathrm{C}\right)$ and $\mathrm{LEU}\left(137.5^{\circ} \mathrm{C}\right)$ fuel occurs during the flow reversal process which last

${ }^{17}$ Range for time refers to the region of oscillations shown in Figure 23. 
from about 16 to $40 \mathrm{~s}$. These temperatures are much lower than Test $A$ and Test $C$ since they are limited by the lower saturation temperature associated with pressure loss and the effectiveness of heat transfer during nucleate boiling.

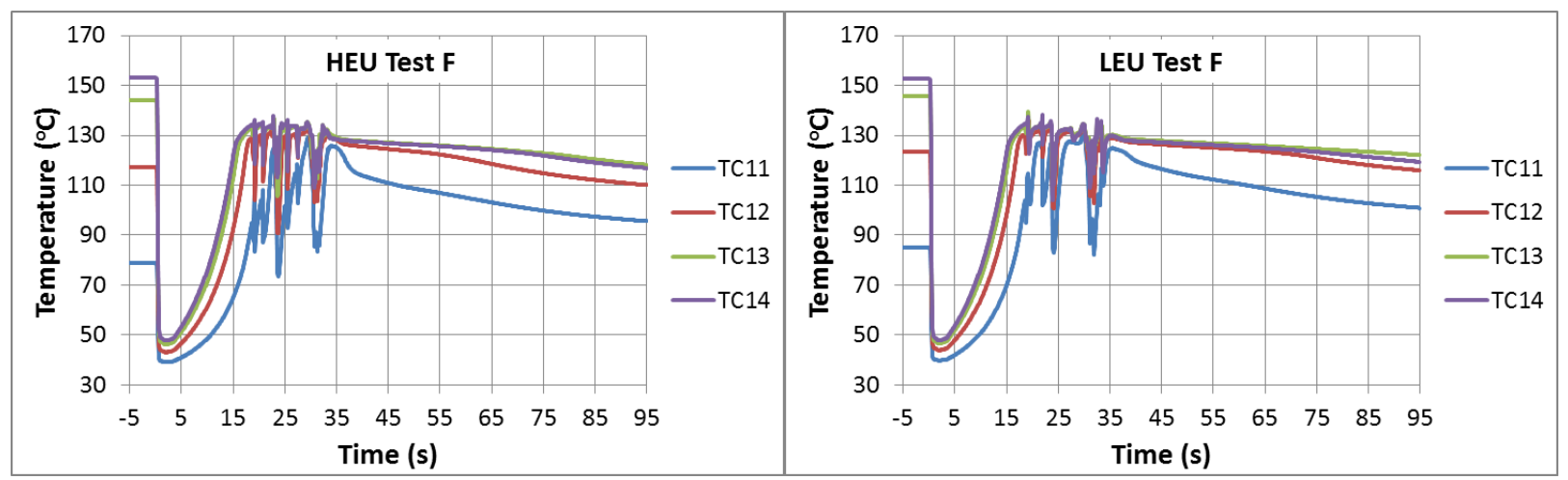

Figure 23 Test F cladding temperature for HEU core (left) and LEU core (right).

\subsection{Test G}

The Test $\mathrm{G}$ transient is defined as an untimely opening of the pool connection valve (total loss of pressure) without opening the bypass valve for an initial steady-state heat flux of $470 \mathrm{~W} / \mathrm{cm}^{2}$. Figure 24 shows a time line of the important events in the transient for an HEU core. The transient was initiated at $\mathrm{t}=0 \mathrm{~s}$ by manually tripping the pool connection valve ABV4-1308. The reactor scram occurs $250 \mathrm{~ms}$ following the valve in wrong position while the pump trip delay is $1640 \mathrm{~ms}$. Other RS trips occur at a later time and do not impact the transient \{Reactor vessel inlet pressure RS(P) [PRCA4-1302 $<9.0 \mathrm{~kg} / \mathrm{cm}^{2}$ at $0.65 \mathrm{~s}$ ], reactor vessel pressure differential RS(dP) [DPRCA4-1301 $<0.5 \mathrm{~kg} / \mathrm{cm}^{2}$ at $3.55 \mathrm{~s}$ ] and flow rate RS(F) [FRCA4-1301 < 4500 at $4.28 \mathrm{~s}$ ] . Valves ABV4-1304/5 begin to close at $2.63 \mathrm{~s}$ and are fully closed $15 \mathrm{~s}$ later. The pump check valves close at $16.65 \mathrm{~s}$. Flow reversal occurs in RELAP5 channel 367 at $19.8 \mathrm{~s}$. This information is summarized and compared to the LEU core in Table 14. The results obtained for an LEU core are nearly identical to that obtained with an HEU core. 


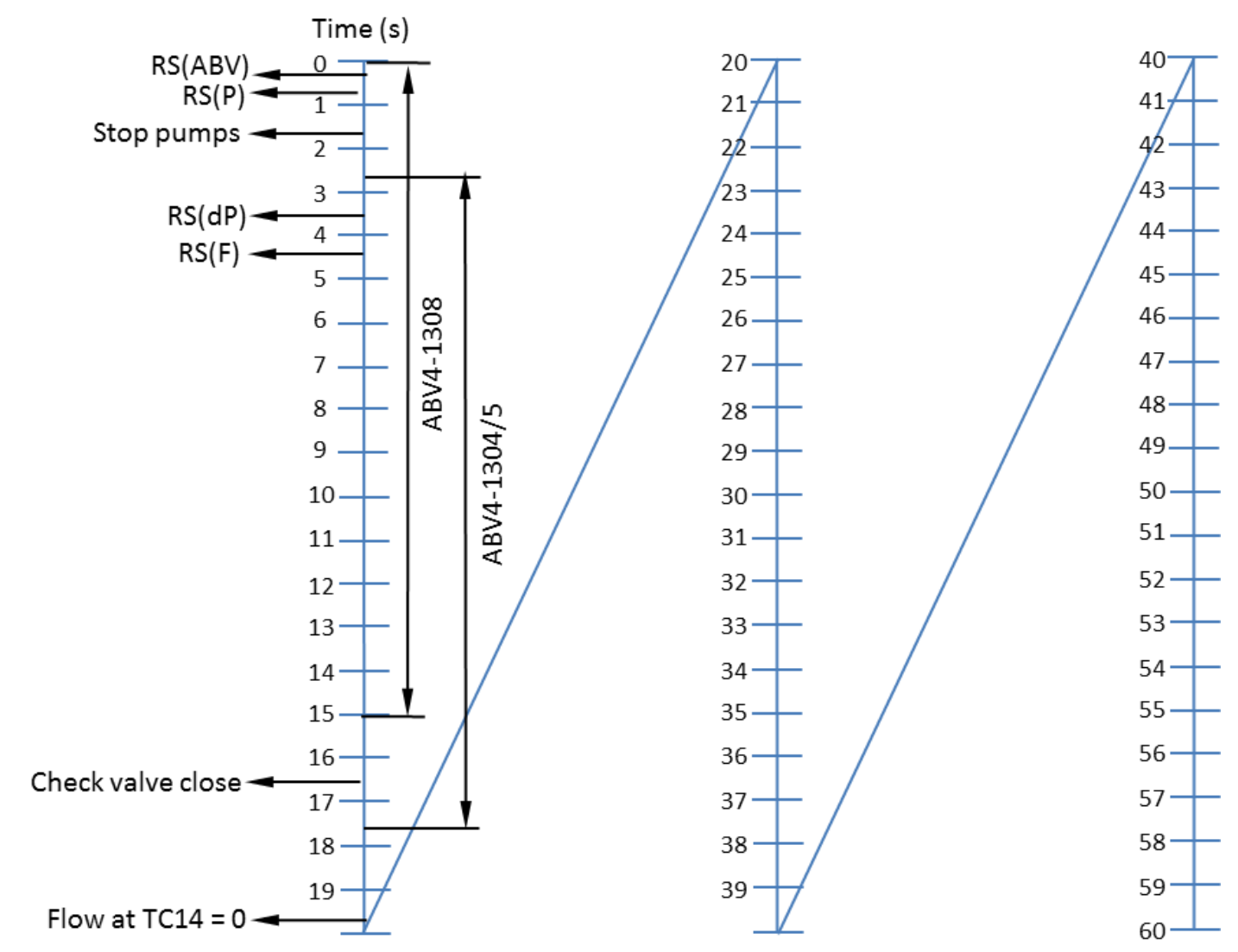

Figure 24 Chronology of important events in Test G transient with HEU core.

Table 14 Chronology of Test G transient for HEU and LEU fuel.

\begin{tabular}{|l|c|c|}
\hline Event & HEU & LEU \\
\hline \hline ABV4-1308 & $0.00 \mathrm{~s}$ & $0.00 \mathrm{~s}$ \\
\hline RS(ABV) & $0.25 \mathrm{~s}$ & $0.25 \mathrm{~s}$ \\
\hline RS(P) & $0.64 \mathrm{~s}$ & $0.65 \mathrm{~s}$ \\
\hline Pump Stop & $1.64 \mathrm{~s}$ & $1.64 \mathrm{~s}$ \\
\hline ABV4-1304/5 & $2.63 \mathrm{~s}$ & $2.63 \mathrm{~s}$ \\
\hline RS(dP) & $3.56 \mathrm{~s}$ & $3.56 \mathrm{~s}$ \\
\hline RS(F) & $4.28 \mathrm{~s}$ & $4.28 \mathrm{~s}$ \\
\hline Pump check valves & $16.57 \mathrm{~s}$ & $16.57 \mathrm{~s}$ \\
\hline Flow at TC14 = 0 & $19.8 \mathrm{~s}$ & $19.9 \mathrm{~s}$ \\
\hline TC14 max time $^{18}$ (temp) & $18-34 \mathrm{~s}\left(136.6^{\circ} \mathrm{C}\right)$ & $18-34 \mathrm{~s}\left(135.6^{\circ} \mathrm{C}\right)$ \\
\hline
\end{tabular}

Figure 25 shows the temperature results for HEU and LEU cores. Both the HEU and LEU cores have peak fuel and cladding temperature near $136^{\circ} \mathrm{C}$, similar to Test $\mathrm{F}$. The peak temperature occurs during the flow reversal process, which occurs between $18 \mathrm{~s}$ and $34 \mathrm{~s}$. Following this, the clad temperatures decrease and long term cooling is established.

${ }^{18}$ Range for time refers to the region of oscillations shown in Figure 24. 

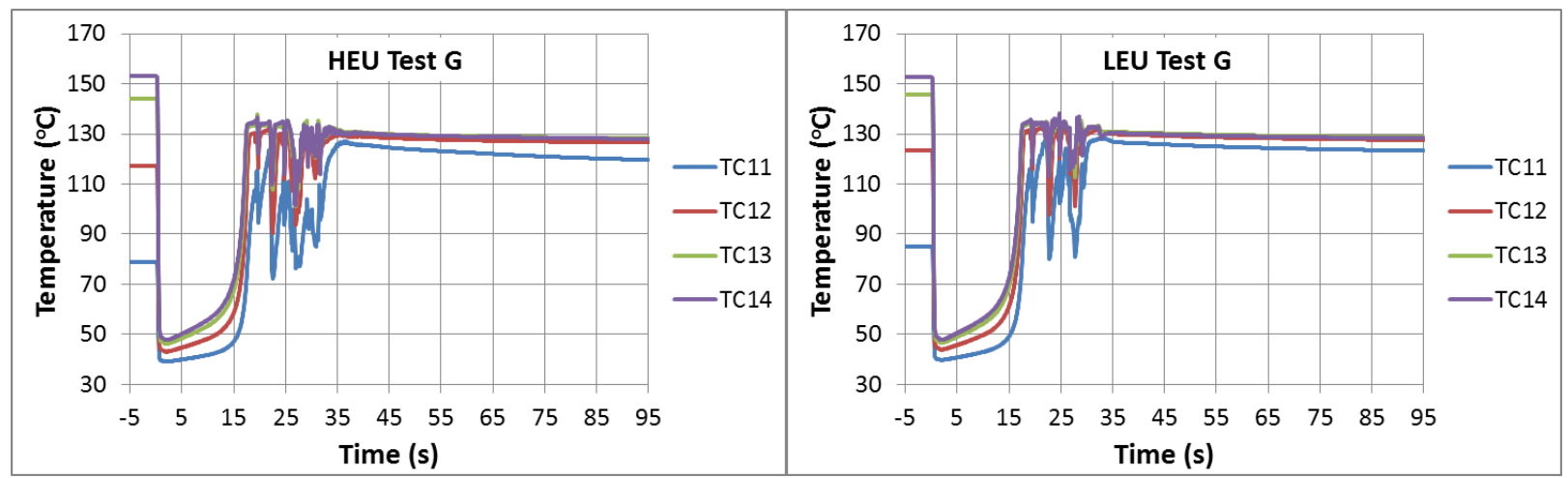

Figure 25 Test G cladding temperature for HEU core (left) and LEU core (right).

The impact of ABV4-1301 not opening can be seen in Figure 26 by inspecting the long term natural circulation flow in the core (node 22) at, for example, 12 hours into the transient (See Appendix $F$ for an indirect verification for long term cooling). In Test $F$, the upward flowing coolant in the fuel elements returns to the bottom of the vessel through the flow path created by the bypass valve ABV4-1301. Coolant in the non-heated channels flows in the same direction as the fuel elements. Thus, the flow rate of the entire core is upward. For Test $\mathrm{G}$, the flow through the fuel elements is still upward but now the return path is through the non-heated or low power channels (bypass and plugged channel). Of note is that the flow between the outer fuel plate and beryllium (RELAP5 channel 367) is primarily downward for Test G.
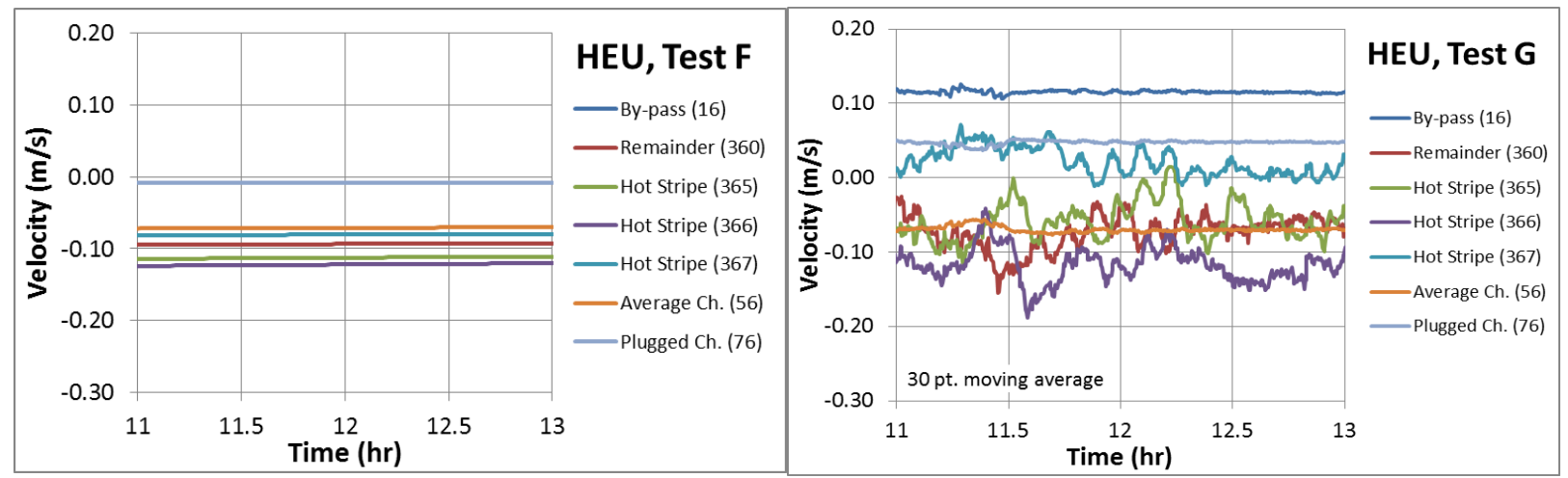

Figure 26 Comparison of flow direction and magnitude for Tests F and G (negative velocity corresponds to upward flow).

With respect to flow reversal, the conclusion from the 1963 tests was that the flow reversal occurred at about $20 \mathrm{~s}$ with bypass valve ABV4-1301 open (Test F) and 40-50 s with bypass valve ABV4-1301 closed (Test G). For the RELAP5 simulations of the representative core, the time at which flow reversal occurs is more difficult to quantify since the flow is two-phase and the transition is not smooth. One approach to quantify the flow reversal time is to compare the two cases relative to the time that the flow first reaches zero in the core. Both tests are initiated with the opening of bypass valve ABV4-1308 and the initial coast down is identical for both (Figure 27). When the bypass valve opens in Test $F$, part of the inlet coolant is diverted into the bypass line, decreasing the flow through the core more rapidly than in 
Test G. When the ABV4-1304/5 valves are closed, the coolant direction in the bypass line is reversed (upward), and the core flow continues in the downward direction at a relatively low flow rate. For Test G, closing of valves ABV4-1304/5 eliminates all major flow paths outside the vessel, causing the core flow rate to decrease rapidly to zero. The end result is that the flow is reduced more quickly in Test $\mathrm{F}$ early in the transient $(5-15 \mathrm{~s})$, but the flow in Test $\mathrm{G}$ reaches zero first, by $\sim 0.5 \mathrm{~s}$ in the hot stripe (channel 366(1)) and by $5 \mathrm{~s}$ in the average fuel channel (56(1)).

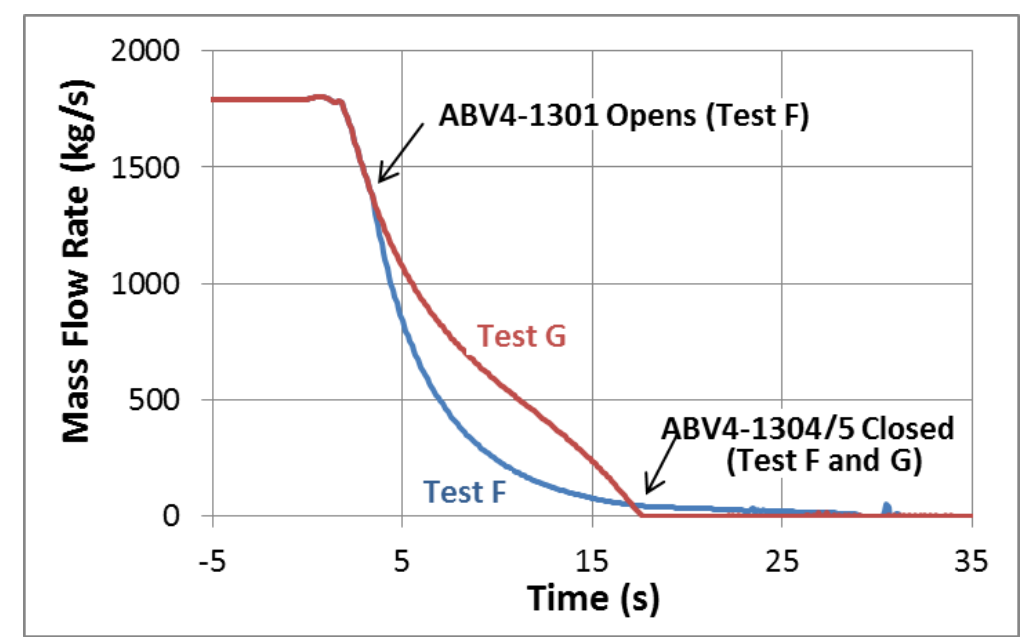

Figure 27 Comparison of Test F and Test G core flow rates (volume 8).

Alternatively, the temperature difference in the core can be used to assess the time at which flow reversal occurs. Figure 28 shows that the temperature difference in the hot stripe (366(22) minus 366(1) ) for Tests $F$ and $G$ is quite chaotic. The temperature difference across the high heat flux channel $(38-34)$ is much more smooth, but the values oscillate due to differences between the local conditions and overall core pressure differential. The flow reversal is more clearly observed from the temperature difference across the average fuel channel (volume 58-54). The flow reversal, or transition from positive to negative temperature difference, occurs $\sim 5 \mathrm{~s}$ sooner in Test $\mathrm{G}$ than Test $\mathrm{F}$.
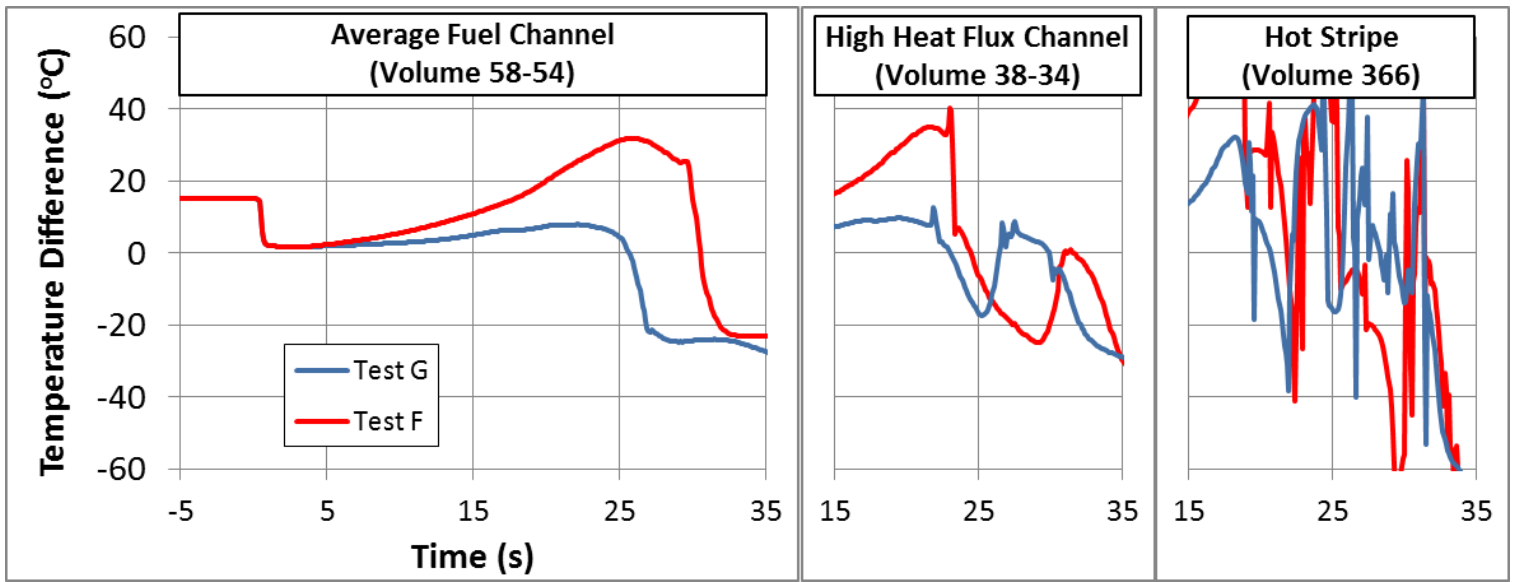

Figure 28 Temperature difference of the core based on different channels for Test F and Test G. 


\section{Boiling Risk}

As discussed for the intermediate calculations, the modifications to update the RELAP5 model for simulating the representative core were significant enough that when applied to the 1963 model, a limited amount of nucleate boiling occurred during flow reversal for Test $A$. The boiling occurred only in the limiting channel of the high heat flux fuel element, which in the RELAP5 model is volume 366. Results for Test $A$ with a representative core also show that nucleate boiling occurs and there is no net generation of void.

The severity of Tests C, F and G are increased due to the increased heat flux or reduced pressure. To further analyze the risks associated with the boiling and void generation in the core, the RELAP5 results were post-processed with the methods described in Appendix G. The post-processing was done to obtain the transient margins for the onset of nucleate boiling (ONB), onset of significant void (OSV), onset of flow instability (OFI) and critical heat flux (CHF).

The increased power associated with Test $C$ results in cladding temperatures similar to Test $A$, however, the time for which nucleate boiling occurs, as indicated by the ONB ratio, is increased and some small amount of net void $(\sim 12 \%)$ is generated during the flow reversal (Figure 29$)$. This figure also shows that the ONB ratio is near 1 during steady state (as expected from steady-state analyses [21]).
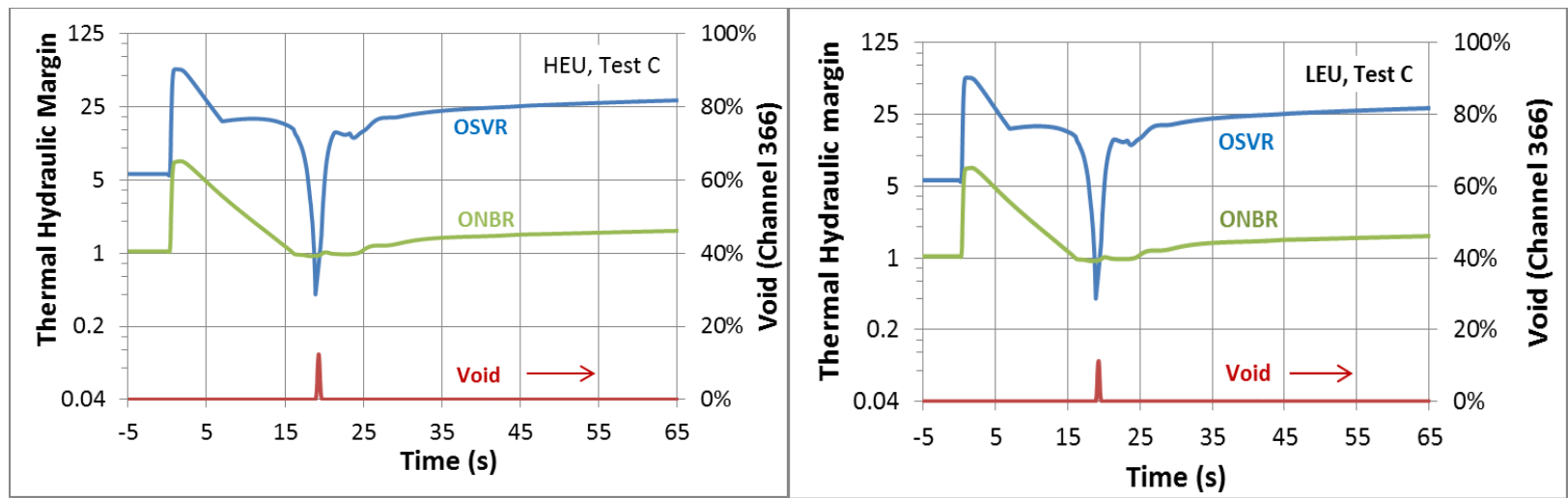

Figure 29 Thermal hydraulic margin and void in channel 366 for Test $C$ at $600 \mathrm{~W} / \mathrm{cm}^{2}$.

For Test $\mathrm{F}$ and Test $\mathrm{G}$, the amount of void is increased due to the reduction in saturation temperature associated with the pressure loss (Figure 30 and Figure 31). It can be seen that there are limited periods of time in which channel 366 is almost completely void. 

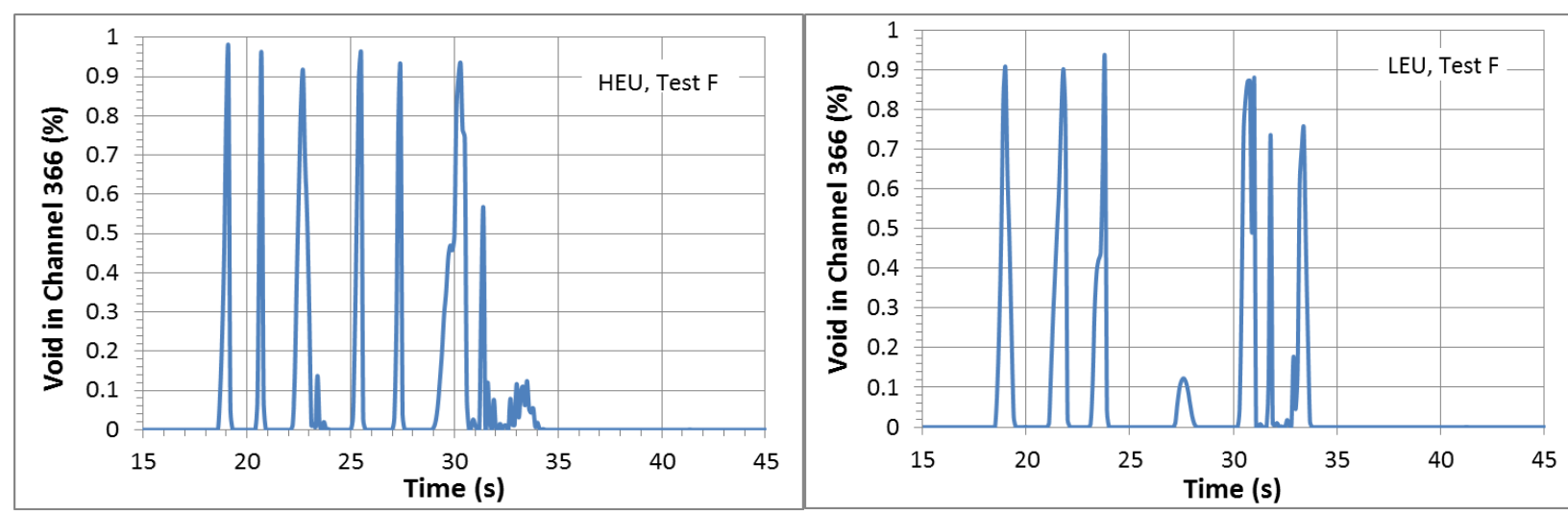

Figure 30 Void $^{19}$ in channel 366 for Test $F$ at $470 \mathrm{~W} / \mathrm{cm}^{2}$.

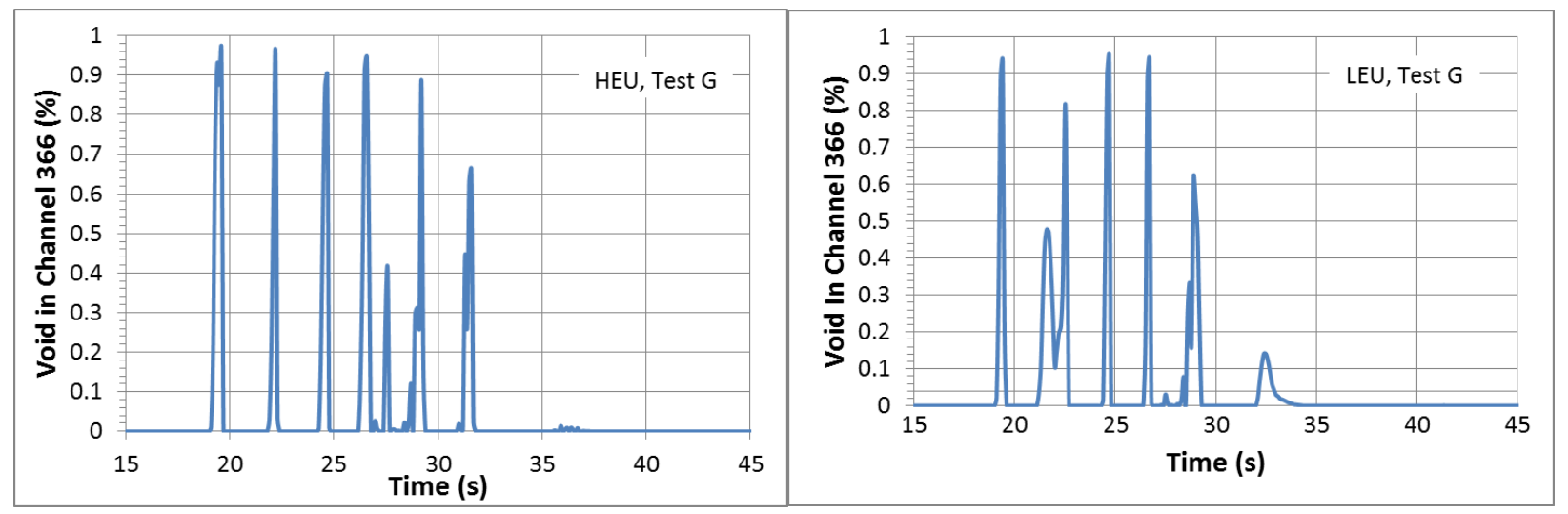

Figure 31 Void in channel 366 for Test $\mathrm{G}$ at $470 \mathrm{~W} / \mathrm{cm}^{2}$.

The channel voiding occurs as a result of the flow reversal process, which can be broken into four stages [22]:

1) Coast down stage: as the downward flowing coolant slows down, it is gradually heated to the point when steam void appears.

2) Vapor generation stage: the steam voids grow and coalesce and begin flowing upward. The vapor soon occupies the whole heated section.

3) Oscillatory flow stage: The steam flows out of the heated channel where it then condenses. The coolant then refloods the channel, and the process repeats for a few cycles.

4) Natural circulation stage: natural circulation flow is established and there is no overheating of the channel.

The oscillatory flow stage, as calculated by RELAP5, appears to have a characteristic period consistent with an instability known as geysering. The geysering period is related to the sum of the times it takes

${ }^{19}$ Volume average void in fuel region of channel 366. 
to heat the fluid to saturation, void the channel, condense the vapor and reflood the channel. Of these, heating the fluid to saturation has been observed to be the largest fraction of time. The periodicity for geysering can be approximated as the time it takes to heat the subcooled liquid to the saturation temperature, also known as the boiling delay time (t) [23]:

$$
t=\frac{\rho V c_{p} \Delta T_{s u b}}{Q}
$$

where $\rho$ is the density, $V$ is the volume, $c_{p}$ is the specific heat, $\Delta T_{s u b}$ is the amount of subcooling and $Q$ is the channel power. To compare with this theory, additional RELAP5 simulations were performed for peak heat flux values of $370,400,430$ and $600 \mathrm{~W} / \mathrm{cm}^{2}$ using the Test $\mathrm{G}$ accident scenario with HEU fuel. The boiling delay time was taken to be the time between the first two occurrences of channel voiding. The average heat flux was approximated from the peak heat flux using the power peaking factor of 1.33 and a decay heat of $5 \%$ at 20 s into the transient (approximately when the channel voiding begins). Figure 32 shows that the RELAP5 results are consistent with the boiling delay time expected from the geysering instability.

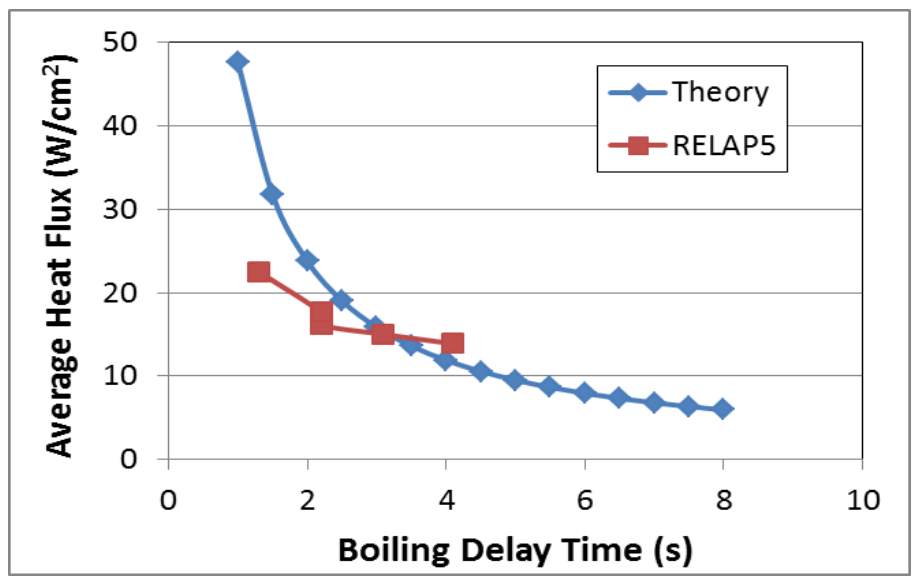

Figure 32 Comparison of RELAP5 and theory for boiling delay time.

Figure 33 shows that the geysering, or voiding of the channel does not result in cladding temperatures much higher than the saturation temperature $\left(\sim 130^{\circ} \mathrm{C}\right)$. In fact, the increase in void generated from increasing the heat flux of Test $G$ from $470 \mathrm{~W} / \mathrm{cm}^{2}$ to $600 \mathrm{~W} / \mathrm{cm}^{2}$ does not lead to a significant change in peak clad temperature. Some conservatism in the applied heat load could be removed by taking into account the spreading of the decay heat power (see assumptions for the intermediate simulations described in section 4). However, for the 1963 core, this spreading resulted in a decrease of the decay heat by $25 \%$ at $25 \mathrm{~s}$ into the transient. A sensitivity study shows that to completely avoid net vapor generation in Test $G$ for the representative core with current assumptions, the steady state power would need to be reduced by a factor of $\sim 1.75$ (corresponding to decrease in the peak heat flux from $470 \mathrm{~W} / \mathrm{cm}^{2}$ to $270 \mathrm{~W} / \mathrm{cm}^{2}$ ). Considering that the spreading is expected to be less for the representative core, the removal of that conservatism is likely not sufficient for avoiding geysering in the core during flow reversal for a peak heat flux of $470 \mathrm{~W} / \mathrm{cm}^{2}$. 

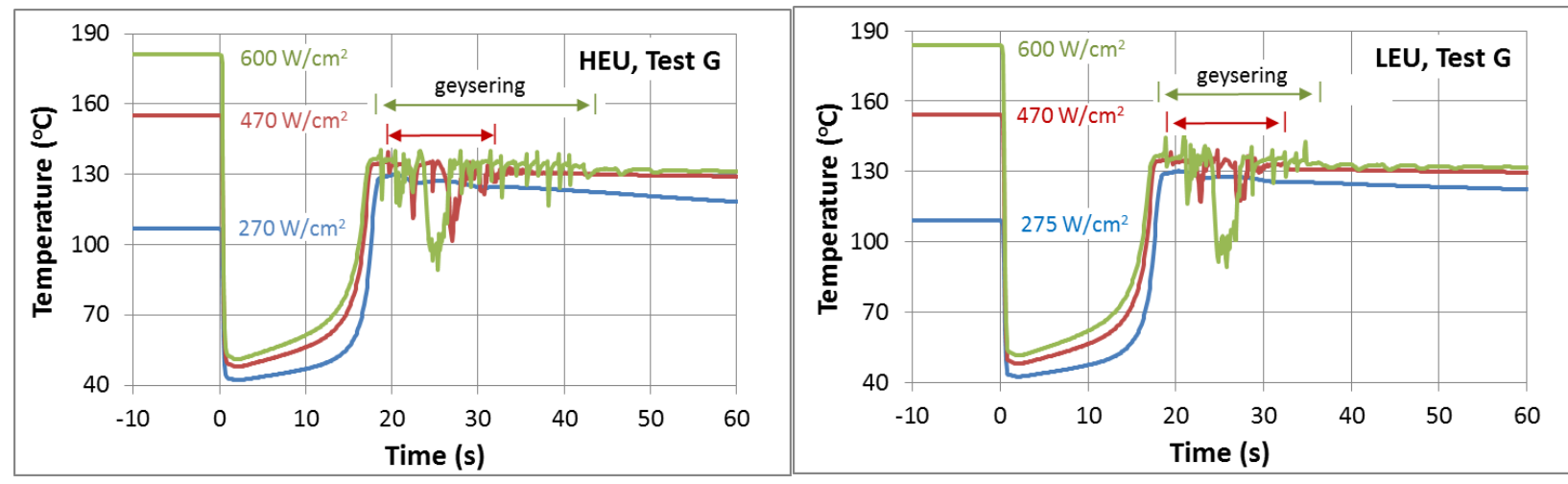

Figure 33 Peak clad temperature for Test $\mathrm{G}$ at 280,470 and $600 \mathrm{~W} / \mathrm{cm}^{2}$.

If voiding is to occur in BR2 during the flow reversal, it is relevant to know how much margin or risk there is to reaching conditions that lead to excessive cladding temperatures. It has been shown that the onset of geysering corresponds to the onset of flow instability, as defined by the empirical correlation of Whittle and Forgan [23]. OFI has also been successfully predicted using the Saha-Zuber OSV correlations, since the two phenomena occur quite close to each other [24]. Figure 34 shows the OSV ratio for both $470 \mathrm{~W} / \mathrm{cm}^{2}$ and $600 \mathrm{~W} / \mathrm{cm}^{2}$. Voiding in the channel corresponds for conditions when the OSV ratio is less than one ${ }^{20}$. The results show that once natural circulation flow is established there is still margin to OSV, even for the hot stripe in the $600 \mathrm{~W} / \mathrm{cm}^{2}$ case.
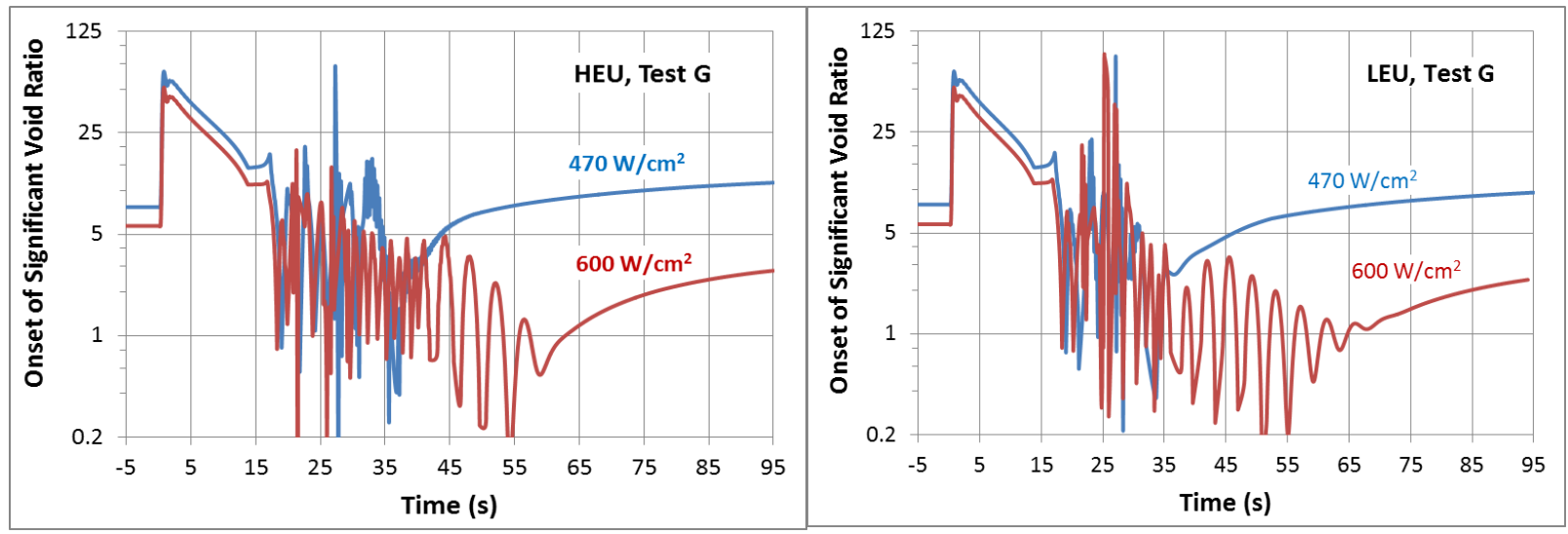

Figure 34 Onset of significant void ratio for Test $\mathrm{G}$ at $470 \mathrm{~W} / \mathrm{cm}^{2}$ and $600 \mathrm{~W} / \mathrm{cm}^{2}$.

It is also necessary to consider the critical heat flux, since post-processing of the RELAP5 results shows a CHFR repeatedly spikes below 1 during the flow reversal (Figure 35). Although CHF is predicted, in this instance it is not the same scenario as typically imagined for $\mathrm{CHF}$ at steady state. During the oscillatory stage of flow reversal, the CHF ratio drops below one because of local conditions caused by geysering and not because the heat flux is high enough to sustain dryout. This is supported by the fact that the CHFR $\gg 1$ both before and after geysering occurs, despite the decay heat being of about the same magnitude ( $4-5 \%$ of nominal).

\footnotetext{
${ }^{20}$ The RELAP5 code uses the Saha-Zuber correlation to determine when net void should be produced in a volume.
} 


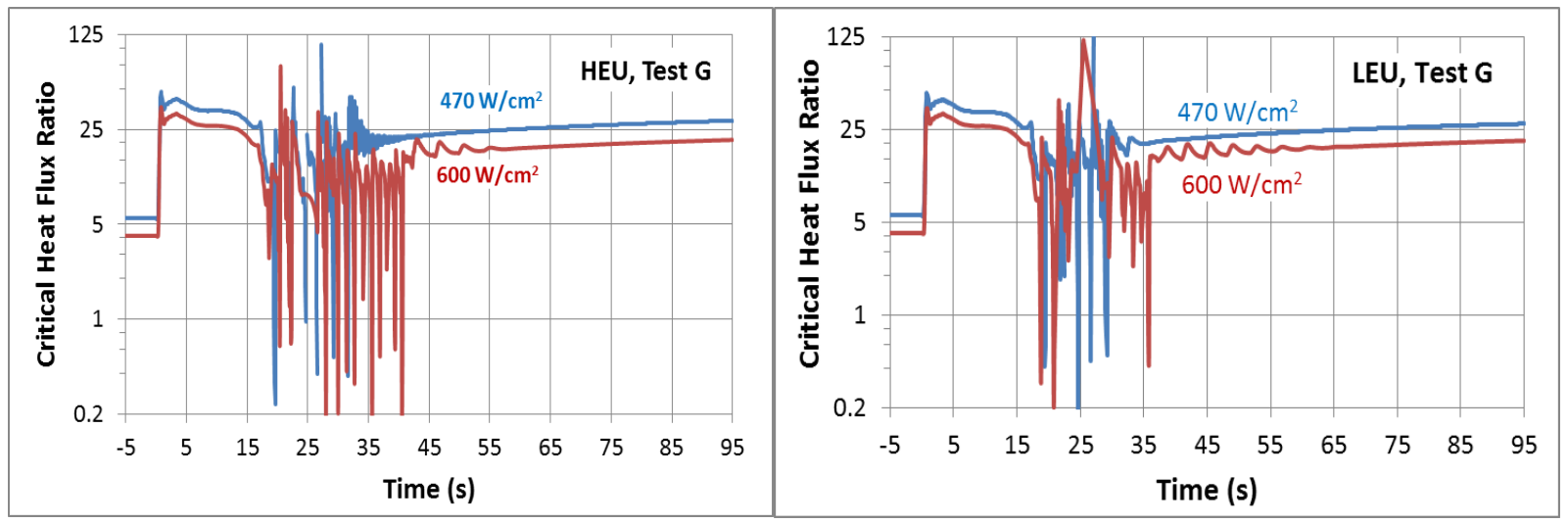

Figure 35 Critical heat flux ratio for Test $\mathrm{G}$ at $470 \mathrm{~W} / \mathrm{cm}^{2}$ and $600 \mathrm{~W} / \mathrm{cm}^{2}$.

Up to now the main focus has been on the boiling risk associated with the flow reversal. However, as shown in Figure 26 of Section 5, the opening of valve ABV4-1301 in Test F allows natural circulation to establish with upward coolant flow in the entire vessel. For Test $G$, the failure of this valve opening limits the natural circulation flow to within the vessel, where there is upward flowing coolant in the heated fuel channels and downward flowing coolant in the low power or unheated channels. The velocity in the vessel was shown to be irregular at $\sim 12$ hours into the transient, which is a result of the continuous boiling in the core. Figure 36 illustrates the difference in primary coolant heat removal due to the state of bypass valve ABV4-1301. With the bypass valve open, Tests $A, C$ and $F$ all go into single phase heat transfer following flow reversal. The inlet temperature for the high heat flux channel (Obtained from Volume 38) increases to a peak value of $\sim 60^{\circ} \mathrm{C}$ at $2.5 \mathrm{hrs}$. The coolant temperature remains relatively constant and the heat transfer remains single phase for the remainder of the $24 \mathrm{hrs}$.

For Test G, the heat removal from the core is primarily through the reactor vessel wall to the pool and shroud. Following flow reversal, the high heat flux channel of the RELAP5 model remained in nucleate boiling but the channel void was zero and the OSV ratio was continually increasing. The trend of increasing OSV ratio reverses at $\sim 200 \mathrm{~s}$ and channel void again appears at $\sim 400 \mathrm{~s}$ ( $\sim 50 \mathrm{~s}$ if forced flow in the reactor vessel shroud continues during the transient). A balance between decay heat and heat removal occurs when the inlet temperature of the high heat flux channel reaches $\sim 110^{\circ} \mathrm{C}$ at $3.5 \mathrm{hrs}$, which is below the saturation temperature of $\sim 120^{\circ} \mathrm{C}$. The coolant temperature decreases to $\sim 90^{\circ} \mathrm{C}$ at $24 \mathrm{hrs}$ but the channel remains in nucleate boiling, generating void for the duration of the calculation (void generation ceases at 1.7 hours if forced flow in the reactor vessel shroud continues during the transient). The results indicate that, despite the increasing pool temperature, the core will remain coolable for at least 24 hours. 


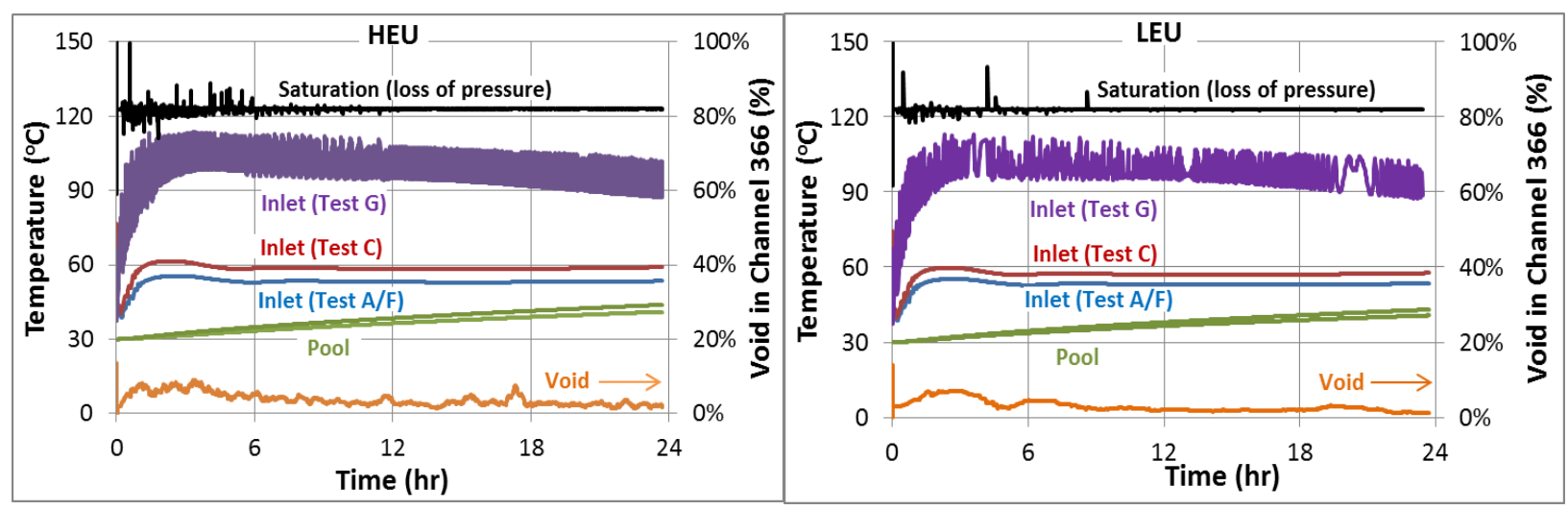

Figure 36 Temperature and Void in Tests A, C, F and G for a transient time of 24 hours $^{21}$.

\section{Summary and Conclusions}

RELAP5 Model Description

A RELAP5 input model was developed for the BR2 reactor to analyze core cooling perturbations and support conversion of the reactor to LEU fuel. In previous work, the model of the reactor vessel and the primary piping were updated taking into account the best modeling practices developed by ANL and BR2 engineers. This included, as an example, calibrating the flow and pressure distribution within the reactor vessel based on BR2 data from 1962 and the hydraulic mock-up facility for various core configurations. The fact that there was good agreement between required minor loss coefficients for many core configurations was significant since it establishes credibility for pressure and flow distribution calculated for the representative core configuration used in this work. The modeling approach has been previously verified by showing that the model produces good agreement with the steady-state and transient cladding temperatures measured in the 1963 loss of flow and loss of pressure experiments labeled Tests A, C, F and G. This document discussed in detail the updated model for use in performing simulations with a representative core configuration.

\section{$\underline{\text { Intermediate Simulations }}$}

A set of intermediate simulations where performed for Test A to bridge the gap between the RELAP5 models for the 1963 and representative core configurations. This included investigating the impact of adding the reactor control system rather than relying on trip times measured in the 1963 experiments, the impact of using the 1979 ANS decay curve rather than including the effect of power spreading following a scram, the addition of the shutdown fission power, and the impact of increasing the power from the 1963 BR2 experiments to values needed to reach the currently allowed heat flux limits. Of note is that the peak cladding temperature increases from $121^{\circ} \mathrm{C}$ to $\sim 200^{\circ} \mathrm{C}$ with the largest contributions coming from changes to the decay heat distribution and increased steady state heat flux $\left(309 \mathrm{~W} / \mathrm{cm}^{2}\right.$ to $\left.470 \mathrm{~W} / \mathrm{cm}^{2}\right)$. The control system impacted the timing of the peak temperature but not

${ }^{21}$ Void has been smoothed with a 100pt moving average. 
its magnitude. The implementation of the model changes to convert from the 1963 core to the representative core results in localized nucleate boiling during the flow inversion of Test $A$.

$\underline{\text { Results for simulations with the representative core at the maximum and temporary heat flux limits. }}$

Boiling was found to occur for each of the core cooling perturbations labeled Tests $A, C, F$ and $G$. While a limited amount of boiling occurred in Test $A$, there was not net generation of void. The peak clad temperature was found to be $\sim 200^{\circ} \mathrm{C}$. The increased heat flux associated with Test $\mathrm{C}$ showed an increased amount of nucleate boiling and the production of a small amount of void in the limiting channel. The clad temperature was again found to be $\sim 200^{\circ} \mathrm{C}$ since it does not increase much beyond the saturation temperature of the coolant. A significant amount of void occurred for Tests $F$ and $G$ during the flow reversal, but no overheating of the fuel plates occurred. Again, the cladding temperature was limited to near the saturation temperature, which was about $130^{\circ} \mathrm{C}$ at near atmospheric pressure.

\section{Boiling Risk}

Analysis of the boiling risks shows that Test $G$ is the most limiting of the cases simulated. Significant voiding occurs in the core as the flow stagnates during the flow reversal process. The voiding is periodic and its timing was shown to be consistent with the instability known as geysering. Despite the significant amount void during flow reversal, no overheating of the fuel plates occurred for a peak heat flux of $470 \mathrm{~W} / \mathrm{cm}^{2}$ or $600 \mathrm{~W} / \mathrm{cm}^{2}$. Once the geysering ceased and natural circulation was established, there was significant margin for both flow instability and critical heat flux. This trend reverses at about $200 \mathrm{~s}$ and voiding restarts at about $400 \mathrm{~s}$. The inlet coolant temperature for the high heat flux channel rises to about $110^{\circ} \mathrm{C}$ at $3.5 \mathrm{hrs}$ before the heat transferred to the pool equals the decay heat. Voiding in the channel continues for the duration of the simulation ( $24 \mathrm{hrs}$ ).

\section{Impact of converting from HEU to LEU fuel}

Simulations of a select set of core cooling perturbations (Labeled Test A, C, F and G in the 1963 experiments) with a representative core configuration show nearly identical peak cladding temperatures, margins to ONB, OSV and CHF, as well as overall system behavior for HEU and LEU fuel at the maximum nominal heat flux limit of $470 \mathrm{~W} / \mathrm{cm}^{2}$ and temporary heat flux limit of $600 \mathrm{~W} / \mathrm{cm}^{2}$. 


\section{References}

[1] E. Sikik, "Update on the representative BR2 core load that is described in the conversion feasibility report," BR2/RFA/ES/2015/05, May 2015.

[2] RELAP5/MOD3.3 Code Manual, Nuclear Safety Analysis Division, July 2003, Information Systems Laboratories, Inc., Rockville, Maryland and Idaho Falls, Idaho.

[3] G. van den Branden, "Conversion Studies: BR2 Reference Data Part 1: Vessel, Reactor core, Load elements", BR2/RCE/GVdB/2011/90/Reference_data_part-ed 5, August 2014.

[4] G. Van Den Branden, "RELAP model Primary Loop in Pool", BR2/RCE/GVdB/2013/188/RELAP_primary_in_pool-ed 1, April 2014.

[5] C.P. Tzanos and B. Dionne, "Computational Fluid Dynamics Analyses of Lateral Heat Conductoin, Coolant Azimuthal Mixing and Heat Transfer Predictions in a BR2 Fuel Assembly Geometry," ANL/RERTR/TM-11-21, 2011.

[6] C.P. Tzanos and B. Dionne, "Analysis of the BR2 loss-of-flow test A," Nucl. Technol., 176. 93 (2011).

[7] J. Licht, B. Dionne, G. van den Branden, E. Sikik and E. Koonen "RELAP5 model description and validation for the BR2 loss-of-flow experiments," ANL/GTRI/TM-14/10, 2015.

[8] B. Dionne, A. Bergeron, J.R. Licht, Y.S. Kim, and G.L. Hofman, "Thermal properties for the thermal-hydraulics analyses of the BR2 maximum nominal heat flux", ANL/RERTR/TM-11-20 Rev 1, January 2015.

[9] B. Dionne and J.G. Stevens, "Applicability of a hot channel factor-based hot stripe approach to model the azimuthal power peaking in a BR2 fuel assembly", 33rd International Meeting on Reduced Enrichment for Research and Test Reactors, October 23-27, 2011.

[10] American National Standard for Decay Heat Power in Light Water Reactors. ANSI/ANS-5.1-1979.

[11] Belgian Engineering Test Reactor BR2. Safety and design, final report", 1996. A revision of the report "Belgian engineering test reactor BR2. Safety and Design, preliminary report" May 1st, 1961.

[12] G. van den Branden, "Conversion study: design basis document LSSS", BR2/RCE/GVdB/2010/53/conversion_DBD_LSSS-ed 1Draft, August 2010.

[13] E. Sikik, "BR2 trip delays that are implemented in the RELAP model," BR2/RCE/ES/18/2015/BR2 Trip Delays for Relap, November 2015.

[14] A. Beeckmans, "Distribution du debit de refrigerant dans la cuve du réacteur BR2," C.E.N.EURATOM technical note 72.0616, August 10th, 1976. 
[15] Operation Group of BR.2 Reactor and Related Installations, C.E.N.-EURATOM technical note NT.71/2435/07/FaM., October 15th, 1962.

[16] C. F. Colebrook. "Turbulent flow in pipes with particular reference to the transition region between Smooth and rough pipe laws." Journal of Institution Civil Engineers. 11. 1939. pp. 133156.

[17] Churchill, S.W. 1977, 'Friction factor spans all fluid flow regimes,' Chem. Eng. (Rugby, U.K.) 84(24), pp.91-91).

[18] G. Van den Branden, "Conversion study pump coast-down test", BR2/RCE/GVdB/2010/73/CONVERSION PUMP COAST-DOWN-ed 1, December 2010.

[19] B. Dionne and C.P. Tzanos, "Estimation of steady-state and transient power distributions for the RELAP analyses of the 1963 loss-of-flow and loss-of-pressure tests at BR2" ANL/RERTR/TM-1119, (2011).

[20] Etude Experimentale Du Flux De Chaleur Maximum Admissible Pour le Complexe BR2, October $9^{\text {th }} 1979$.

[21] J. Licht, A. Bergeron, B. Dionne, G. Van den Branden, S. Kalcheva, E. Sikik and E. Koonen, "Steady-state thermal-hydraulics analyses for the conversion of the BR2 reactor to LEU," ANL/GTRI/TM-14/8, 2015.

[22] L.Y. Cheng and P.R. Tichler, "Analysis of flow reversal test," BNL-62621, 1996.

[23] R.B. Duffey and U.S. Rohatgi, "Physical interpretation of geysering phenomena and periodic boiling instability at low flows," BNL 62703, 1996.

[24] M. Kalimullah, A.P. Olson, B. Dionne, E.E. Feldman and J.E. Matos, "Reversal of OFI and CHF in Research Reactors Operating at 1 to 50 bar," ANL/GTRI/TM-13/14, 2013. 


\section{Appendix A MCNP Calculations}

The total energy released by the fission of heavy nuclei in a nuclear reactor comes from several contributions: kinetic energy of the fission products, prompt and delayed neutrons, prompt and delayed gammas, beta energy, gammas from capture and anti-neutrinos. Except the anti-neutrinos which can be neglected, all the above contributions must be accounted for an accurate representation of the energy distribution released during the fission process.

\section{Methodology}

The code MCNP does not model all phenomena cited above which contribute to the nuclear power and does not calculate the magnitude either, only the distribution. Therefore, one has to introduce some hypotheses to normalize the calculated results to obtain the parameters of interest. The different contributions considered relevant to the evaluation of the total power are summarized in Table A-1.

Table A-1.Individual contribution to the nuclear power and methods to evaluate them

\begin{tabular}{|c|c|c|}
\hline Contribution & Evaluation & MCNP tallies or values \\
\hline $\begin{array}{l}\text { kinetic energy of fission } \\
\text { fragments (Q1) }\end{array}$ & Calculated & F6:n \\
\hline $\begin{array}{l}\text { kinetic energy of fission } \\
\text { neutrons (Q2) }\end{array}$ & Calculated & F6:n \\
\hline $\begin{array}{l}\text { gamma energy from }(n, g) \\
\text { capture (Q3) }\end{array}$ & Calculated & F6:p \\
\hline prompt gamma energy (Q4) & Calculated & F6:p (with pikmt) \\
\hline beta decay energy (Q5) & $\begin{array}{l}\text { assumed deposited in fuel only } \\
\text { and to have same distribution as } \\
\text { fission distribution }\end{array}$ & $\begin{array}{l}\text { Relative fraction of core total } \\
6.5 \mathrm{MeV} / \text { fission } 235 \mathrm{U} \text { scaled base } \\
\text { on the local fission distribution }\end{array}$ \\
\hline delayed gamma energy (Q6) & $\begin{array}{l}\text { assumed to have prompt gamma } \\
\text { distribution }\end{array}$ & $\begin{array}{l}\text { Relative fraction of core total } \\
6.33 \mathrm{MeV} / \text { fission } 235 \mathrm{U} \text { scaled } \\
\text { base on the prompt gamma } \\
\text { distribution (used of the PIKMT } \\
\text { card) }\end{array}$ \\
\hline
\end{tabular}

All of the calculated contributions are based on the MCNP heating tally, "F6". The beta decay energy is assumed to be deposited only in the fuel, worth $6.5 \mathrm{MeV} /$ fission of $235 \mathrm{U}$ and its distribution is assumed to be the same as the fission one (obtained using " $F 6$ mode $n$ " tally). The evaluation of the delayed gamma energy is more complicated. Its magnitude is assumed to be constant and worth $6.33 \mathrm{MeV} /$ fission of $235 \mathrm{U}$. Its distribution is not calculated by MCNP and it is assumed that the distribution is the same as the prompt gamma one. Unfortunately, by default, there is no distinction between the capture and prompt gamma energy using a F6 tally. However, it is possible to disable the capture reaction in MCNP thanks to the card PIKMT, and thus to obtain the prompt gamma distribution. Using this approach, two MCNP calculations, with and without the use of the PIKMT card, are required. The total recoverable energy per fission, $Q$, is the sum of the different contributions described in Table A-1 The MCNP score of a F6 tally is expressed in MeV/MCNP-neutron-source-particle. One has to 
multiply this score by the number of neutrons per second, $v$ (also calculated by MCNP), to obtain the energy per fission. Thus, by tallying the entire core and normalizing the number by $v$ one can deduce $Q$ :

$$
\begin{aligned}
& S_{i}=\left(Q_{1, i}+Q_{2, i}+Q_{3, i}+Q_{4, i}\right) \cdot v+Q_{5} \cdot \frac{\left(F 6: n_{\text {fuel }}\right)_{i}}{\sum_{i}\left(F 6: n_{\text {fuel }}\right)_{i}}+Q_{6} \cdot \frac{\left(F 6: p_{-} p i k m t\right)_{i}}{\sum_{i}\left(F 6: p_{-} p i k m t\right)_{i}} \\
& Q=\sum_{i} s_{i}
\end{aligned}
$$

where

$\mathrm{Q}$ (MeV/fission): total recoverable energy per fission.

$Q_{1, i}, Q_{2, i}, Q_{3, i}, Q_{4, i}$ (MeV/neutron): local recoverable energy per neutron due to the fission fragments, kinetic energy of the neutrons, gamma capture and prompt gamma, respectively.

$\mathrm{Q}_{5}, \mathrm{Q}_{6}$ (MeV/fission): total recoverable energy due to beta decay and delayed gamma, i.e., 6.5 and 6.33 MeV/fission, respectively.

$\mathrm{S}_{\mathrm{i}}$ (MeV/fission): local recoverable energy.

v: number of neutrons created per fission.

Once $Q$ is known, the number of fissions created per second, $\alpha$, in the reactor is deduced from the total nuclear power, $\mathrm{P}$, via the relation:

$$
\alpha=\frac{P}{Q \cdot e}
$$

where:

$$
\begin{aligned}
& \alpha \text { (fissions/second): number of fissions created per second in the reactor } \\
& P(M W) \text { : total nuclear power } \\
& Q(M e V / \text { fission): total recoverable energy per fission } \\
& \text { e (MeV/MJ): constant, from } 1 \mathrm{eV}=1.602 \times 10-19 \mathrm{~J} \text {. }
\end{aligned}
$$

One can then deduce the power deposited in a region of the reactor, $\mathrm{P}_{\text {region, }}$ by tallying the region with the adequate F6 tally, normalizing the results to have the local energy deposited per fission, $Q_{\text {region }}$ (MeV/fission), and multiplying the result by the product, $\alpha \cdot e$ :

$$
P_{\text {region }}=Q_{\text {region }} \cdot \alpha \cdot e
$$

where: 
$\alpha$ (fissions/second): number of fissions created per second in the reactor

$\mathrm{P}_{\text {region }}(\mathrm{MW})$ : nuclear power deposited in the region

$\mathrm{Q}_{\text {region }}(\mathrm{MeV} /$ fission): recoverable energy per fission in the region

e (MeV/MJ): constant, from $1 \mathrm{eV}=1.602 \times 10-19 \mathrm{~J}$. 


\section{Appendix B Power Distribution and Kinetics Parameters}

Power distribution

Table B-1. Power distribution for representative core with HEU fuel.

\begin{tabular}{|c|c|c|c|c|c|c|c|c|c|c|c|c|c|}
\hline \multirow{2}{*}{\multicolumn{2}{|c|}{ Component }} & \multicolumn{3}{|c|}{ Remainder of High Heat Flux } & \multicolumn{4}{|c|}{ High heat flux } & \multicolumn{3}{|c|}{ Average Fuel } & \multicolumn{2}{|c|}{ Plugged Channel } \\
\hline & & Structure & Beryllium & Fuel & Plate 4 & Plate 5 & Plate 6 & Beryllium & Structure & Beryllium & Fuel & Structure & Beryllium \\
\hline \multicolumn{2}{|c|}{$\begin{array}{r}\text { RELAP5 Volume Connections } \\
\text { (left/Right) }\end{array}$} & Sym-360 & $360-16$ & $360-360$ & $360-365$ & $365-366$ & $366-367$ & $367-16$ & Sym-56 & $56-16$ & Sym-56 & Sym-76 & $76-16$ \\
\hline \multicolumn{2}{|r|}{ Heat Structure } & 301 & 368 & 360 & 364 & 365 & 366 & 367 & 501 & 560 & 561 & 702 & 760 \\
\hline \multicolumn{2}{|r|}{ RELAP5 Table } & 705 & 725 & 708 & 760 & 600 & 700 & 720 & 735 & 730 & 710 & 755 & 750 \\
\hline \multicolumn{2}{|r|}{ Relative Power } & $0.17 \%$ & $0.06 \%$ & $4.07 \%$ & $0.03 \%$ & $0.04 \%$ & $0.05 \%$ & $0.00 \%$ & $3.73 \%$ & $1.27 \%$ & $85.25 \%$ & $2.89 \%$ & $2.45 \%$ \\
\hline \multicolumn{2}{|c|}{ Power [MW] @ $470 \mathrm{~W} / \mathrm{cm}^{2}$} & 0.13312 & 0.04677 & 3.14121 & 0.02173 & 0.02703 & 0.03478 & 0.00134 & 2.87571 & 0.98414 & 65.81532 & 2.23014 & 1.88870 \\
\hline \multicolumn{2}{|c|}{ Power [MW] @ $600 \mathrm{~W} / \mathrm{cm}^{2}$} & 0.16985 & 0.05967 & 4.00789 & 0.02773 & 0.03449 & 0.04437 & 0.00170 & 3.66914 & 1.25568 & 83.97422 & 2.84545 & 2.40981 \\
\hline \multirow{22}{*}{$\begin{array}{l}\text { Power Ratios (Axial } \\
\text { Segment) }\end{array}$} & 1 & $2.48 \mathrm{E}-05$ & $9.54 \mathrm{E}-06$ & $0.00 \mathrm{E}+00$ & $0.00 \mathrm{E}+00$ & $0.00 \mathrm{E}+00$ & $0.00 \mathrm{E}+00$ & $2.73 \mathrm{E}-07$ & $5.62 \mathrm{E}-04$ & $2.07 E-04$ & $0.00 \mathrm{E}+00$ & $9.68 \mathrm{E}-04$ & $6.38 \mathrm{E}-04$ \\
\hline & 2 & $2.61 \mathrm{E}-05$ & $9.21 \mathrm{E}-06$ & $7.16 \mathrm{E}-04$ & $5.19 \mathrm{E}-06$ & $6.71 \mathrm{E}-06$ & $8.88 \mathrm{E}-06$ & $2.63 \mathrm{E}-07$ & $5.96 \mathrm{E}-04$ & $2.00 \mathrm{E}-04$ & $1.63 \mathrm{E}-02$ & 7.09E-04 & $4.20 \mathrm{E}-04$ \\
\hline & 3 & $3.44 \mathrm{E}-05$ & $1.21 \mathrm{E}-05$ & 8.19E-04 & 5.79E-06 & 7.69E-06 & $1.05 \mathrm{E}-05$ & $3.46 \mathrm{E}-07$ & $7.84 \mathrm{E}-04$ & $2.64 \mathrm{E}-04$ & $1.90 \mathrm{E}-02$ & $8.81 \mathrm{E}-04$ & $5.34 \mathrm{E}-04$ \\
\hline & 4 & $4.27 \mathrm{E}-05$ & $1.50 \mathrm{E}-05$ & $1.01 \mathrm{E}-03$ & $6.87 \mathrm{E}-06$ & $9.56 \mathrm{E}-06$ & $1.20 \mathrm{E}-05$ & $4.28 \mathrm{E}-07$ & $9.64 \mathrm{E}-04$ & $3.25 \mathrm{E}-04$ & $2.29 \mathrm{E}-02$ & $1.05 \mathrm{E}-03$ & $6.45 \mathrm{E}-04$ \\
\hline & 5 & $5.11 \mathrm{E}-05$ & $1.78 \mathrm{E}-05$ & $1.22 \mathrm{E}-03$ & $8.94 \mathrm{E}-06$ & $1.12 \mathrm{E}-05$ & $1.54 \mathrm{E}-05$ & $5.10 \mathrm{E}-07$ & $1.14 \mathrm{E}-03$ & $3.85 \mathrm{E}-04$ & $2.72 \mathrm{E}-02$ & $1.23 \mathrm{E}-03$ & 7.57E-04 \\
\hline & 6 & $5.91 \mathrm{E}-05$ & $2.07 \mathrm{E}-05$ & $1.42 \mathrm{E}-03$ & $1.05 \mathrm{E}-05$ & $1.32 \mathrm{E}-05$ & 1.77E-05 & $5.91 \mathrm{E}-07$ & $1.32 \mathrm{E}-03$ & $4.44 \mathrm{E}-04$ & $3.10 \mathrm{E}-02$ & $1.41 \mathrm{E}-03$ & 8.67E-04 \\
\hline & 7 & $6.73 \mathrm{E}-05$ & $2.36 \mathrm{E}-05$ & $1.60 \mathrm{E}-03$ & $1.12 \mathrm{E}-05$ & $1.54 \mathrm{E}-05$ & $1.98 \mathrm{E}-05$ & $6.73 \mathrm{E}-07$ & $1.49 \mathrm{E}-03$ & $5.02 \mathrm{E}-04$ & $3.46 \mathrm{E}-02$ & $1.59 \mathrm{E}-03$ & $9.74 \mathrm{E}-04$ \\
\hline & 8 & $7.59 \mathrm{E}-05$ & $2.64 \mathrm{E}-05$ & $1.80 \mathrm{E}-03$ & $1.30 \mathrm{E}-05$ & $1.71 \mathrm{E}-05$ & $2.23 \mathrm{E}-05$ & $7.55 \mathrm{E}-07$ & $1.66 \mathrm{E}-03$ & $5.61 \mathrm{E}-04$ & $3.85 \mathrm{E}-02$ & $1.77 \mathrm{E}-03$ & $1.08 \mathrm{E}-03$ \\
\hline & 9 & $8.46 \mathrm{E}-05$ & $2.95 \mathrm{E}-05$ & $2.01 \mathrm{E}-03$ & $1.43 \mathrm{E}-05$ & $1.81 \mathrm{E}-05$ & $2.42 \mathrm{E}-05$ & $8.42 \mathrm{E}-07$ & $1.83 \mathrm{E}-03$ & $6.21 \mathrm{E}-04$ & $4.19 \mathrm{E}-02$ & $1.99 \mathrm{E}-03$ & $1.18 \mathrm{E}-03$ \\
\hline & 10 & $9.37 \mathrm{E}-05$ & $3.27 \mathrm{E}-05$ & $2.25 \mathrm{E}-03$ & $1.59 \mathrm{E}-05$ & $1.96 \mathrm{E}-05$ & $2.55 \mathrm{E}-05$ & $9.34 \mathrm{E}-07$ & $2.01 \mathrm{E}-03$ & $6.85 \mathrm{E}-04$ & $4.63 \mathrm{E}-02$ & $1.79 \mathrm{E}-03$ & $1.29 \mathrm{E}-03$ \\
\hline & 11 & $1.02 \mathrm{E}-04$ & $3.57 \mathrm{E}-05$ & $2.48 \mathrm{E}-03$ & $1.70 \mathrm{E}-05$ & $2.14 \mathrm{E}-05$ & $2.80 \mathrm{E}-05$ & $1.02 \mathrm{E}-06$ & $2.18 \mathrm{E}-03$ & $7.45 \mathrm{E}-04$ & $5.08 \mathrm{E}-02$ & $1.51 \mathrm{E}-03$ & $1.38 \mathrm{E}-03$ \\
\hline & 12 & $1.09 \mathrm{E}-04$ & $3.81 \mathrm{E}-05$ & $2.66 \mathrm{E}-03$ & $1.82 \mathrm{E}-05$ & $2.22 \mathrm{E}-05$ & $2.83 \mathrm{E}-05$ & $1.09 \mathrm{E}-06$ & $2.32 \mathrm{E}-03$ & $7.94 \mathrm{E}-04$ & $5.40 \mathrm{E}-02$ & $1.49 \mathrm{E}-03$ & $1.46 \mathrm{E}-03$ \\
\hline & 13 & $1.14 \mathrm{E}-04$ & $4.00 \mathrm{E}-05$ & $2.81 \mathrm{E}-03$ & $1.87 \mathrm{E}-05$ & $2.32 \mathrm{E}-05$ & $2.86 \mathrm{E}-05$ & $1.14 \mathrm{E}-06$ & $2.42 \mathrm{E}-03$ & $8.31 \mathrm{E}-04$ & $5.69 \mathrm{E}-02$ & $1.42 \mathrm{E}-03$ & $1.51 \mathrm{E}-03$ \\
\hline & 14 & 1.17E-04 & $4.10 \mathrm{E}-05$ & $2.87 \mathrm{E}-03$ & $1.91 \mathrm{E}-05$ & $2.32 \mathrm{E}-05$ & $2.81 \mathrm{E}-05$ & 1.17E-06 & $2.47 \mathrm{E}-03$ & $8.51 \mathrm{E}-04$ & $5.84 \mathrm{E}-02$ & $1.45 \mathrm{E}-03$ & $1.54 \mathrm{E}-03$ \\
\hline & 15 & $1.17 \mathrm{E}-04$ & $4.12 \mathrm{E}-05$ & $2.91 \mathrm{E}-03$ & $1.97 \mathrm{E}-05$ & $2.38 \mathrm{E}-05$ & $2.97 \mathrm{E}-05$ & $1.18 \mathrm{E}-06$ & $2.48 \mathrm{E}-03$ & $8.52 \mathrm{E}-04$ & $5.89 \mathrm{E}-02$ & $1.45 \mathrm{E}-03$ & $1.54 \mathrm{E}-03$ \\
\hline & 16 & $1.15 \mathrm{E}-04$ & $3.99 \mathrm{E}-05$ & $2.87 \mathrm{E}-03$ & $1.98 \mathrm{E}-05$ & $2.43 \mathrm{E}-05$ & 3.07E-05 & $1.14 \mathrm{E}-06$ & $2.43 \mathrm{E}-03$ & $8.31 \mathrm{E}-04$ & $5.83 \mathrm{E}-02$ & $1.43 \mathrm{E}-03$ & $1.50 \mathrm{E}-03$ \\
\hline & 17 & $1.09 \mathrm{E}-04$ & $3.80 \mathrm{E}-05$ & $2.74 \mathrm{E}-03$ & $1.87 \mathrm{E}-05$ & $2.26 \mathrm{E}-05$ & $2.84 \mathrm{E}-05$ & 1.09E-06 & $2.33 \mathrm{E}-03$ & $7.94 \mathrm{E}-04$ & $5.65 \mathrm{E}-02$ & $1.34 \mathrm{E}-03$ & $1.43 \mathrm{E}-03$ \\
\hline & 18 & $1.01 \mathrm{E}-04$ & $3.52 \mathrm{E}-05$ & $2.55 \mathrm{E}-03$ & $1.74 \mathrm{E}-05$ & $2.10 \mathrm{E}-05$ & $2.74 \mathrm{E}-05$ & $1.01 \mathrm{E}-06$ & $2.17 \mathrm{E}-03$ & $7.37 \mathrm{E}-04$ & $5.34 \mathrm{E}-02$ & $1.23 \mathrm{E}-03$ & $1.33 \mathrm{E}-03$ \\
\hline & 19 & $8.96 \mathrm{E}-05$ & $3.12 \mathrm{E}-05$ & $2.25 \mathrm{E}-03$ & $1.56 \mathrm{E}-05$ & $1.90 \mathrm{E}-05$ & $2.39 \mathrm{E}-05$ & $8.93 \mathrm{E}-07$ & $1.94 \mathrm{E}-03$ & $6.59 \mathrm{E}-04$ & $4.78 \mathrm{E}-02$ & $1.13 \mathrm{E}-03$ & $1.20 \mathrm{E}-03$ \\
\hline & 20 & $7.62 \mathrm{E}-05$ & $2.65 \mathrm{E}-05$ & $1.94 \mathrm{E}-03$ & $1.36 \mathrm{E}-05$ & $1.65 \mathrm{E}-05$ & $2.14 \mathrm{E}-05$ & $7.57 \mathrm{E}-07$ & $1.66 \mathrm{E}-03$ & $5.62 \mathrm{E}-04$ & $4.22 \mathrm{E}-02$ & $9.99 \mathrm{E}-04$ & $1.03 \mathrm{E}-03$ \\
\hline & 21 & 5.97E-05 & $2.08 \mathrm{E}-05$ & $1.77 \mathrm{E}-03$ & $1.20 \mathrm{E}-05$ & $1.46 \mathrm{E}-05$ & $1.99 \mathrm{E}-05$ & $5.93 \mathrm{E}-07$ & $1.30 \mathrm{E}-03$ & $4.38 \mathrm{E}-04$ & $3.76 \mathrm{E}-02$ & 8.44E-04 & $8.38 \mathrm{E}-04$ \\
\hline & 22 & $5.53 \mathrm{E}-05$ & $2.17 \mathrm{E}-05$ & $0.00 \mathrm{E}+00$ & $0.00 \mathrm{E}+00$ & $0.00 \mathrm{E}+00$ & $0.00 \mathrm{E}+00$ & $6.19 \mathrm{E}-07$ & $1.23 \mathrm{E}-03$ & $4.61 \mathrm{E}-04$ & $0.00 \mathrm{E}+00$ & $1.22 \mathrm{E}-03$ & $1.31 \mathrm{E}-03$ \\
\hline
\end{tabular}


Table B-2. Power distribution for representative core with LEU fuel.

\begin{tabular}{|c|c|c|c|c|c|c|c|c|c|c|c|c|c|}
\hline & \multirow[b]{2}{*}{ Component } & \multicolumn{3}{|c|}{ Remainder of High Heat Flux } & \multicolumn{4}{|c|}{ High heat flux } & \multicolumn{3}{|c|}{ Average Fuel } & \multicolumn{2}{|c|}{ Plugged Channel } \\
\hline & & Structure & Beryllium & Fuel & Plate 4 & Plate 5 & Plate 6 & Beryllium & Structure & Beryllium & Fuel & Structure & Beryllium \\
\hline \multicolumn{2}{|c|}{$\begin{array}{r}\text { RELAP5 Volume Connections } \\
\text { (left/Right) }\end{array}$} & Sym-360 & 360-16 & $360-360$ & $360-365$ & $365-366$ & $366-367$ & 367-16 & Sym-56 & $56-16$ & Sym-56 & Sym-76 & $76-16$ \\
\hline \multicolumn{2}{|r|}{ Heat Structure } & 301 & 368 & 360 & 364 & 365 & 366 & 367 & 501 & 560 & 561 & 702 & 760 \\
\hline \multicolumn{2}{|r|}{ RELAP5 Table } & 705 & 725 & 708 & 760 & 600 & 700 & 720 & 735 & 730 & 710 & 755 & 750 \\
\hline \multicolumn{2}{|c|}{ Relative Power } & $0.20 \%$ & $0.01 \%$ & $4.08 \%$ & $0.03 \%$ & $0.04 \%$ & $0.05 \%$ & $0.00 \%$ & $4.09 \%$ & $0.15 \%$ & $86.85 \%$ & $2.46 \%$ & $2.06 \%$ \\
\hline \multicolumn{2}{|c|}{ Power [MW] @ $470 \mathrm{~W} / \mathrm{cm}^{2}$} & 0.14159 & 0.00498 & 2.95272 & 0.01986 & 0.02645 & 0.03578 & 0.00014 & 2.96227 & 0.10577 & 62.87745 & 1.78108 & 1.49191 \\
\hline \multicolumn{2}{|c|}{ Power [MW] @ $600 \mathrm{~W} / \mathrm{cm}^{2}$} & 0.18247 & 0.00642 & 3.80509 & 0.02559 & 0.03408 & 0.04611 & 0.00018 & 3.81741 & 0.13630 & 81.02854 & 2.29524 & 1.92258 \\
\hline \multirow{22}{*}{$\begin{array}{l}\text { Power Ratios (Axial } \\
\text { Segment) }\end{array}$} & 1 & $2.51 \mathrm{E}-05$ & $1.52 \mathrm{E}-06$ & $0.00 \mathrm{E}+00$ & $0.00 \mathrm{E}+00$ & $0.00 \mathrm{E}+00$ & $0.00 \mathrm{E}+00$ & $4.36 \mathrm{E}-08$ & $5.54 \mathrm{E}-04$ & $3.44 \mathrm{E}-05$ & $0.00 \mathrm{E}+00$ & $8.61 \mathrm{E}-04$ & $5.52 \mathrm{E}-04$ \\
\hline & 2 & $3.30 \mathrm{E}-05$ & $1.11 \mathrm{E}-06$ & $7.68 \mathrm{E}-04$ & $5.43 \mathrm{E}-06$ & $7.23 \mathrm{E}-06$ & $1.06 \mathrm{E}-05$ & 3.17E-08 & $6.70 \mathrm{E}-04$ & $2.52 \mathrm{E}-05$ & $1.78 \mathrm{E}-02$ & $6.26 \mathrm{E}-04$ & $3.64 \mathrm{E}-04$ \\
\hline & 3 & $4.25 \mathrm{E}-05$ & $1.42 \mathrm{E}-06$ & $8.65 \mathrm{E}-04$ & $6.23 \mathrm{E}-06$ & $9.09 \mathrm{E}-06$ & $1.24 \mathrm{E}-05$ & 4.07E-08 & $8.70 \mathrm{E}-04$ & $3.18 \mathrm{E}-05$ & $2.04 \mathrm{E}-02$ & $7.78 \mathrm{E}-04$ & $4.64 \mathrm{E}-04$ \\
\hline & 4 & $5.20 \mathrm{E}-05$ & $1.74 \mathrm{E}-06$ & $1.06 \mathrm{E}-03$ & $7.04 \mathrm{E}-06$ & $1.01 \mathrm{E}-05$ & $1.51 \mathrm{E}-05$ & $4.98 \mathrm{E}-08$ & $1.06 \mathrm{E}-03$ & $3.86 \mathrm{E}-05$ & $2.44 \mathrm{E}-02$ & $9.32 \mathrm{E}-04$ & $5.60 \mathrm{E}-04$ \\
\hline & 5 & $6.02 \mathrm{E}-05$ & $2.08 \mathrm{E}-06$ & $1.28 \mathrm{E}-03$ & 9.07E-06 & $1.26 \mathrm{E}-05$ & $1.85 \mathrm{E}-05$ & $5.95 \mathrm{E}-08$ & $1.24 \mathrm{E}-03$ & $4.53 \mathrm{E}-05$ & $2.86 \mathrm{E}-02$ & $1.08 \mathrm{E}-03$ & $6.53 \mathrm{E}-04$ \\
\hline & 6 & $6.44 \mathrm{E}-05$ & $2.43 \mathrm{E}-06$ & $1.52 \mathrm{E}-03$ & $1.10 \mathrm{E}-05$ & $1.46 \mathrm{E}-05$ & $2.04 \mathrm{E}-05$ & $6.94 \mathrm{E}-08$ & $1.40 \mathrm{E}-03$ & $5.17 \mathrm{E}-05$ & $3.25 \mathrm{E}-02$ & $1.24 \mathrm{E}-03$ & $7.45 \mathrm{E}-04$ \\
\hline & 7 & $7.29 \mathrm{E}-05$ & $2.72 \mathrm{E}-06$ & $1.71 \mathrm{E}-03$ & $1.30 \mathrm{E}-05$ & $1.68 \mathrm{E}-05$ & $2.39 \mathrm{E}-05$ & $7.78 \mathrm{E}-08$ & $1.56 \mathrm{E}-03$ & $5.75 \mathrm{E}-05$ & $3.58 \mathrm{E}-02$ & $1.39 \mathrm{E}-03$ & 8.33E-04 \\
\hline & 8 & $8.12 \mathrm{E}-05$ & $3.07 \mathrm{E}-06$ & $1.90 \mathrm{E}-03$ & $1.37 \mathrm{E}-05$ & $1.84 \mathrm{E}-05$ & $2.49 \mathrm{E}-05$ & $8.76 \mathrm{E}-08$ & $1.73 \mathrm{E}-03$ & $6.35 \mathrm{E}-05$ & $3.95 \mathrm{E}-02$ & $1.54 \mathrm{E}-03$ & $9.18 \mathrm{E}-04$ \\
\hline & 9 & $8.85 \mathrm{E}-05$ & $3.35 \mathrm{E}-06$ & $2.09 \mathrm{E}-03$ & $1.49 \mathrm{E}-05$ & $2.00 \mathrm{E}-05$ & $2.65 \mathrm{E}-05$ & $9.58 \mathrm{E}-08$ & $1.89 \mathrm{E}-03$ & $6.95 \mathrm{E}-05$ & $4.28 \mathrm{E}-02$ & $1.72 \mathrm{E}-03$ & $1.00 \mathrm{E}-03$ \\
\hline & 10 & $9.68 \mathrm{E}-05$ & $3.69 \mathrm{E}-06$ & $2.29 \mathrm{E}-03$ & $1.59 \mathrm{E}-05$ & $2.14 \mathrm{E}-05$ & $2.82 \mathrm{E}-05$ & $1.05 \mathrm{E}-07$ & $2.07 \mathrm{E}-03$ & $7.61 \mathrm{E}-05$ & $4.71 \mathrm{E}-02$ & $1.53 \mathrm{E}-03$ & $1.09 \mathrm{E}-03$ \\
\hline & 11 & $1.05 \mathrm{E}-04$ & $4.01 \mathrm{E}-06$ & $2.52 \mathrm{E}-03$ & $1.70 \mathrm{E}-05$ & $2.31 \mathrm{E}-05$ & 3.03E-05 & $1.15 \mathrm{E}-07$ & $2.24 \mathrm{E}-03$ & $8.24 \mathrm{E}-05$ & $5.15 \mathrm{E}-02$ & $1.26 \mathrm{E}-03$ & $1.17 \mathrm{E}-03$ \\
\hline & 12 & $1.11 \mathrm{E}-04$ & $4.21 \mathrm{E}-06$ & $2.69 \mathrm{E}-03$ & $1.84 \mathrm{E}-05$ & $2.37 \mathrm{E}-05$ & $3.10 \mathrm{E}-05$ & $1.20 \mathrm{E}-07$ & $2.38 \mathrm{E}-03$ & $8.76 \mathrm{E}-05$ & $5.50 \mathrm{E}-02$ & $1.24 \mathrm{E}-03$ & $1.23 \mathrm{E}-03$ \\
\hline & 13 & $1.46 \mathrm{E}-04$ & $4.41 \mathrm{E}-06$ & $2.80 \mathrm{E}-03$ & $1.87 \mathrm{E}-05$ & $2.40 \mathrm{E}-05$ & $3.15 \mathrm{E}-05$ & $1.26 \mathrm{E}-07$ & $3.08 \mathrm{E}-03$ & $9.13 \mathrm{E}-05$ & 5.77E-02 & $1.19 \mathrm{E}-03$ & $1.27 \mathrm{E}-03$ \\
\hline & 14 & $1.64 \mathrm{E}-04$ & $4.52 \mathrm{E}-06$ & $2.87 \mathrm{E}-03$ & $1.85 \mathrm{E}-05$ & $2.45 \mathrm{E}-05$ & $3.28 \mathrm{E}-05$ & $1.29 \mathrm{E}-07$ & $3.40 \mathrm{E}-03$ & $9.33 \mathrm{E}-05$ & $5.92 \mathrm{E}-02$ & $1.21 \mathrm{E}-03$ & $1.29 \mathrm{E}-03$ \\
\hline & 15 & $1.62 \mathrm{E}-04$ & $4.49 \mathrm{E}-06$ & $2.87 \mathrm{E}-03$ & $1.86 \mathrm{E}-05$ & $2.42 \mathrm{E}-05$ & $3.27 \mathrm{E}-05$ & $1.28 \mathrm{E}-07$ & $3.34 \mathrm{E}-03$ & $9.33 \mathrm{E}-05$ & $5.96 \mathrm{E}-02$ & $1.21 \mathrm{E}-03$ & $1.29 \mathrm{E}-03$ \\
\hline & 16 & $1.17 \mathrm{E}-04$ & $4.37 \mathrm{E}-06$ & $2.83 \mathrm{E}-03$ & $1.89 \mathrm{E}-05$ & $2.35 \mathrm{E}-05$ & $3.16 \mathrm{E}-05$ & $1.25 \mathrm{E}-07$ & $2.50 \mathrm{E}-03$ & $9.16 \mathrm{E}-05$ & $5.88 \mathrm{E}-02$ & $1.19 \mathrm{E}-03$ & $1.25 \mathrm{E}-03$ \\
\hline & 17 & $1.11 \mathrm{E}-04$ & $4.18 \mathrm{E}-06$ & $2.70 \mathrm{E}-03$ & $1.76 \mathrm{E}-05$ & $2.38 \mathrm{E}-05$ & 3.07E-05 & $1.19 \mathrm{E}-07$ & $2.39 \mathrm{E}-03$ & $8.78 \mathrm{E}-05$ & $5.66 \mathrm{E}-02$ & $1.11 \mathrm{E}-03$ & 1.19E-03 \\
\hline & 18 & $1.12 \mathrm{E}-04$ & $3.80 \mathrm{E}-06$ & $2.42 \mathrm{E}-03$ & $1.55 \mathrm{E}-05$ & $2.01 \mathrm{E}-05$ & $2.74 \mathrm{E}-05$ & $1.09 \mathrm{E}-07$ & $2.26 \mathrm{E}-03$ & $8.16 \mathrm{E}-05$ & $5.32 \mathrm{E}-02$ & $1.02 \mathrm{E}-03$ & $1.11 \mathrm{E}-03$ \\
\hline & 19 & $1.01 \mathrm{E}-04$ & $3.33 \mathrm{E}-06$ & $2.09 \mathrm{E}-03$ & $1.31 \mathrm{E}-05$ & $1.81 \mathrm{E}-05$ & $2.42 \mathrm{E}-05$ & $9.52 \mathrm{E}-08$ & $2.03 \mathrm{E}-03$ & $7.30 \mathrm{E}-05$ & $4.76 \mathrm{E}-02$ & $9.35 \mathrm{E}-04$ & $9.95 \mathrm{E}-04$ \\
\hline & 20 & $8.66 \mathrm{E}-05$ & $2.82 \mathrm{E}-06$ & $1.81 \mathrm{E}-03$ & $1.13 \mathrm{E}-05$ & $1.60 \mathrm{E}-05$ & $2.19 \mathrm{E}-05$ & $8.06 \mathrm{E}-08$ & $1.74 \mathrm{E}-03$ & $6.31 \mathrm{E}-05$ & $4.21 \mathrm{E}-02$ & $8.28 \mathrm{E}-04$ & $8.58 \mathrm{E}-04$ \\
\hline & 21 & $7.00 \mathrm{E}-05$ & $2.31 \mathrm{E}-06$ & $1.66 \mathrm{E}-03$ & $1.05 \mathrm{E}-05$ & $1.43 \mathrm{E}-05$ & $1.94 \mathrm{E}-05$ & $6.60 \mathrm{E}-08$ & $1.39 \mathrm{E}-03$ & $5.15 \mathrm{E}-05$ & $3.81 \mathrm{E}-02$ & $6.99 \mathrm{E}-04$ & $6.93 \mathrm{E}-04$ \\
\hline & 22 & $5.22 \mathrm{E}-05$ & $3.17 \mathrm{E}-06$ & $0.00 \mathrm{E}+00$ & $0.00 \mathrm{E}+00$ & $0.00 \mathrm{E}+00$ & $0.00 \mathrm{E}+00$ & $9.06 \mathrm{E}-08$ & $1.14 \mathrm{E}-03$ & $7.08 \mathrm{E}-05$ & $0.00 \mathrm{E}+00$ & $1.01 \mathrm{E}-03$ & $1.09 \mathrm{E}-03$ \\
\hline
\end{tabular}


$\underline{\text { Kinetics parameters }}$

Table B-3. Reactivity as function of time and control rod displacement.

\begin{tabular}{|c|c|c|c|}
\hline \multirow{2}{*}{ Rod Displacement } & \multirow{2}{*}{ Time } & \multicolumn{2}{|c|}{ Reactivity } \\
\hline & & HEU & LEU \\
\hline $\mathrm{mm}$ & $\mathrm{s}$ & $\$$ & $\$$ \\
\hline 0 (fully withdrawn) & 0 & 0 & 0 \\
\hline 50 & 0.059 & -0.072 & -0.084 \\
\hline 100 & 0.099 & -0.246 & -0.278 \\
\hline 150 & 0.129 & -0.604 & -0.677 \\
\hline 200 & 0.149 & -1.160 & -1.260 \\
\hline 250 & 0.175 & -1.937 & -2.099 \\
\hline 300 & 0.204 & -2.913 & -3.115 \\
\hline 350 & 0.229 & -4.086 & -4.303 \\
\hline 400 & 0.254 & -5.448 & -5.672 \\
\hline 450 & 0.289 & -6.993 & -7.208 \\
\hline 500 & 0.309 & -8.712 & -8.878 \\
\hline 550 & 0.339 & -10.581 & -10.696 \\
\hline 600 & 0.379 & -12.527 & -12.591 \\
\hline 650 & 0.404 & -14.422 & -14.386 \\
\hline 700 & 0.429 & -16.057 & -15.919 \\
\hline 750 & 0.454 & -17.250 & -16.989 \\
\hline 800 & 0.489 & -17.967 & -17.648 \\
\hline 850 & 0.529 & -18.335 & -17.960 \\
\hline 900 (fully inserted) & 0.604 & -18.475 & -18.104 \\
\hline
\end{tabular}

Table B-4. Reactivity kinetics information.

\begin{tabular}{|l|c|c|}
\hline & HEU & LEU \\
\hline$\Lambda$, Generation time $(\mu \mathrm{s})$ & 81.1565 & 69.8975 \\
\hline$\beta$, Delayed neutron fraction & 0.006856 & 0.006618 \\
\hline
\end{tabular}

Table B-5. Reactivity kinetics information.

\begin{tabular}{|c|c|c|c|c|}
\hline & \multicolumn{2}{|c|}{ HEU } & \multicolumn{2}{c|}{ LEU } \\
\hline $\begin{array}{c}\text { Delayed neutron } \\
\text { group }\end{array}$ & $\begin{array}{c}\text { Relative fraction } \\
\beta_{\mathrm{i}} / \beta\end{array}$ & $\begin{array}{c}\text { Decay constant } \\
\lambda_{\mathrm{i}}\end{array}$ & $\begin{array}{c}\text { Relative fraction } \\
\beta_{\mathrm{i}} / \beta\end{array}$ & $\begin{array}{c}\text { Decay constant } \\
\lambda_{\mathrm{i}}\end{array}$ \\
\hline 1 & 0.032317 & 0.012490 & 0.032048 & 0.012490 \\
\hline 2 & 0.166117 & 0.031820 & 0.169704 & 0.031732 \\
\hline 3 & 0.161971 & 0.109372 & 0.160320 & 0.109436 \\
\hline 4 & 0.458049 & 0.317000 & 0.456149 & 0.317379 \\
\hline 5 & 0.134029 & 1.353830 & 0.134634 & 1.350007 \\
\hline 6 & 0.047824 & 8.636524 & 0.046919 & 8.648171 \\
\hline
\end{tabular}




\section{Appendix C Evaluation of Power Following Scram}

The transient power following shutdown is a summation of the fission and decay heat components. The fission component is calculated by the RELAP5 point kinetics model. The decay heat in BR2 depends on the core loading and the power history of each fuel element. This appendix describes the assumptions made in determining a "mixed-core" decay heat for use in the RELAP5 model. Table C-1 shows the number of fuel elements and their average for each cycle (4 cycles assumed). It was also assumed that the reactor operation time was 30 days with a 40 day shutdown period. The decay heat calculations are based on the decay heat formulas and constants given by ANSI/ANS-5.1-2005 [C-1], assuming thermal fission of ${ }^{235} \mathrm{U}$ at $200 \mathrm{MeV} /$ fission and accounting for fission product absorption.

Table C-1. Average power and number of fuel elements in each cycle.

\begin{tabular}{|l|c|c|c|c|}
\hline & $\begin{array}{c}\text { Fresh Fuel } \\
\text { (0\% burnup) }\end{array}$ & $\begin{array}{c}\text { Once Burned } \\
(16 \% \text { burnup })\end{array}$ & $\begin{array}{c}\text { Twice Burned } \\
(32 \% \text { burned })\end{array}$ & $\begin{array}{c}\text { Thrice Burned } \\
\text { (46\% burned })\end{array}$ \\
\hline Number of Assemblies & 6 & 5 & 13 & 7 \\
\hline Average Power (MCNP) & $2.43 \mathrm{MW}$ & $3.27 \mathrm{MW}$ & $2.37 \mathrm{MW}$ & $1.44 \mathrm{MW}$ \\
\hline
\end{tabular}

The "mixed-core" decay heat is a summation of the power histories for each cycle and depends on when in the operation time period that the reactor trip occurs. The fact that there are different numbers of fuel elements in each burnup group and not every fuel element is used from cycle to cycle has been neglected. A variable that needs to be considered is the time at which the reactor trips within the 30 day operation period (power distribution provided from MCNP calculations is for beginning of cycle conditions). Figure $\mathrm{C}-1$ shows the power-irradiation time relationship at three different times after the trip (1 s, $30 \mathrm{~s}$ and $60 \mathrm{~s}$ ). At beginning of cycle conditions, the decay heat is highly dependent on the operation time, while it becomes asymptotic for longer time periods. The reactor operation time has been selected to be 24 hours since the decay heat produced within the $60 \mathrm{~s}$ transient time for which flow reversal occurs is not significantly different from the 30 day case. It can be seen in Figure C- 2 that the impact is small at about $60 \mathrm{~s}$ after the trip but becomes an important factor for longer term cooling (1 day).

Figure C-3 shows the mixed-core decay power for the high heat flux fuel element calculated above compared to the decay power calculated by RELAP5 with the ANSI/ANS-5.1-1979 [C-2] standard available in the code (assuming that the whole core is operated at the same average power density for 30 days prior to scram). These results compare well and justify the use of the ANSI/ANS-5.1-1979 standard. Also shown is the fission power determined from the RELAP5 point kinetics model. This value is found to be about $0.7 \%$ of the total power $20 \mathrm{~s}$ after shutdown. The total decay power used for the representative core is the sum of the residual fission power plus the decay heat calculated from the ANSI/ANS-5.1-1979 standard (labeled fission + decay). For comparison, the total decay power used for the hot stripe of the $6^{\text {th }}$ plate in Test $A / 400 / 1$ of the 1963 core configuration is shown. Based on a historical analysis, the residual fission power was neglected for the 1963 core configuration since it was found to be $<0.1 \%$ [C-3]. This decay power curve takes into account the spreading of the decay heat due to the gamma energy distribution and the fact that $93 \%$ of the decay power was produced in the 2 hours 
prior to scram. Ultimately, the total decay power for the hot stripe of the $6^{\text {th }}$ plate at 20 s increases from $2.6 \%$ to $4.8 \%$ when moving from the assumptions used in the 1963 core configuration to that used in the representative core.

Finally, a sensitivity analyses was performed to evaluate the importance of photoneutrons in the total power after the trip. Results indicated that photoneutrons account for no more than $0.25 \%$ of the nominal power (the maximum occurs at about $25 \mathrm{~s}$ into the transient) and that this value decreases with time. The photoneutrons have been neglected in the RELAP5 model.

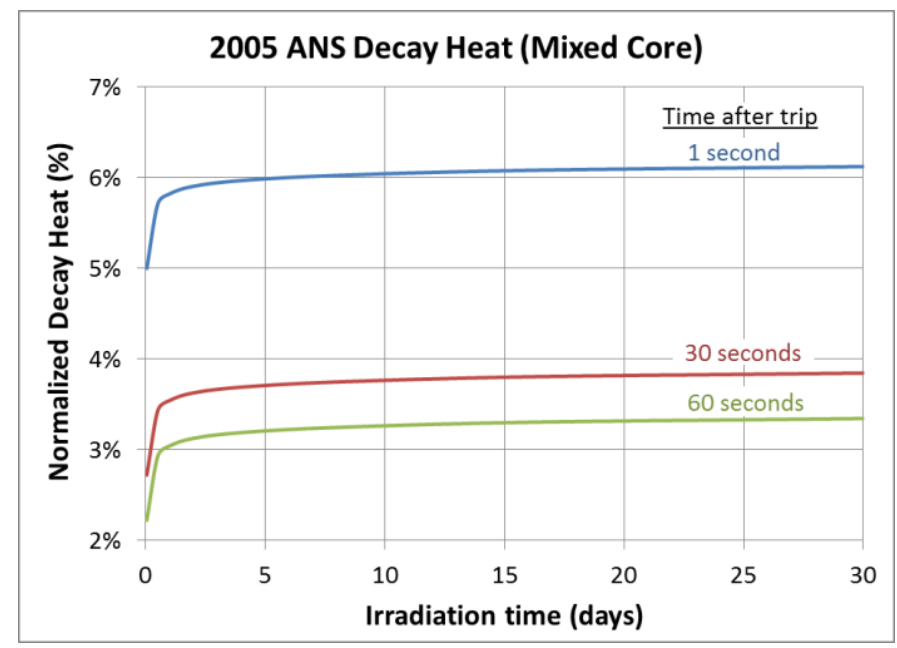

Figure C-1. Relationship between decay heat and irradiation time for different times after the trip.

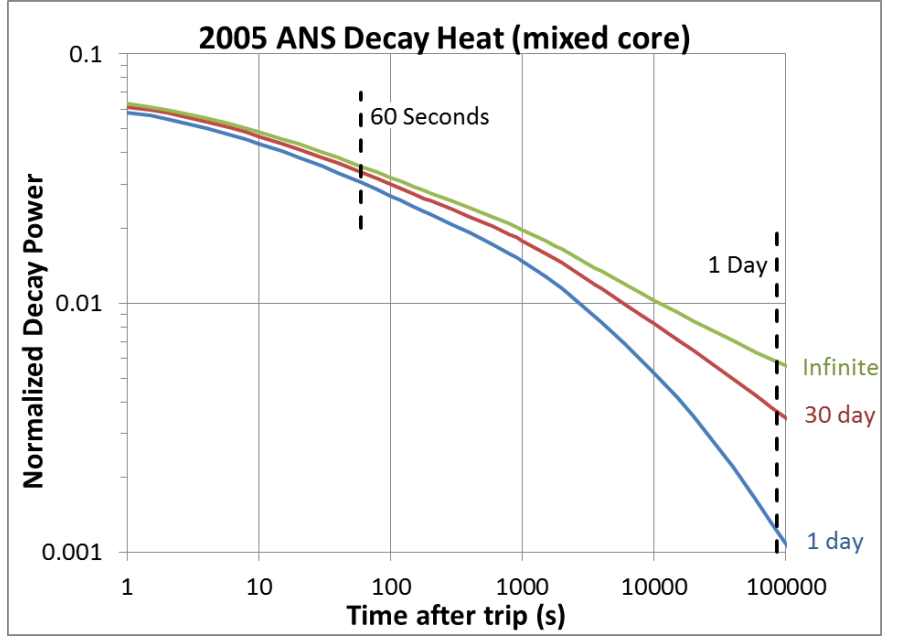

Figure C-2. Mixed-core decay heat following trip for different irradiation times (1 day, 30 day and infinite). 


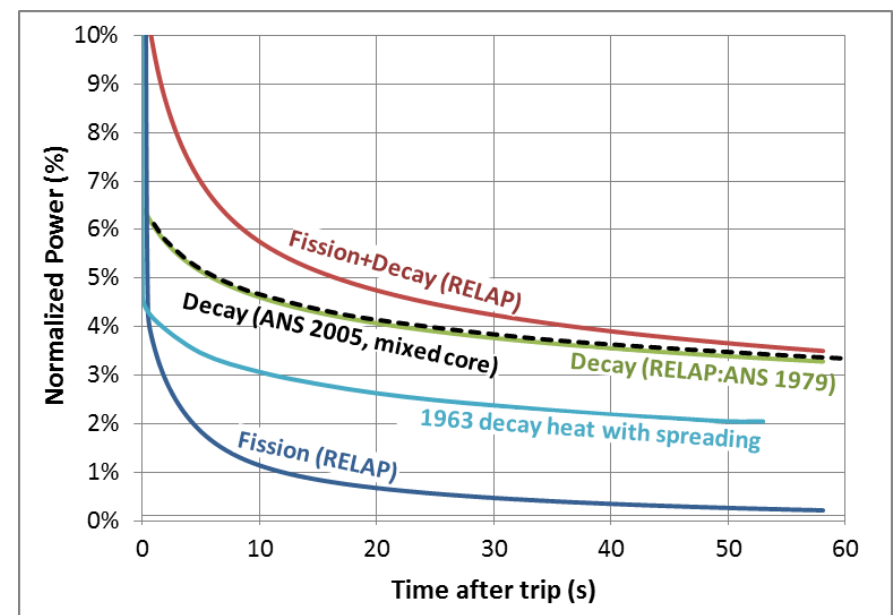

Figure C-3. Contributions to the overall heat load following trip for mixed core and $\mathbf{3 0}$ day irradiation.

\section{$\underline{\text { References }}$}

[C-1] American Nuclear Society, ANSI/ANS-5.1-2005, Decay Heat Power in Light Water Reactors, April 1st, 2005.

[C-2] American National Standard for Decay Heat Power in Light Water Reactors. ANSI/ANS-5.1-1979.

[C-3] B. Dionne and C.P. Tzanos, "Estimation of steady-state and transient power distributions for the RELAP analyses of the 1963 loss-of-flow and loss-of-pressure tests at BR2" ANL/RERTR/TM-1119, (2011). 


\section{Appendix D Control Systems}

\section{Control Blocks (CB)}

CB $1-6$ are the control blocks for the valves.

CB $11-150$ and CB $9000-9014$ are controllers for relevant reactor measurements

CB $1001-1003$ are controllers for the primary flow rate

CB $2001-2003$ are controllers for the primary inlet pressure.

CB $4001-4003$ are controllers for the secondary heat exchanger coolant temperature

The table below describes each of the control blocks.

\begin{tabular}{|c|c|c|c|}
\hline Control Block & Inputs & Table & Description \\
\hline CB 1 (abvPUMP) & Time & $\begin{array}{c}\text { Table } \\
1\end{array}$ & $\begin{array}{l}\text { Controller for the check valve downstream from } \\
\text { the primary pumps. Used in the representative } \\
\text { core calculations to mimic the closing of the check } \\
\text { valve to match the coast down curve. }\end{array}$ \\
\hline CB 2 (abv1305) & Time & $\begin{array}{c}\text { Table } \\
2\end{array}$ & Controller for abv4-1305, hot leg valve \\
\hline CB 3 (abv1301) & Time & $\begin{array}{c}\text { Table } \\
3\end{array}$ & Controller for abv4-1301, bypass valve \\
\hline CB 4 (abv1304) & Time & $\begin{array}{c}\text { Table } \\
4\end{array}$ & Controller for abv4-1304, cold leg valve \\
\hline CB 5 (abv1308) & Time & $\begin{array}{c}\text { Table } \\
5\end{array}$ & Controller for abv4-1308, pool connection valve \\
\hline CB 6 (abvPZR) & Time & $\begin{array}{c}\text { Table } \\
6\end{array}$ & $\begin{array}{l}\text { Controller for isolating the pressurizer during loss } \\
\text { of pressure simulations }\end{array}$ \\
\hline CB 11 (TC 11) & $\begin{array}{l}\text { httemp } 36600201 \\
\text { httemp } 36600301\end{array}$ & & Thermocouple 11, deg C \\
\hline CB 12 (TC 12) & $\begin{array}{l}\text { httemp } 36600601 \\
\text { httemp } 36600701 \\
\end{array}$ & & Thermocouple 12 , deg C \\
\hline CB 13 (TC 13) & $\begin{array}{l}\text { httemp } 36601001 \\
\text { httemp } 36601101 \\
\end{array}$ & & Thermocouple 13, deg C \\
\hline CB 14 (TC 14) & $\begin{array}{l}\text { httemp } 36601401 \\
\text { httemp } 36601501\end{array}$ & & Thermocouple 14, deg C \\
\hline CB 20 (DP4-1301) & $\begin{array}{l}\text { P } 255020000 \\
\text { P } 215020000\end{array}$ & & $\begin{array}{l}\text { DPRCA4-1301 pressure difference reactor } \\
\text { p } 255020000-215020000+5.2678 \mathrm{e} 4\left(\text { rho }^{*} \mathrm{~g} * \mathrm{~h}=\right. \\
5.409 * 993 * 9.81)\end{array}$ \\
\hline CB 21 (dPcore) & $\begin{array}{l}\text { P } 34010000 \\
\text { P } 38010000\end{array}$ & & $\begin{array}{l}\text { Pressure drop across core (not measured) } \\
\text { p } 34010000-\text { p } 38010000+1.3762 \mathrm{e} 4(\mathrm{dz} * \text { rho*g }= \\
1.4132 * 993 * 9.81)\end{array}$ \\
\hline CB 30 (P4-1302) & P 25301000 & & $\begin{array}{l}\text { PRCA4-1302 relative inlet pressure reactor } \\
\text { p } 253010000-1.54577 \mathrm{e} 5(\text { rho*g*h and atm, } \\
993 * 9.81 * 5.5+101000)\end{array}$ \\
\hline
\end{tabular}




\begin{tabular}{|c|c|c|}
\hline CB 40 (T4-1301) & tempf 504020000 & TRAS4-1301 inlet temperature reactor \\
\hline CB 50 (F4-1301) & $\begin{array}{l}\text { rho } 24010000 \\
\text { mflowj } 504010000\end{array}$ & $\begin{array}{l}\text { FRCA4-1301 primary flow rate } \\
\text { Mflowj } 50401000 \text { / rho } 24010000 * 3600\end{array}$ \\
\hline CB 60 (DT4-1301) & $\begin{array}{l}\text { tempf } 232010000 \\
\text { tempf } 504010000\end{array}$ & $\begin{array}{l}\text { DTRA4-1301 temperature difference reactor } \\
\text { tempf } 23201000 \text { - tempf } 50401000\end{array}$ \\
\hline CB 70 (T4-1301) & tempf 23201000 & TRA4-1304 outlet temperature reactor \\
\hline CB 80 (PI4-1301) & p 412020000 & PIAS4-1301 pressure suction side primary pumps \\
\hline CB 90 (PI4-1303) & p 416010000 & PIAS4-1303 pressure side primary pumps \\
\hline CB 150 (DP-1308) & $\begin{array}{l}\text { p } 293010000 \\
(-) \text { p } 295010000\end{array}$ & DP-1308, pressure difference across ABV4-1308 \\
\hline CB 1001 (P sum) & CB 30 & \multirow{3}{*}{$\begin{array}{l}\text { Proportional-integral controller to set pressurizer } \\
\text { pressure CB } 30\end{array}$} \\
\hline CB 1002 (P int) & CB 1001 & \\
\hline CB 1003 (P contr) & CB 1002, CB 1001 & \\
\hline CB 2001 (dP sum) & CB 20 & \multirow{3}{*}{$\begin{array}{l}\text { Proportional-integral controller to control pump } \\
\text { speed based on CB } 20\end{array}$} \\
\hline CB 2002 (dP int) & CB 2001 & \\
\hline CB 2003 (dP cont) & CB 2002, CB 2001 & \\
\hline CB 4001 (deltat) & Tempf 8010000 & \multirow{3}{*}{$\begin{array}{l}\text { Proportional-integral controller to control inlet } \\
\text { temperature based on CB } 40\end{array}$} \\
\hline CB 4002 (stmvlvps) & CB 4001 & \\
\hline CB 4003 (valvepos) & CB 4002, CB 4001 & \\
\hline CB 9000 (aTCFue) & $\begin{array}{l}\text { httemp } 36600205 \\
\text { httemp } 36600206 \\
\text { httemp } 36600305 \\
\text { httemp } 36600306\end{array}$ & $\begin{array}{l}\text { First step in determining average fuel temperature } \\
\text { associated with TC11. This controller sums all of } \\
\text { the fuel temperature nodes Sum up the fuel } \\
\text { temperature values at each node and subtract } \\
4 * 273.15 \text { to convert to } C \text {. }\end{array}$ \\
\hline CB 9001 (bTCFue) & $\begin{array}{l}\text { httemp } 36600605 \\
\text { httemp } 36600606 \\
\text { httemp } 36600705 \\
\text { httemp } 36600706\end{array}$ & $\begin{array}{l}\text { First step in determining average fuel temperature } \\
\text { associated with TC12. This controller sums all of } \\
\text { the fuel temperature nodes Sum up the fuel } \\
\text { temperature values at each node and subtract } \\
4 * 273.15 \text { to convert to } C \text {. }\end{array}$ \\
\hline CB 9002 (cTCFue) & $\begin{array}{l}\text { httemp } 36601005 \\
\text { httemp } 36601006 \\
\text { httemp } 36601105 \\
\text { httemp } 36601106\end{array}$ & $\begin{array}{l}\text { First step in determining average fuel temperature } \\
\text { associated with TC13. This controller sums all of } \\
\text { the fuel temperature nodes Sum up the fuel } \\
\text { temperature values at each node and subtract } \\
4 * 273.15 \text { to convert to } C \text {. }\end{array}$ \\
\hline CB 9003 (dTCFue) & $\begin{array}{l}\text { httemp } 36601405 \\
\text { httemp } 36601406 \\
\text { httemp } 36601505 \\
\text { httemp } 36601506\end{array}$ & $\begin{array}{l}\text { First step in determining average fuel temperature } \\
\text { associated with TC13. This controller sums all of } \\
\text { the fuel temperature nodes Sum up the fuel } \\
\text { temperature values at each node and subtract } \\
4 * 273.15 \text { to convert to } C \text {. }\end{array}$ \\
\hline CB 9011 (TC11Fuel) & CB 9000 & \multirow{4}{*}{$\begin{array}{l}\text { Second step in determining average fuel } \\
\text { temperature. Divide by } 4 \text { to get fuel temperature. }\end{array}$} \\
\hline CB 9012 (TC12Fuel) & CB 9001 & \\
\hline CB 9013 (TC13Fuel) & CB 9002 & \\
\hline CB 9014 (TC14Fuel) & CB 9003 & \\
\hline CB 9999 (rktpow) & rktpow 0 & Reactor power setting \\
\hline
\end{tabular}




\section{Variable Trips}

The following variable trips were extracted from the sections of Ref. [D-1]. Time delays were acquired from Ref. [D-2] and private communication ${ }^{22}$.

\begin{tabular}{|c|c|c|c|}
\hline $\begin{array}{l}\text { Section of } \\
\text { Ref. [D-1] }\end{array}$ & Measurement & Trip \# & Description \\
\hline \multirow{3}{*}{4.2} & \multirow{3}{*}{$\begin{array}{l}\text { Pressure Difference Reactor } \\
\text { (DPRCA4-1301) }\end{array}$} & Trip 20/21 & $\begin{array}{l}\text { Relay scram if CB20 > 5.25 kg/cm² } \\
\text { Delay time: } 250 \mathrm{~ms}\end{array}$ \\
\hline & & Trip 22/23 & $\begin{array}{l}\text { Relay scram if CB21<1.8 kg/ } \mathrm{cm}^{2} \\
\text { Delay time: } 250 \mathrm{~ms}\end{array}$ \\
\hline & & Trip 24/25 & $\begin{array}{l}\text { Open ABV4-1301 if CB22 <0.5 kg/cm² } \\
\text { Delay time: } 2460 \mathrm{~ms}\end{array}$ \\
\hline \multirow{3}{*}{4.3} & \multirow{3}{*}{$\begin{array}{l}\text { Relative inlet pressure reactor } \\
\text { (PRCA4-1302) }\end{array}$} & Trip 30/31 & $\begin{array}{l}\text { Electronic scram if CB30 }<9.0 \mathrm{~kg} / \mathrm{cm}^{2} \\
\text { Delay time: } 25 \mathrm{~ms}\end{array}$ \\
\hline & & Trip 32/33 & $\begin{array}{l}\text { Close ABV4-1304/5 CB30 }<5 \mathrm{~kg} / \mathrm{cm}^{2} \\
\text { Delay time: } 1641 \mathrm{~ms}\end{array}$ \\
\hline & & Trip 34/35 & $\begin{array}{l}\text { Close ABV4-1301CB30 < } 5 \mathrm{~kg} / \mathrm{cm}^{2} \\
\text { Delay time: } 2640 \mathrm{~ms}\end{array}$ \\
\hline 4.4 & $\begin{array}{l}\text { Inlet temperature reactor } \\
\text { (TRAS4-1301) }\end{array}$ & No trips & \\
\hline \multirow{2}{*}{4.5} & \multirow{2}{*}{$\begin{array}{l}\text { Primary flow rate } \\
\text { (FRCA4-1301) }\end{array}$} & Trip 50/51 & $\begin{array}{l}\text { Relay scram if CB50 }<4500 \mathrm{~m}^{3} / \mathrm{hr} \\
\text { Delay time: } 250 \mathrm{~ms}\end{array}$ \\
\hline & & Trip 52/53 & $\begin{array}{l}\text { Open ABV4-1301 if CB50 }<2000 \mathrm{~m}^{3} / \mathrm{hr} \\
\text { Delay time: } 2460 \mathrm{~ms}\end{array}$ \\
\hline 4.6 & $\begin{array}{l}\text { Temperature difference reactor } \\
\text { (DTRA4-1301) }\end{array}$ & No trips & \\
\hline 4.7 & $\begin{array}{l}\text { Outlet temperature reactor } \\
\text { (TRA4-1304) }\end{array}$ & No trips & \\
\hline \multirow{2}{*}{4.8} & \multirow{2}{*}{$\begin{array}{l}\text { Pressure suction side primary } \\
\text { pumps (PIAS4-1301) }\end{array}$} & Trip 80/81 & $\begin{array}{l}\text { Close ABV4-1304/5 if CB80 }<2 \mathrm{~kg} / \mathrm{cm}^{2} \\
\text { Delay time: } 1641 \mathrm{~ms}\end{array}$ \\
\hline & & Trip 82/83 & $\begin{array}{l}\text { Close ABV4-1301 if CB80 }<2 \mathrm{~kg} / \mathrm{cm}^{2} \\
\text { Delay time: } 2460 \mathrm{~ms}\end{array}$ \\
\hline \multirow[t]{2}{*}{4.9} & \multirow{2}{*}{$\begin{array}{l}\text { Pressure side primary pumps } \\
\text { (PIAS4-1303) }\end{array}$} & Trip 90/91 & $\begin{array}{l}\text { Close ABV4-1304/5 if CB80 }<7.2 \\
\mathrm{~kg} / \mathrm{cm}^{2} \\
\text { Delay time: } 1641 \mathrm{~ms}\end{array}$ \\
\hline & & Trip 92/93 & $\begin{array}{l}\text { Close ABV4-1301 if CB80 }<7.2 \mathrm{~kg} / \mathrm{cm}^{2} \\
\text { Delay time: } 2640 \mathrm{~ms}\end{array}$ \\
\hline 5.0 & $\begin{array}{l}\text { Pressure difference across pool } \\
\text { connection valve (not measured) }\end{array}$ & $\begin{array}{l}\text { Trip } \\
150 / 151\end{array}$ & $\begin{array}{l}\text { Open ABV4-1308 if CB150 }<3 \mathrm{~kg} / \mathrm{cm}^{2} \\
\text { Delay time: } 1641 \mathrm{~ms}\end{array}$ \\
\hline \multirow{2}{*}{$\mathrm{N} / \mathrm{A}$} & \multirow{2}{*}{$\begin{array}{l}\text { ABV4-1304/5, ABV4-1301, ABV4- } \\
1308 \text { in wrong position }\end{array}$} & Trip 143 & $\begin{array}{l}\text { Pump trip if Trip } 1042 \text { is true } \\
\text { Delay time: } 1640 \mathrm{~ms}\end{array}$ \\
\hline & & Trip 144 & $\begin{array}{l}\text { Relay scram if Trip } 1042 \text { is true } \\
\text { Delay time: } 250 \mathrm{~ms}\end{array}$ \\
\hline
\end{tabular}

${ }^{22}$ Sikik, E., Private communication, November $12^{\text {th }}, 2015$ 
The following variable trips are for manual control:

Trip 1: manual pump trip

Trip 2: manual power trip

Trip 3: manual ABV4-1308 valve trip

Trip 4: manual ABV4-1301 valve trip

Trip 5: manual ABV4-1304 valve trip

Trip 6: manual ABV4-1305 valve trip

Trip 7: manually suppress ABV4-1304

Trip 8: manually suppress ABV4-1305

Trip 9: manual valve trip (connection of pressurizer to primary loop)

Trip 10: manually suppress ABV4-1301 for Test G

Trip 15: manual valve trip (connection of anti-syphon to primary loop)

The following are miscellaneous variable trips:

Trip 11: this trip is for the check valve following the pumps. In representative core this valve trips when the flow is $<100 \mathrm{~kg} / \mathrm{s}$ in pump check valves. Not used for 1963 tests.

Trip 12: this trip disables all trips to facilitate startup calculations and achieve steady values.

Trip 13: Dummy trip, always 0

Trip 14: Dummy trip, always 1

Trip 274: This trip compares the uppermost cell pressure with atmosphere, with pressure correction for cell height. If the pressure falls below this value, the anti-syphon trip is true.

Trip 611 through Trip 666 are reserved for LOCA simulations 
$\underline{\text { Logical trips }}$

\begin{tabular}{|c|c|c|c|c|c|}
\hline Logical Trip & Input & & Input & Latch & Description \\
\hline Trip 1001 & Trip 11 & AND & Trip 12 & Yes & $\begin{array}{l}\text { These trips are combined to trip abvPUMP } \\
\text { (check valve) }\end{array}$ \\
\hline Trip 1011 & Trip 25 & OR & Trip 53 & No & \multirow{7}{*}{$\begin{array}{l}\text { These trips are combined to trip ABV4-1301 } \\
\text { (bypass valve). }\end{array}$} \\
\hline Trip 1012 & Trip 1011 & OR & Trip 35 & No & \\
\hline Trip 1013 & Trip 1012 & OR & Trip 83 & No & \\
\hline Trip 1014 & Trip 1013 & OR & Trip 93 & No & \\
\hline Trip 1015 & Trip 1014 & OR & Trip 4 & No & \\
\hline Trip 1016 & Trip 1015 & AND & Trip 12 & Yes & \\
\hline Trip 1017 & Trip 1016 & AND & Trip 8 & Yes & \\
\hline Trip 1021 & Trip 33 & OR & Trip 81 & No & \multirow{5}{*}{$\begin{array}{l}\text { These trips are combined to trip ABV4-1304 } \\
\text { (cold leg) and/or ABV4-1305 (hot leg) }\end{array}$} \\
\hline Trip 1022 & Trip 1021 & OR & Trip 91 & No & \\
\hline Trip 1023 & Trip 1022 & AND & Trip 12 & No & \\
\hline Trip 1024 & Trip 1023 & OR & Trip 5 & Yes & \\
\hline Trip 1025 & Trip 1023 & OR & Trip 6 & Yes & \\
\hline Trip 1031 & Trip 3 & OR & Trip 151 & No & \multirow{2}{*}{$\begin{array}{l}\text { These trips are combined to trip abv4-1308 } \\
\text { (pool connection valve) }\end{array}$} \\
\hline Trip 1032 & Trip 1031 & AND & Trip 12 & Yes & \\
\hline Trip 1041 & Trip 1017 & OR & Trip 1024 & No & \multirow{2}{*}{$\begin{array}{l}\text { These trips indicate the movement of } \\
\text { valves ABV4-1304/5, ABV4-1301 and } 1308\end{array}$} \\
\hline Trip 1042 & Trip 1041 & OR & Trip 1032 & No & \\
\hline Trip 1051 & Trip 21 & OR & Trip 23 & No & \multirow[t]{6}{*}{ These trips are combined to trip the scram } \\
\hline Trip 1052 & Trip 1051 & OR & Trip 31 & No & \\
\hline Trip 1053 & Trip 1052 & OR & Trip 51 & No & \\
\hline Trip 1054 & Trip 1053 & OR & Trip 2 & No & \\
\hline Trip 1055 & Trip 1054 & OR & Trip 144 & No & \\
\hline Trip 1056 & Trip 1055 & AND & Trip 12 & Yes & \\
\hline Trip 1061 & Trip 143 & OR & Trip 1 & No & \multirow{2}{*}{$\begin{array}{l}\text { These trips are combined to trip the pump } \\
\text { motors }\end{array}$} \\
\hline Trip 1062 & Trip 1061 & AND & Trip 12 & YES & \\
\hline Trip 1063 & $\begin{array}{l}\text { Trip } 1062 \\
\text { (inverted) }\end{array}$ & OR & $\begin{array}{lr}\text { Trip } 12 \\
\text { (inverted) }\end{array}$ & No & $\begin{array}{l}\text { These trips are combined to trip the pump } \\
\text { velocities. It is the inverse of Trip } 1042\end{array}$ \\
\hline Trip 1274 & Trip 12 & AND & Trip 274 & No & \multirow{2}{*}{$\begin{array}{l}\text { These two trips mimic the float valve in the } \\
\text { anti-syphon. }\end{array}$} \\
\hline Trip 1275 & $\begin{array}{l}\text { Trip } 12 \\
\text { (inverted) }\end{array}$ & AND & $\begin{array}{l}\text { Trip } 274 \\
\text { (inverted) }\end{array}$ & No & \\
\hline
\end{tabular}

Appendix D References

[D-1] G. van den Branden, "Conversion study: design basis document LSSS", BR2/RCE/GVdB/2010/53/conversion_DBD_LSSS-ed 1Draft, August 2010.

[D-2] E. Sikik, "BR2 trip delays that are implemented in the RELAP model," BR2/RCE/ES/18/2015/BR2 Trip Delays for Relap, November 2015. 


\section{Appendix E 1963 Test Chronology}

\begin{tabular}{|c|c|c|c|c|c|c|c|c|}
\hline Type & $T$ & C & & C HRONOLOGY & OF THE & \multicolumn{3}{|c|}{ TRANSIENT } \\
\hline Recording Visicorder & $n^{*}$ & & $\mathrm{~A} / 400 / 1$ & & Date & 28 & 09 & 63 \\
\hline Test & $n^{*}$ & & 26 & & Hour & 23 & $\mathrm{n}$ & 00 \\
\hline
\end{tabular}

IMPORTANT EVENTS

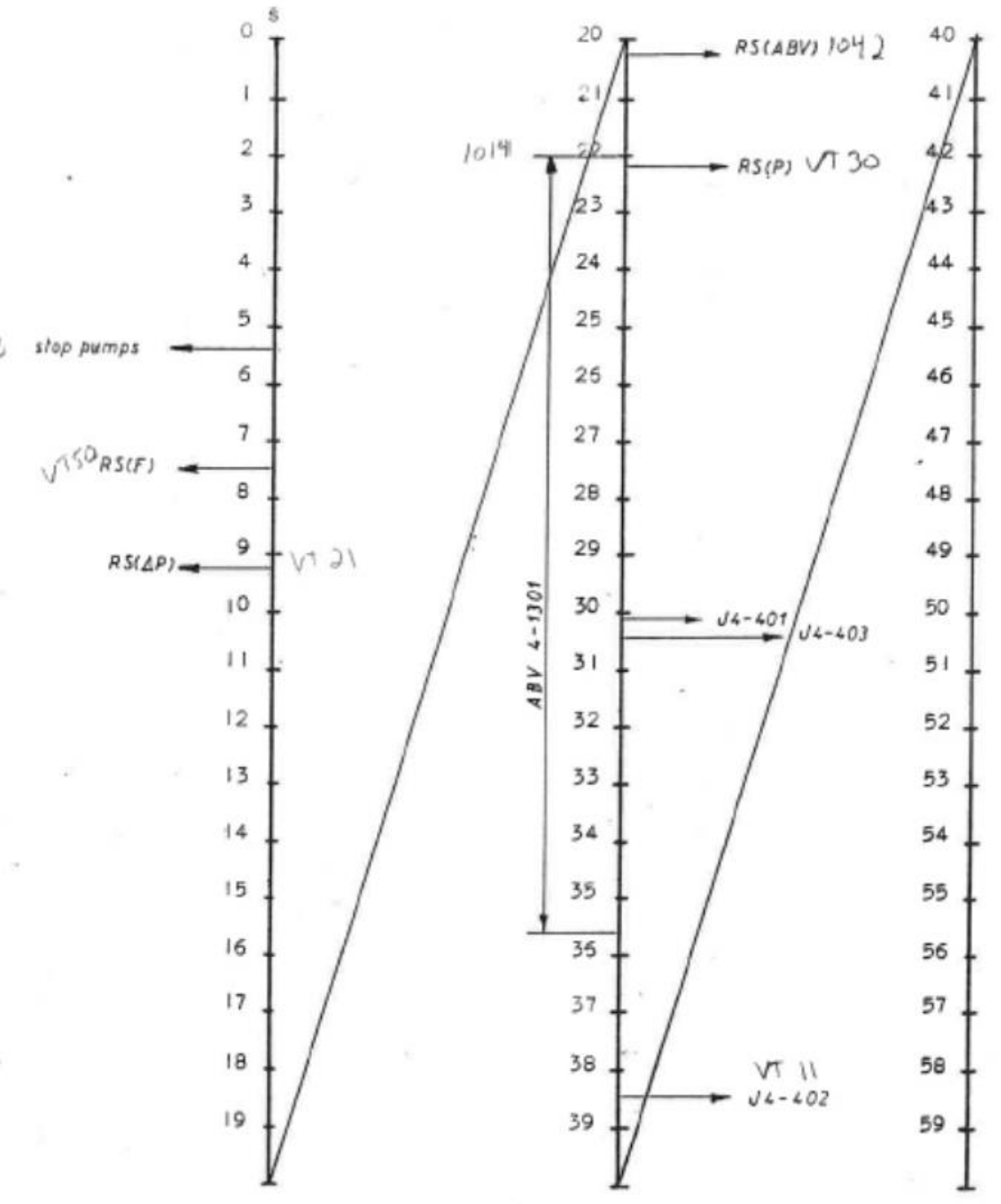

Figure E-1 Test A Chronology 


\begin{tabular}{|c|c|c|c|c|c|c|c|c|}
\hline Type & $T$ & $\mathrm{c}$ & & CERONOLOGY & OF THE & \multicolumn{3}{|c|}{ TRANSIENT } \\
\hline Recording Visicorder & $n^{*}$ & & $c / 600 / 1$ & & Date & 24 & 09 & 63 \\
\hline Test & $n^{*}$ & & 6 & & Hour & $19 \mathrm{~h}$ & & $29^{\prime}$ \\
\hline
\end{tabular}

IMPCRTANT EVENTS
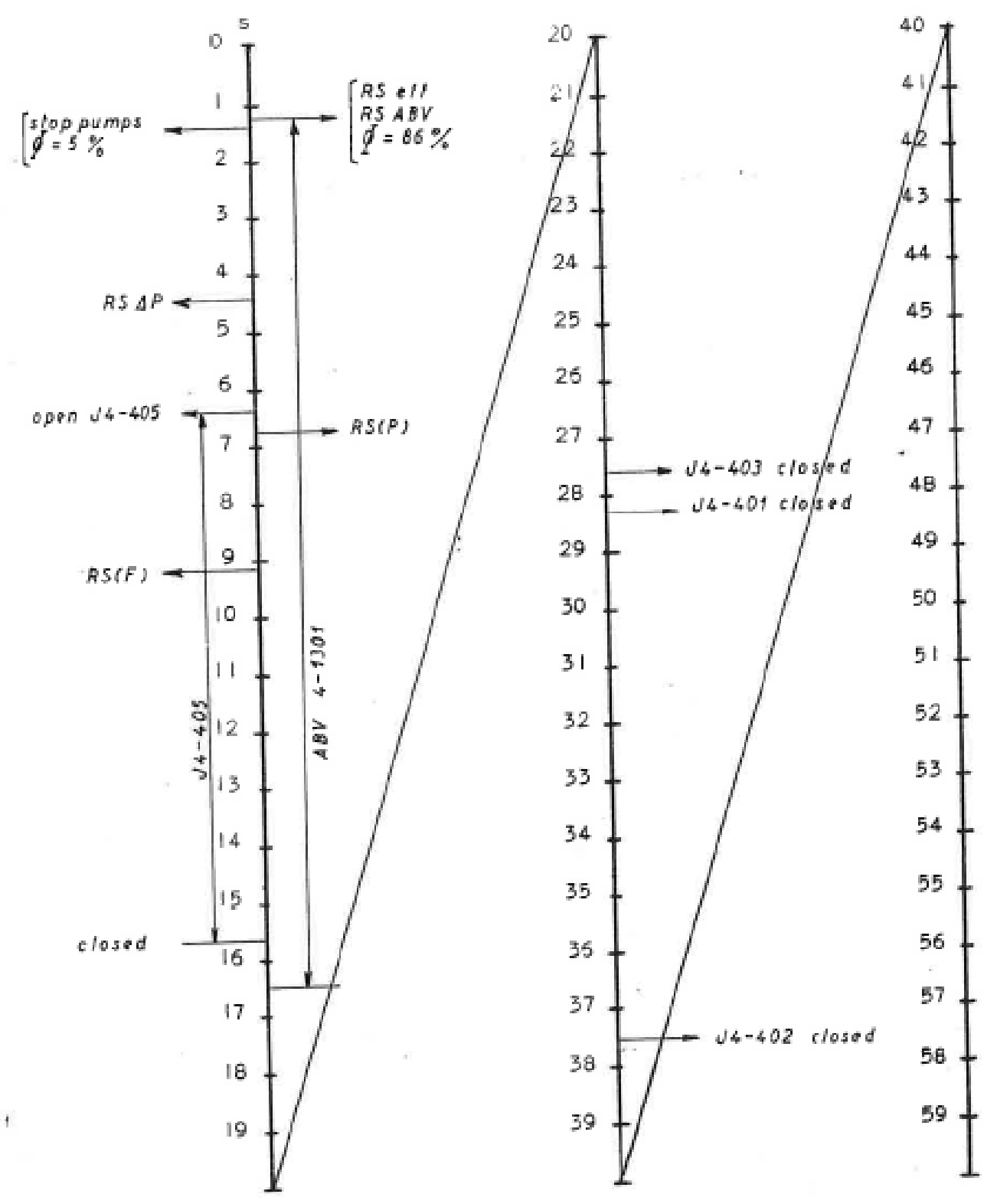

Figure E-1 Test C Chronology 

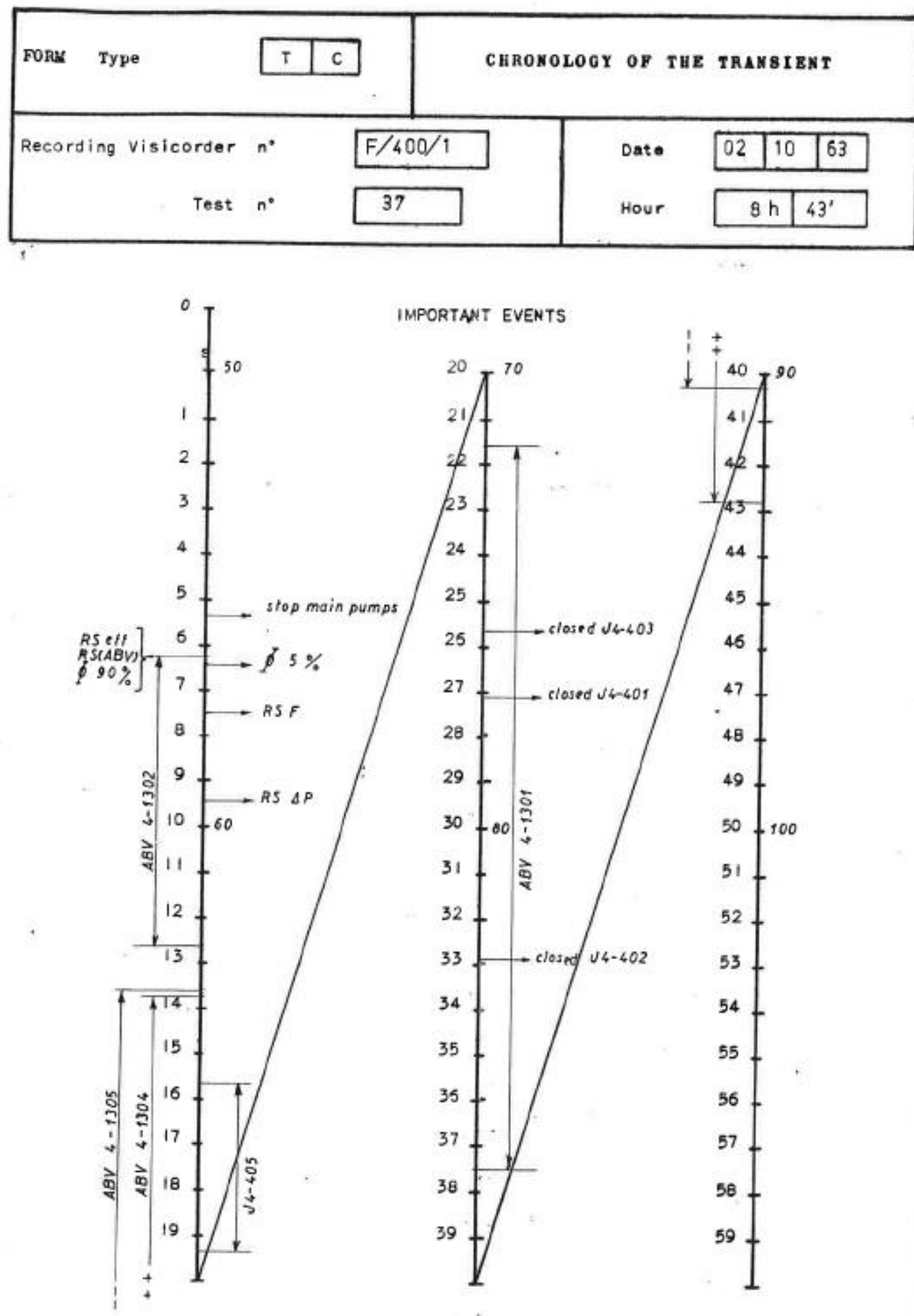

Figure E-1 Test F Chronology 


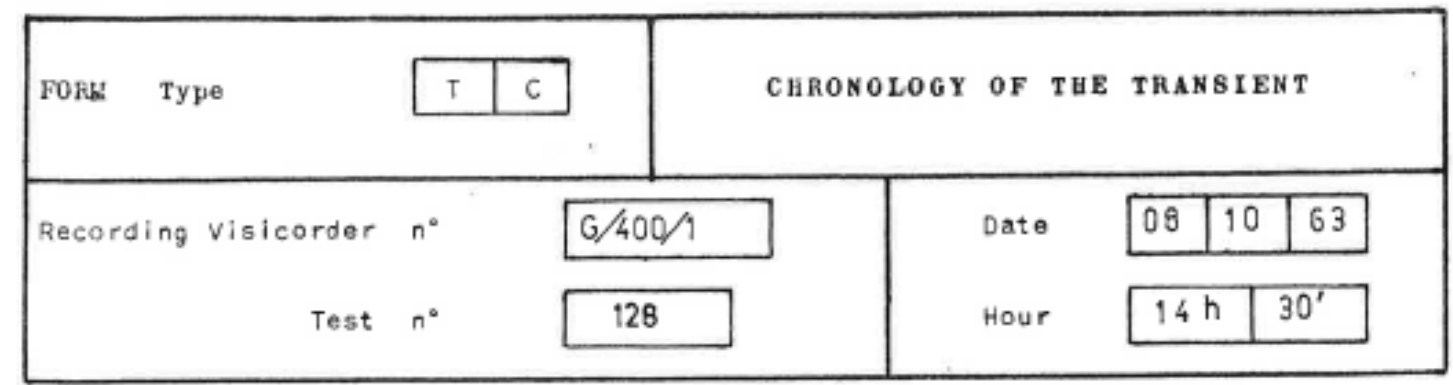

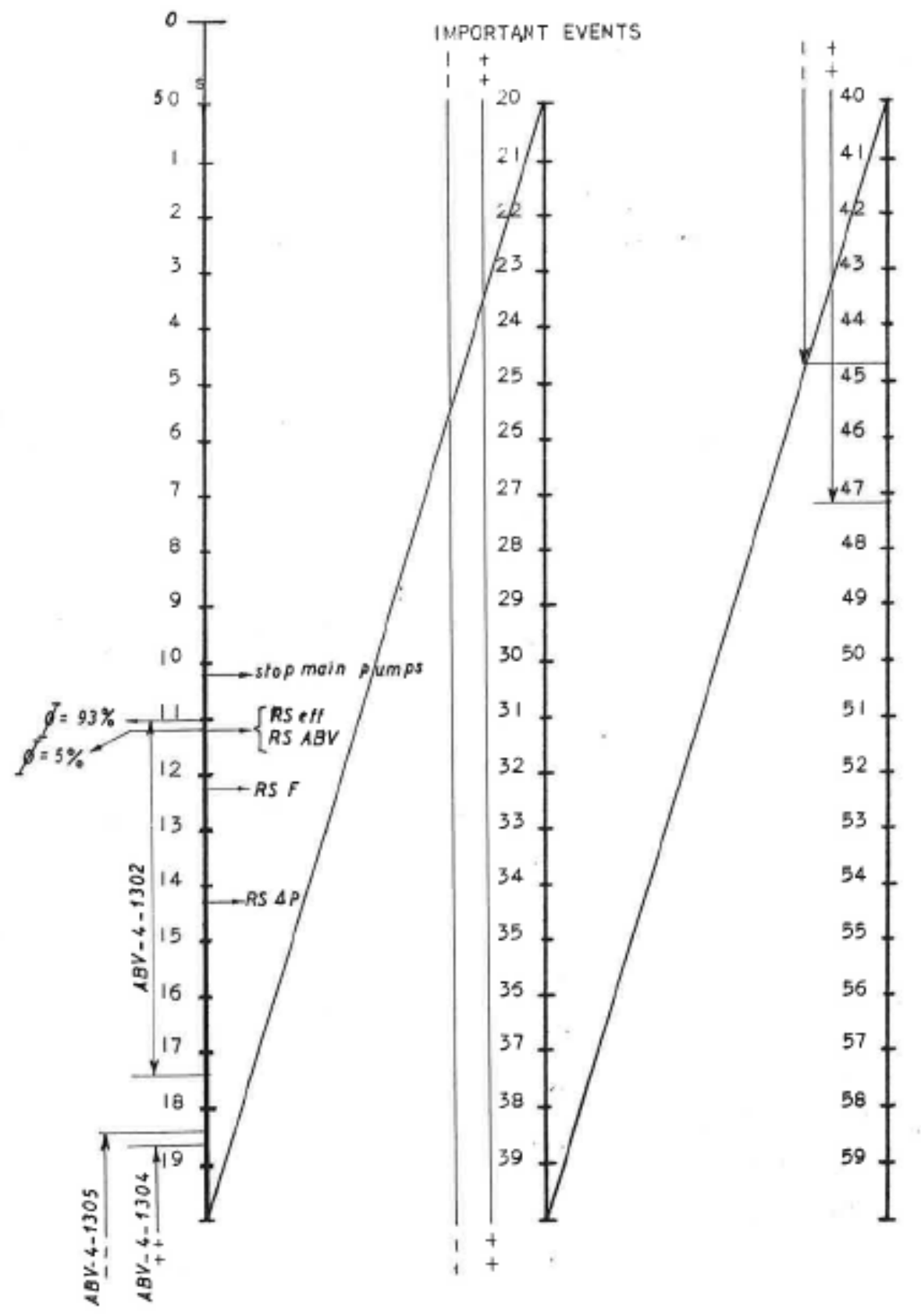

Figure E-1 Test G Chronology 


\section{Appendix F Validation for Long Term Cooling}

Experimental data available for the instrumented fuel assembly for the 1963 test program is limited to $\sim 100 \mathrm{~s}$ beyond the initiation of the transient. To indirectly validate the RELAP5 model for long term cooling of the fuel elements, comparisons were made with available coolant temperature measurements across the instrumented fuel element for the 1963 Test $F$ transient to verify that the power versus flow rate ratio is in good agreement $\left(\left(\frac{\text { Power }}{\text { Flow Rate }}\right) \sim\left(T_{\text {outlet }}-T_{\text {inlet }}\right)\right)$. By comparing steady state and peak temperature measurements with simulations, it was determined that the inlet temperature measurement was consistent with location 366(1) in the RELAP5 model (first node of channel 366 in the high heat flux fuel element) (See Figure F-1). Volume 38 of the RELAP5 model was consistent with the measured outlet temperature. Figure F-2 shows that reasonable agreement was achieved for temperature difference across the fuel element between RELAP5 simulations (Volume 38 Volume 366(1) ) and measurement.

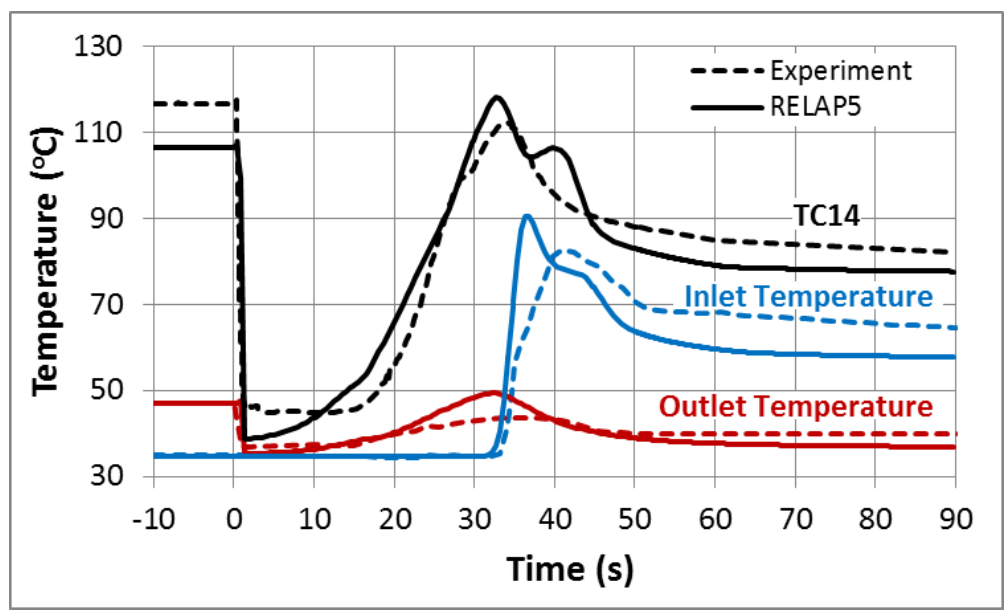

Figure F-1 Comparison of RELAP5 simulation and experimental measurement of cladding and coolant temperature for 1963 Test F.



Figure F-2 Comparison of RELAP5 simulation and experimental measurement of temperature difference across measured fuel element for 1963 Test $F$. 


\section{Appendix G RELAP5 Post-Processing}

This appendix describes the post-processing methodology to determine thermal-hydraulic margins using transient data generated from the RELAP5 representative core model. The margins and correlations were as follows:

- Onset of nucleate boiling (ONB), Bergles-Rohsenow correlation[G-1],

- Onset of significant void (OSV), Saha-Zuber [G-2],

- Onset of flow instability (OFI), Whittle-Forgan [G-3], and

- Critical heat flux (CHF), 2006 Groeneveld look-up tables [G-4] extended to higher mass flux as described by Ref. [G-5].

Performing the calculations for margins as a function of time and axial location requires a significant amount of data from the RELAP5 results. Because of this, the calculations are limited to the hot stripe containing the limiting conditions. Based on the safety analysis results obtained from PLTEMP analysis of the BR2 representative core [G-6], the limiting condition occurs for the hot stripe located in the $6^{\text {th }}$ channel of the high heat flux fuel element (RELAP5 volume 366) and the face of plate 6 (RELAP5 structure 366) that is in contact with this channel. This is assumed to be true for the transient conditions. Figure G-1 provides a sketch of the hot stripe components and nodes from the RELAP5 model that have been used for these calculations.

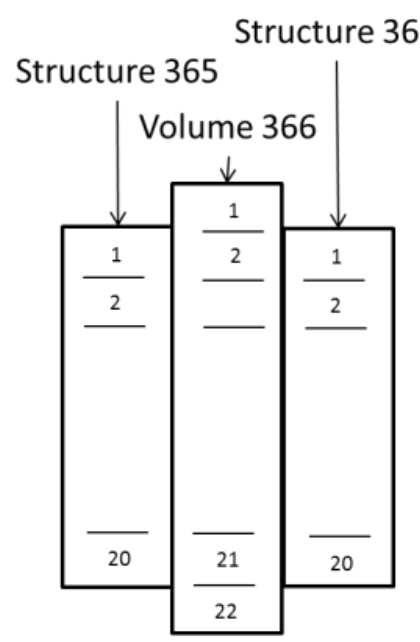

Figure G-1. Node and component layout in RELAP5 model.

\section{Implementation of thermal-hydraulic margins}

\section{Onset of nucleate boiling ratio (for constant power) ONBR $\underline{\underline{c p}}$}

Defined as: $\quad O N B R_{c p}=\frac{\left(T_{w, O N B, c p}-T_{I n}\right)}{\left(T_{w}-T_{I n}\right)}$,

$T_{w, O N B, c p}$ Wall temperature (K) at ONB for constant power, obtained from Bergles-Rohsenow correlation [G-1]: 


$$
Q^{\prime \prime}=1082.9 \cdot(P)^{1.156} \cdot\left[1.8 \cdot\left(T_{w, O N B, c p}-T_{s a t}\right)\right]^{\frac{2.16}{P^{0.0234}}}
$$

Parameters obtained from RELAP5 Results:

$T_{\text {In }} \quad$ Inlet temperature (K), Volume 366 Node 1 or Node 22 (down flow uses Node 1 and up flow uses Node 22)

$\dot{m} \quad$ Local mass flow rate $(\mathrm{kg} / \mathrm{s})$, Volume 366 Nodes 2-21

$T_{w} \quad$ Local wall temperature (K), Structure 366 Nodes 1-20

$P \quad$ Local pressure (converted from Pa to bar), Volume 366 Nodes 2-21

$T_{\text {sat }} \quad$ Local saturation temperature (K), Volume 366 Nodes 2-21

$Q^{\prime \prime} \quad$ Local heat flux $\left(\mathrm{W} / \mathrm{m}^{2}\right)$, Structure 366 Nodes 1-20

\section{Onset of significant void ratio (Saha-Zuber) OSVR $\underline{S Z}$}

Defined as: $\quad F I R_{S Z}={ }^{Q}{ }^{\prime}{ }^{\prime} / Q^{\prime \prime}$

$Q^{\prime \prime}{ }_{S Z} \quad$ Heat flux $\left(\mathrm{W} / \mathrm{m}^{2}\right)$ at which Fl occurs, determined by Saha-Zuber correlation [G-2]:

$$
Q_{W F}^{\prime \prime}=\frac{\dot{m} \cdot\left(h-h_{f o}\right)}{A_{f}} \cdot \max \left(\frac{455}{P e}, 0.0065\right)
$$

Parameters obtained from RELAP5 Results:

Q" $\quad$ Local heat flux $\left(\mathrm{W} / \mathrm{m}^{2}\right)$, from plate 366 into volume 366

$\dot{m} \quad$ Absolute value of inlet mass flow rate $(\mathrm{kg} / \mathrm{s}$ ), Volume 366 Node 1 or Node 22 (down flow uses Node 1 and up flow uses Node 22)

$h \quad$ Local enthalpy $(\mathrm{J} / \mathrm{kg})$, Volume 366 Node 2-21

$h_{f o} \quad$ Local enthalpy of fluid at liquid saturation $(\mathrm{J} / \mathrm{kg})$, Volume 366 Node 2-21

$A_{f} \quad$ Flow area $\left(\mathrm{m}^{2}\right)$, Volume 366

Pe Local Peclet number, $P e=\frac{\dot{m} D_{h} C_{p}}{A_{f} k}$

$D_{h} \quad$ Hydraulic diameter $(\mathrm{m})$, Volume 366

$C_{p} \quad$ Local specific heat (J/kg-K), Volume 366 Node 2-21

$k \quad$ Local thermal conductivity $(\mathrm{W} / \mathrm{m}-\mathrm{K})$, Volume 366 Node 2-21

\section{Flow instability ratio (Whittle-Forgan) FIR $W_{F}$}

Defined as: $\quad F I R_{W F}=Q_{W F} / Q$

$Q_{W F} \quad$ Power (W) at which Fl occurs, determined by Whittle-Forgan correlation [G-3]:

$$
Q_{W F}=\frac{\dot{m} c_{p}\left(T_{\text {sat }, \text { exit }}-T_{\text {in }}\right)}{1+\eta /\left(\frac{L}{D_{h}}\right)}
$$


Parameters obtained from RELAP5 Results:

Q Power (W) input into volume 366

$Q=\sum_{\text {Node } 1}^{\text {Node } 20}\left(Q^{\prime \prime}{ }_{365,0} \cdot A_{s}\right)+\sum_{\text {Node } 1}^{\text {Node } 20}\left(Q^{\prime \prime}{ }_{366, i} \cdot A_{s}\right)$, where $\mathrm{A}_{\mathrm{s}}$ is the node surface area $\left(\mathrm{m}^{2}\right), \mathrm{Q}_{365,0}$ is the heat flux $\left(\mathrm{W} / \mathrm{m}^{2}\right)$ into volume 366 from structure 365 and $\mathrm{Q}^{\prime \prime}{ }_{366, \text { i i }}$ is the heat flux $\left(\mathrm{W} / \mathrm{m}^{2}\right)$ into volume 366 from structure 366

$\dot{m} \quad$ Absolute value of inlet mass flow rate $(\mathrm{kg} / \mathrm{s})$, Volume 366 Node 1 or Node 22 (down flow uses Node 1 and up flow uses Node 22)

$T_{\text {in }} \quad$ Inlet temperature (K), Volume 366 Node 1 or Node 22 (down flow uses Node 1 and up flow uses Node 22)

$T_{\text {sat,exit }}$ Saturation temperature at exit (K), Volume 366 Node 1 or Node 22 (down flow uses Node 1 and up flow uses Node 22)

$C_{p} \quad$ Average specific heat (J/kg-K), Volume 366 Node 2-21

$D_{h} \quad$ Hydraulic diameter $(\mathrm{m})$, Volume 366

$L \quad$ Heated length (m), Volume 366

$\eta \quad$ Whittle-Forgan parameter $=32.5$

\section{Critical heat flux ratio (2006 Groeneveld look-up table), CHFR}

Defined as: $\quad C H F R=C H F / Q^{\prime \prime}$

CHF Critical heat flux $\left(\mathrm{W} / \mathrm{m}^{2}\right)$, determined by 2006 Groeneveld look-up tables [G-4] extended to high mass flux as described by Ref. [G-5]:

$$
\begin{aligned}
& C H F=C H F\left(D_{h}=0.008, P, G, X\right)\left(\frac{0.008}{D_{h}}\right)^{1 / 2} \cdot 1000 \text { for } \mathrm{G}<=8000 \\
& C H F=C H F\left(D_{h}=0.008, P, G, X\right)\left(\frac{0.008}{D_{h}}\right)^{1 / 2} \cdot\left(\frac{G}{8000}\right)^{0.376} \cdot 1000 \text { for } \mathrm{G}>8000
\end{aligned}
$$

$\operatorname{CHF}\left(D_{h}=0.008, P, G, X\right)$ is obtained by performing a 3D interpolation of the 2006 Groeneveld look-up tables

Parameters obtained from RELAP5 Results:

Q" $\quad$ Local heat flux $\left(\mathrm{W} / \mathrm{m}^{2}\right)$, from plate 366 into volume 366

$D_{h} \quad$ Hydraulic diameter $(\mathrm{m})$, Volume 366

$P \quad$ Local pressure (converted from Pa to kPa), Volume 366 Nodes 2-21

$G \quad$ Local mass flux $\left(\mathrm{kg} / \mathrm{m}^{2}-\mathrm{s}\right), G=\frac{\dot{m}}{A_{f}}$

$\dot{m} \quad$ Absolute value of local mass flow rate $(\mathrm{kg} / \mathrm{s})$, Volume 366 Nodes 2-21

$A_{f} \quad$ Flow area $\left(\mathrm{m}^{2}\right)$, Volume 366

$X \quad$ Local quality, Volume 366 Node 2-21 


\section{Appendix G References}

[G-1] A. E. Bergles and W. M. Rohsenow, "Determination of forced-convection surface-boiling heat transfer," Trans. ASME, J. Heat Transfer, 86, pp. 365-372, (1964).

[G-2] P. Saha and N. Zuber, "Point of net vapor generation and vapor void fraction in Subcooled boiling," Proceedings of Fifth International Heat Transfer Conference, September 3-7, 1974, Tokyo, Japan, Vol. 4, pp. 175--179.

[G-3] R. H. Whittle and R. Forgan, "A correlation for the minima in the pressure drop versus flow-rate curves for sub-cooled water flowing in narrow heated channels," Nuclear Engineering and Design, 1967, pp. 89-99.

[G-4] D.C. Groeneveld, J.Q. Shan, A.Z. Vasić, L.K.H. Leung, A. Durmayaz, J. Yang, S.C. Cheng, and A. Tanase, "The 2006 CHF look-up table," Nuclear Engineering and Design 237 (2007) 1909-1922.

[G-5] M. Kalimullah, et al., "An evaluation of subcooled CHF correlations and databases for research reactors operating at 1 to 50 bar pressure" RERTR 2012 - 34th International Meeting on Reduced Enrichment for Research and Test Reactors, October 14-17, 2012, Warsaw, Poland.

[G-6] J. Licht, A. Bergeron, B. Dionne, G. Van den Branden, S. Kalcheva, E. Sikik and E. Koonen, "Steady-state thermal-hydraulics analyses for the conversion of the BR2 reactor to LEU," ANL/GTRI/TM-14/8, 2015. 
(This page intentionally left blank) 


\section{Argonne}

\section{Nuclear Engineering Division}

Argonne National laboratory

9700 South Cass Avenue, Bldg. 208

Argonne, IL 60439

www.anl.gov 